\author{
UNIVERSIDADE DE SÃO PAULO \\ INSTITUTO DE QUÍMICA DE SÃO CARLOS \\ PROGRAMA DE PÓS-GRADUAÇÃO \\ ÁREA: QUIIMICA ANALÍTICA
}

\title{
ESPUMAS POLIURETÂNICAS DERIVADAS DE ÓLEO DE MAMONA UTILIZADAS NA ADSORÇÃO DE BIFENILAS POLICLORADAS (PCBs) PRESENTES EM ÓLEO MINERAL ISOLANTE
}

\author{
Marcio Antonio Ferreira Camargo
}

Tese apresentada ao Instituto de Química de São Carlos, da Universidade de São Paulo, como parte dos requisitos para a obtenção do título de Doutor em Ciências (Química Analítica)

Orientador: Prof. Dr. Gilberto Orivaldo Chierice 
A Deus

por seu infinito Amor

Aos meus pais, Manoel

e Dora, pelo amor e apoio que sempre me dedicaram, minha saudade, meu amor e reconhecimento eterno 
A minha esposa Carmen,

pelo incentivo, amor, carinho e compreensão 


\section{AGRADECIMENTOS}

Agradeço a Deus por dar-me força de vontade e saúde para a realização deste trabalho.

Ao Prof. Dr. Gilberto Orivaldo Chierice, pela oportunidade, confiança e pelo apoio total na realização deste projeto, a minha gratidão.

Ao Dr. Salvador Claro Neto e ao Antonio José Reimer (Toninho) pela ajuda e disponibilidade.

Aos colegas e funcionários do Grupo de Química Analítica e Tecnologia de Polímeros (GQATP).

Ao Prof. Dr. Éder Tadeu Gomes Cavalheiro e aos colegas do Laboratório de Análise Térmica, Eletroanalítica e Química de Soluções (LATEQS).

À Profa. Dr ${ }^{a}$ Maria Olímpia de Oliveira Rezende e à Dra Maria Diva Landgraf, do Grupo de Química Ambiental, pela disponibilidade e paciência na realização das análises cromatográficas.

Às bibliotecárias e funcionários da Biblioteca Prof. Johannes Rüdiger Lechat, pela disponibilidade.

Aos técnicos da Central de Análises Químicas Instrumentais (CAQI), pelas análises realizadas.

Aos docentes do IQSC na transmissão de conhecimentos em suas disciplinas, durante as aulas na pós-graduação.

Ao Prof. Dr. Hidetake Imasato e à Profa Dra. Janice Rodrigues Perussi e a todos os colegas do Grupo de Fotossensibilizadores, pelo carinho e amizade durante nosso período de convivência no laboratório. 
Ao corpo técnico-administrativo do programa de pós-graduação do IQSC.

Ao Eng. Químico Cláudio A. Galdeano e funcionários da empresa MGM Diagnósticos, Campinas - SP, pelo fornecimento de óleo mineral isolante utilizado neste trabalho.

À FESP / UEMG - Universidade do Estado de Minas Gerais - Campus de Passos - MG, e à Fundação de Amparo à Pesquisa do Estado de Minas Gerais FAPEMIG, pela bolsa concedida. 
"A engrenagem da vida não é de grosseira manufatura humana, mas da mais requintada obra-prima já conseguida pelas leis quânticas do Senhor".

Erwin Schöedinger (1887-1961) 


\section{SUMÁRIO}

Sumário

Lista de Figuras

vii

Lista de Tabelas

$x$

Listas de símbolos e abreviações $x i$

Resumo

Abstract XV

Objetivos

xvii

\section{CAPÍTULO I}

\section{INTRODUÇÃO}

1. Óleos Minerais Isolantes

1.1. Constituição dos óleos minerais isolantes

1.2. Características físico-químicas

1.2.2. Densidade

1.2.3. Rigidez dielétrica

1.2.4. Fator de perdas dielétricas

1.2.6. Índice de Neutralização 


\section{CAPÍTULO II}

\section{REVISÃO BIBLIOGRÁFICA}

2. Bifenilas Policloradas (PCBs)

2.2. Classificação de congêneres de PCBs proposta por Ballschmiter e Zell

2.3. Propriedades físico-químicas dos PCBs

2.4. Nomenclatura

2.5. Produção e usos

2.6. Ocorrência no Ambiente

2.7. Exposição ocupacional e efeitos

3. Interação elétron doador-aceptor (transferência de carga) 
4.1. Degradação aeróbica

4.2. Declorinação redutiva

5. Compostos tóxicos no meio ambiente

6. Sorção de compostos orgânicos

6.1. Definições

6.2. Equilíbrio de sorção

6.3. Sistema de classificação do processo de sorção

6.4. Modelos de equilíbrio de sorção

6.5. Cinética do processo de sorção

6.6. Fatores que afetam a sorção

6.7. Características da solução

6.8. Área superficial do sorvente

6.9. Propriedades químicas do sorvente

6.10. Sorção em materiais orgânicos

7.1. Reação de polimerização 


\section{CAPÍTULO III}

PARTE EXPERIMENTAL

9. Procedimentos Analíticos

9.1. Normas ASTM-D4059 e ABNT NBR 13882

9.2. Procedimentos para óleos minerais isolantes

9.3. Amostragem

9.4. Adsorção de PCBs

9.5. Extração de PCBs

9.6. Clean-up

9.7. Cromatografia gasosa

9.8. Soluções - padrão (Arocloros 1242, 1254 e 1260)

9.10. Determinação de PCBs em óleo mineral isolante 


\section{CAPÍTULO IV}

\section{RESULTADOS E DISCUSSÃO}

10. Sorção de Bifenilas policloradas (PCBs)

10.1. Curvas de saturação

10.1.1. Espuma funcionalizada contendo polissulfeto de amônio

10.1.2. Espuma funcionalizada contendo tiodiglicol

76

10.1.3. Espuma não funcionalizada

10.2. Curvas de saturação de espuma não funcionalizada utilizada com massas de $0,1 \mathrm{~g}$ e $2,0 \mathrm{~g}$

10.3. Curvas de saturação das espumas contendo tiodiglicol polissulfeto de amônio e espuma não funcionalizada a $40^{\circ} \mathrm{C}$

10.4. Curvas de saturação da espuma não funcionalizada nas temperaturas de $20^{\circ} \mathrm{C}, 40^{\circ} \mathrm{C}$ e $60^{\circ} \mathrm{C}$

10.5. Óleo mineral isolante, isento de PCBs

10.6. Dessorção dos PCBs adsorvidos na espuma de poliuretano

\section{CAPÍtULO V}

\section{CONCLUSÕES}


11.1. Sugestões para trabalhos futuros 


\section{LISTA DE FIGURAS}

Figura 1: Reação de formação da bifenila

Figura 2: Estruturas químicas de congêneres do Aroclor $1242 \ldots \ldots \ldots \ldots \ldots \ldots \ldots \ldots$

Figura 3: $\quad$ Estruturas químicas de congêneres do Aroclor 1254.

Figura 4: Estruturas químicas de congêneres do Aroclor 1260.

Figura 5: Estrutura química da bifenila policlorada $(\mathrm{PCB})$.

Figura 6: Rotas propostas para os principais componentes e hexahepta-CB de Aroclor 1260.

Figura 7: Sistema de classificação de isotermas.

Figura 8: Representação esquemática da isoterma de Langmuir.

Figura 9: Representação esquemática da isoterma BET.

Figura 10: Representação esquemática da isoterma de Freundlich

Figura 11: Reação de formação do uretano.

Figura 12: Reação de formação do poliuretano.

Figura 13: Etapas de síntese de espuma de poliuretano.

Figura 14: Reação de formação do pré-polímero.

Figura 15: Estrutura química do óleo de mamona. 
Figura 16: Micrografias das espumas de poliuretânica derivada de óleo de mamona (500X e 1000X).

Figura 17: Coluna de vidro termostatizada, contendo espuma poliuretânica derivada de óleo de mamona

Figura 18: Cromatograma típico da solução padrão Arocloro 1242 .............. 69

Figura 19: Cromatograma típico da solução padrão Arocloro 1254 .............. 69

Figura 20: Cromatograma típico da solução padrão Arocloro 1260.

Figura 21: Cromatograma típico da mistura da solução padrão de Arocloros 1242, 1254 e 1260.

Figura 22: Curva analítica preparada utilizando uma mistura dos três padrões nas seguintes concentrações: $1 \mathrm{mg} \mathrm{kg}^{-1}, 2 \mathrm{mg} \mathrm{kg}^{-1}, 2,5$ $\mathrm{mg} \mathrm{kg}^{-1}, 4 \mathrm{mg} \mathrm{kg}^{-1}, 5 \mathrm{mg} \mathrm{kg}^{-1}$ e $10 \mathrm{mg} \mathrm{kg}^{-1}$

Figura 23: Cromatograma típico de uma amostra de óleo mineral isolante contendo PCBs

Figura 24: Cromatograma típico de uma amostra de óleo mineral isolante isento de PCBs

Figura 25: Curva de saturação da espuma contendo $10 \%$ de polissulfeto de amônio para a adsorção de $\mathrm{PCBs}$ a $40^{\circ} \mathrm{C}$

Figura 26: Curva de saturação da espuma contendo $10 \%$ de tiodiglicol para a adsorção de $\mathrm{PCBs}$ a $40^{\circ} \mathrm{C}$

Figura 27: Curva de saturação da espuma $(0,1 \mathrm{~g})$ não funcionalizada para a adsorção de PCBs a $40^{\circ} \mathrm{C}$ 
Figura 28: Curva de saturação da espuma $(2,0 \mathrm{~g})$ não funcionalizada para a adsorção de $\mathrm{PCBs}$ a $40^{\circ} \mathrm{C}$

Figura 29: Curva de saturação das espumas contendo (A) tiodiglicol (B) polissulfeto de amônio e (C) espuma não funcionalizada para a adsorção de $\mathrm{PCBs}$ a $40^{\circ} \mathrm{C}$

Figura 30: Curva de saturação da espuma não funcionalizada para a adsorção de PCBs a 20,40 e $60^{\circ} \mathrm{C}$

Figura 31: Óleo Nynas Novo isento de PCBs, antes de contato e após contato com espuma não funcionalizada (após redução de $55 \%$ no teor de PCBs).

Figura 32: Dessorção de PCBs adsorvidos em 2,0 g de espuma poliuretânica derivada de óleo de mamona. 


\section{LISTA DE TABELAS}

Tabela 1: Composição e grau de cloração de misturas comerciais de PCBs

Tabela 2: Nomenclatura de homólogos de PCBs de acordo com a IUPAC...

Tabela 3: Propriedades físico- químicas de alguns Arocloros (PCBs)

Tabela 4: $\quad$ Uso dos PCBs classificados de acordo com o tipo de Arocloro.....

Tabela 5: Modelos matemáticos para a representação do equilíbrio de adsorção em vários tipos de sorventes.

Tabela 6: Composição média do óleo de mamona. 


\section{LISTA DE SÍMBOLOS E ABREVIAÇÕES}

\begin{tabular}{ll} 
ABNT & Associação Brasileira de Normas Técnicas \\
ars & Parâmetro da isotérmica de Fritz-Schlunder \\
$a_{i}$ & Atividade do componente $i$ \\
aR & Parâmetro da isoterma de Radke-Prausnitz \\
aRP & Parâmetro da isoterma de Redlich-Peterson \\
ASTM & American society for testing and materials \\
b & Coeficiente de sorção relacionado com a entalpia de sorção \\
Co & Concentração inicial do soluto \\
Ce & Concentração de equilíbrio do soluto na fase líquida \\
CG & Cromatografia em fase gasosa \\
CL & Concentração na fase líquida \\
$C_{s}$ & Concentração na fase sólida \\
d & Densidade \\
D & Difusividade intraparticular do soluto \\
DCE & Detector por captura de elétrons \\
D & Energia das ligações químicas entre moléculas \\
E & Constante da lei de Coulomb \\
E' & Parâmetro da isoterma de Dubinin-Astakhov \\
EPA & E.U. Environmental Protection Agency \\
EURO & Europa \\
h & Velocidade de sorção inicial da cinética de $2^{\text {a }}$ ordem \\
HDI & Hexametileno diisocianato \\
IEC & International electrotechnical commission \\
\hline
\end{tabular}




\begin{tabular}{ll} 
IPDI & Isofurona diisocianato \\
IUPAC & International Union of Pure and Applied Chemistry \\
Kd & Coeficiente de distribuição da isoterma linear \\
KF & Constante da isoterma de Freundlich \\
KFs & Parâmetro da isoterma de Fritz-Schlunder \\
MDI & Difenilmetano diisocianato \\
MEV & Microscopia eletrônica de varredura \\
NBR & Norma brasileira \\
PCB & Bifenila policlorada \\
PCDD & Dibenzodioxinas policloradas \\
PCDF & Dibenzofuranos policlorados \\
POP & Poluentes orgânicos persistentes \\
PVC & Cloreto de polivinila \\
TDI & Tolueno diisocianato \\
WHO & World health organization \\
& \\
\hline
\end{tabular}




\section{RESUMO}

Os PCBs, do inglês Polychlorinated Biphenyls (bifenilas policloradas), é o nome genérico dado à classe de compostos organoclorados resultante da reação do grupo bifenila com cloro anidro na presença de catalisador. São tóxicos, persistentes, bioacumulativos e representam o risco de provocar efeitos nocivos à saúde humana e ao meio ambiente. Grandes quantidades de PCBs foram produzidos em vários países entre 1927 e 1977. Nos Estados Unidos a proibição ocorreu em 1977. Utilizados como fluidos dielétricos em transformadores elétricos e capacitores em todo o mundo, comercialmente conhecidos como Ascarel, dentre outras denominações, tais como Aroclor, Pyralene, Clorophen, Inerteen, Asbestol e Kneclor. Devido à alta toxicidade, a produção e comercialização dos PCBs foram proibidas no mundo todo a partir de 1980. No Brasil, transformadores que tiveram o óleo mineral isolante, contaminado por PCBs, estando em uso ou em armazenamento, segundo os critérios da Norma ABNT NBR 13882, a destinação final do óleo isolante deverá ser feita por incineração e ou descontaminação a valores inferiores a $50 \mathrm{mg} / \mathrm{kg}$. Neste trabalho realizado no Instituto de Química de São Carlos - Universidade de São Paulo, desenvolveu-se um procedimento para a descontaminação de óleo contaminado com valor conhecido acima de $50 \mathrm{mg} / \mathrm{kg}$, por percolação em coluna contendo espuma de poliuretano derivada de óleo de mamona, produzida pelo Laboratório de Química Analítica e Tecnologia de Polímeros (GQATP), obtendo-se uma redução de 55\% dos níveis de PCBs em óleo contaminado. As espumas foram funcionalizadas com tiodiglicol e polissulfeto de amônio, obtendo-se respectivamente $24 \%$ e $11 \%$ de redução dos níveis de PCBs em óleo contaminado. Observou-se que a espuma de poliuretano produzida pelo 
GQATP, funciona como um adsorvente eficaz na remoção de PCBs, e que a utilização de n-hexano na dessorção da espuma, permite remover praticamente todos os PCBs adsorvidos. Portanto, esses tipos de espumas podem servir como adsorventes altamente eficazes na remoção dos PCBs presentes nos óleos minerais isolantes e, portanto, contribuir significativamente para a proteção do meio ambiente. 


\begin{abstract}
PCBs, (polychlorinated biphenyls), is the generic name given to the class of organochlorine compounds resulting from the reaction of the biphenyl group with anhydrous chlorine in the presence of catalyst. They are toxic, persistent, bioaccumulative and pose the risk of causing harm to human health and the environment. Large quantities of PCBs were produced in several countries between 1927 and 1977. In the United States the prohibition occurred in 1977. Used as dielectric fluids in electrical transformers and capacitors in the world, commercially known as Ascarel, among other names such as Aroclor, Pyralene, Clorophen, Inerteen, and Asbestol Kneclor. Due to high toxicity, production and marketing of PCBs have been banned worldwide since 1980. In Brazil, transformers that had insulating mineral oil, contaminated with PCBs, while in use or in storage, according to the criteria of the Standard NBR 13,882, the final destination of insulating oil should be by incineration or decontamination and the values below $50 \mathrm{mg} / \mathrm{kg}$. In a previous work carried out at the Chemistry Institute of Sao Carlos - University of Sao Paulo, a procedure was developed for the decontamination of oil contaminated with known value above $50 \mathrm{mg} / \mathrm{kg}$ of percolation column containing polyurethane foam derived from castor oil produced Laboratory of Analytical Chemistry and Technology of Polymers (GQATP), resulting in a $55 \%$ reduction in the levels of PCBs in contaminated oil. Foams were functionalized with thiodiglycol and Ammonium polysulfide, yielding respectively $24 \%$ and $11 \%$ reduction in the levels of PCBs in contaminated oil. It was observed that the polyurethane foam produced by GQATP function as an effective adsorbent for removal of PCBs, and that the use of $n$-hexane desorption of the foam allows to remove virtually all PCBs adsorbed. So these types
\end{abstract}


of foam can serve as highly efficient adsorbents for the removal of PCBs present in the insulating mineral oil, and thus contribute significantly to environmental protection. 


\section{OBJETIVOS}

O objetivo geral deste trabalho foi estudar a descontaminação de Bifenilas policloradas (PCBs) em óleos minerais isolantes por adsorção, utilizando-se espuma de poliuretano derivada de óleo de mamona.

Os objetivos específicos foram:

Determinar a influência de variáveis como temperatura e massa de espuma utilizada, fixando o volume utilizado na extração.

Comparar a eficiência da espuma normal obtida com o pré-polímero, denominado 253 , e o poliol para espuma rígida, com aquelas funcionalizadas contendo tiodiglicol e polissulfeto de amônio.

Verificar se após a passagem de um óleo novo isento de PCBs, na espuma contendo PCBs adsorvido, causaria a dessorção dos PCBs.

Verificar a eficiência do processo de dessorção dos PCBs adsorvidos pela espuma. 


\section{Capítulo I - Introdução}

\section{1. Óleos minerais isolantes}

O óleo mineral isolante tem sido utilizado em transformadores elétricos desde 1890, iniciando-se em 1855 com uma patente conferida a Addenbrooke e Ferranti, continua a ser o dielétrico líquido mais utilizado em transformadores, em associação com o papel isolante (APPELT,1975).

\subsection{Constituição dos óleos minerais isolantes}

As características ideais desejáveis para um dielétrico líquido a ser utilizado em transformadores, decorrem das funções que the são exigidas: elevada rigidez dielétrica, baixas perdas dielétricas, elevado coeficiente de transmissão térmica, baixa viscosidade para permitir uma fácil circulação, baixo ponto de fluidez, elevado ponto de combustão, baixa constante dielétrica, baixa atividade química, etc.

Designam-se por óleos minerais os óleos derivados diretamente do petróleo natural, distinguindo-se assim dos outros óleos de origem vegetal ou animal. Os óleos minerais isolantes são obtidos por processos de refinação e extração adequados a partir de determinadas frações de destilação do petróleo. Em princípio, isto é, ignorando impurezas ou traços de aditivos especiais, são exclusivamente constituídos por hidrocarbonetos, pertencentes aos seguintes grupos:

Hidrocarbonetos saturados de cadeia aberta (alcanos) na indústria petrolífera designados por parafinas, de cadeia linear ou ramificada, conhecidos, respectivamente, por parafinas normais e isoparafinas; 
( 1 )

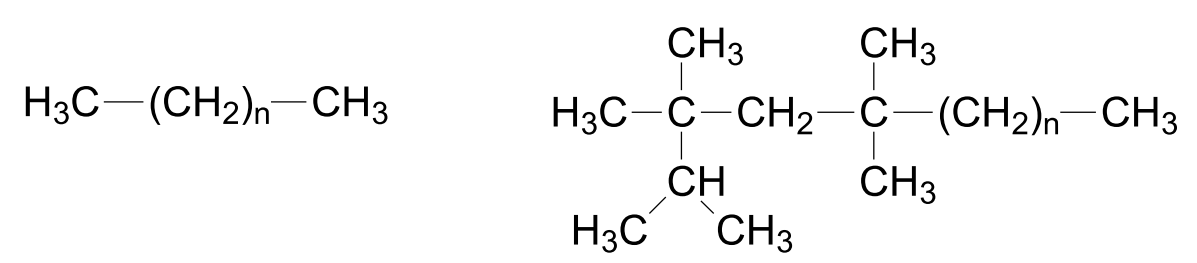

( II )

Hidrocarbonetos saturados de cadeia fechada (cicloalcanos), na indústria petrolífera designados por naftenos;

( III )<smiles>CCCC1CCCC1</smiles>

( IV )

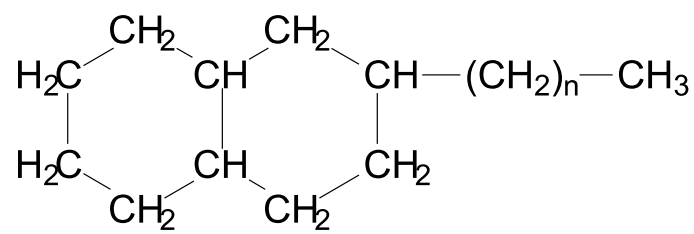

Hidrocarbonetos aromáticos, normalmente presentes em pequena quantidade.

$(\mathrm{V})$<smiles>CCCc1ccccc1</smiles>

( VII )

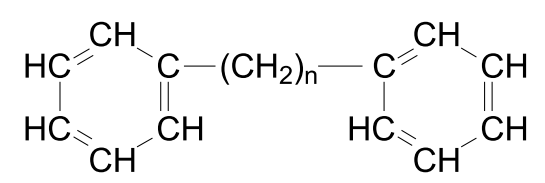

( VI )<smiles>CCCc1ccc2ccccc2c1</smiles>

( VIII )<smiles>CCCc1ccc2c(c1)CC1CCCCC1C2</smiles> 
Não se encontram nos óleos minerais isolantes hidrocarbonetos oleofínicos (alcenos) nem acetilênicos (alcinos), que são produtos indesejáveis devido à sua atividade química já relativamente elevada, o que resultaria em más características de envelhecimento dos óleos minerais isolantes (APPELT,1975).

A simplicidade da constituição dos óleos minerais isolantes, do ponto de vista da identificação dos grandes grupos de espécies químicas neles presentes, é apenas aparente. O número de hidrocarbonetos correspondentes teoricamente possíveis é extremamente grande. Assim, por exemplo, correspondendo à fórmula molecular $\mathrm{C}_{20} \mathrm{H}_{42}$ (que representa apenas parafinas) há 366319 isômeros possíveis (ERHART, 1966). No entanto, as limitações das características físico - químicas impostas, restringe consideravelmente o número de espécies distintas nos óleos minerais isolantes.

Um óleo mineral isolante é especificado por um conjunto de características que tem por objetivo identificar o produto (características físico-químicas gerais) e seu comportamento em serviço (características funcionais), isto é, as suas características como fluido dielétrico.

\subsection{Características Físico- Químicas}

\subsubsection{Cor e aparência}

A cor de um óleo isolante é determinada pela luz transmitida e é expressa por um valor numérico baseado na comparação com uma série de padrões de cores. Não é uma propriedade crítica, mas pode ser útil para avaliação comparativa. Um número de cor que aumenta rapidamente ou é muito alto pode ser uma indicação de deterioração ou contaminação do óleo. 
Além da cor, a aparência do óleo pode apresentar turbidez ou sedimentos, que podem indicar a presença de água livre, borra insolúvel, carbono, fibras, sujeira ou outros contaminantes (ABNT NBR 14483, 2005).

\subsubsection{Densidade}

Conforme a norma (ABNT NBR 7148, 2001), a densidade é usada para identificação do tipo de óleo. Em climas frios, a densidade do óleo pode ser importante na determinação de sua adequabilidade para uso. Por exemplo, cristais de gelo formados a partir de água separada podem flutuar no óleo de alta densidade e conduzir à abertura de arco elétrico na fusão posterior. Não há evidência de que a densidade seja afetada pela deterioração normal do óleo.

\subsubsection{Rigidez dielétrica}

A rigidez dielétrica segundo a norma (ABNT NBR-IEC 60156, 2005) é uma medida da capacidade do óleo resistir às condições normais de uso no equipamento elétrico. O óleo seco e limpo apresenta uma rigidez dielétrica inerentemente alta. Água livre e partículas sólidas, particularmente estas últimas, em combinação com altos níveis de água dissolvida, tendem a migrar para regiões de alta solicitação elétrica e reduzir drasticamente a rigidez dielétrica. A medida da rigidez dielétrica, portanto, serve principalmente para indicar a presença de contaminantes, tais como água ou partículas. Um valor baixo de rigidez dielétrica pode indicar que um ou mais destes elementos está presente. Entretanto, uma alta rigidez dielétrica não indica, necessariamente, a ausência de contaminantes. 


\subsubsection{Fator de perdas dielétricas}

Segundo a norma (ABNT NBR 12133, 1991) estes parâmetros são muito sensíveis à presença de contaminantes polares solúveis, produtos de envelhecimento ou coloides no óleo. As alterações nos níveis de contaminantes podem ser monitoradas pela medição destes parâmetros, mesmo quando a contaminação for tão pequena que esteja próxima do limite da deteç̧ão química.

A determinação de perdas dielétricas pode ser realizada através da medição do fator de potência ou do fator de dissipação. Limites aceitáveis para estes parâmetros dependem muito do tipo do equipamento. Entretanto, valores altos do fator de dissipação dielétrica ou valores baixos de resistividade podem afetar prejudicialmente o fator de potência e/ou a resistência de isolamento do equipamento elétrico.

\subsubsection{Teor de água}

Os transformadores são secos durante o processo de fabricação até que as medições ou procedimentos-padrão resultem em um teor de umidade na isolação celulósica inferior a $0,5 \%$, dependendo dos requisitos do comprador e do fabricante. Após a secagem inicial, o teor de umidade do sistema de isolação cresce continuamente. Há duas causas para o aumento da água na isolação do transformador:

- entrada de umidade proveniente da atmosfera;

- degradação da celulose e do óleo.

O óleo serve como um meio de transferência da umidade no interior do transformador. A água está presente no óleo em forma solúvel (dissolvida) e está também presente como hidrato adsorvido por produtos polares de envelhecimento. 
As partículas, tais como fibras de celulose, podem conter água. O teor de água no óleo é diretamente proporcional à concentração relativa de água (saturação relativa) até o nível de saturação (ABNT NBR 10710, 2006).

\subsection{6. Índice de neutralização}

De acordo com a norma (ABNT NBR 14248, 2009), o índice de neutralização (acidez) do óleo é a medida dos componentes ácidos presentes no óleo. O índice de neutralização de um óleo usado decorre da formação de produtos da oxidação ácida. Os ácidos e outros produtos de oxidação afetam, em conjunto com a água e contaminantes sólidos, o dielétrico e outras propriedades do óleo. Os ácidos têm um impacto na degradação dos materiais celulósicos e podem também ser responsáveis pela corrosão de peças de metal de um transformador. A taxa de aumento da acidez de um óleo em serviço é um indicador da taxa de envelhecimento do óleo.

\subsubsection{Tensão interfacial}

A tensão interfacial entre o óleo e a água é um ensaio para detectar contaminantes polares solúveis e produtos de oxidação. Esta característica varia com rapidez durante os estágios iniciais de envelhecimento, mas tende a estabilizar quando a deterioração é ainda moderada. Uma rápida diminuição da tensão interfacial pode também ser uma indicação de problemas de compatibilidade entre o óleo e alguns materiais do transformador (vernizes, gaxetas, etc.) ou de contaminação durante o enchimento com óleo. Com transformadores sobrecarregados a deterioração dos materiais é rápida e a tensão interfacial é uma ferramenta para a detecção da deterioração (ABNT NBR 6234,1965). 


\subsection{Contaminação em óleos minerais isolantes por PCBs}

As bifenilas policloradas (PCBs) são uma família de hidrocarbonetos aromáticos clorados sintéticos, com boas propriedades térmicas e elétricas. Estas propriedades combinadas com a excelente estabilidade química tornaram-nas úteis em numerosas aplicações comerciais. Entretanto, sua estabilidade química e resistência à biodegradação deram origem à preocupação relacionada com a poluição ambiental, higiene e segurança do trabalho.

A preocupação crescente sobre o impacto ambiental dos PCBs restringiu progressivamente o seu uso desde o início dos anos 70 e seu uso em novas instalações e equipamentos foi banido por acordo internacional em 1986. O teor de PCB do óleo em equipamentos novos deve ser medido para confirmar se o óleo está isento de PCB. Daí em diante, sempre que houver um risco de contaminação potencial (tratamento de óleo, reparos em transformador, etc.) o óleo deve ser analisado, de acordo com a norma ABNT NBR 13882. Se o teor de PCB exceder limites definidos, devem ser adotadas medidas conforme indicado na norma ABNT NBR 8371.

No Brasil não se tem registros da produção de PCBs, sendo todo o produto importado principalmente dos Estados Unidos e Alemanha. As restrições para seu uso foram implementadas através da Portaria Interministerial 19, de 2 de janeiro de 1981. Essa portaria estabelece, entre outras coisas, a proibição de fabricação, comercialização e uso de PCBs em todo território nacional. Entretanto, permite que os equipamentos já instalados continuem em funcionamento até sua substituição integral ou a troca do fluido dielétrico por produto isento de PCBs. A referida portaria também proíbe o descarte de PCBs ou produtos contaminados em cursos d'água, exposição de equipamentos contendo PCBs a intempéries, além de regulamentar o 
local de instalação dos equipamentos que contenham PCBs que ainda estejam funcionando (PENTEADO; VAZ ,2001).

Além dessa Portaria, há a Instrução Normativa 001 SEMA/ STC/CRC, do Ministério do Interior, de 10 de junho de 1983, que disciplina as condições a serem observadas no manuseio, armazenagem e transporte de PCBs e/ou resíduos contaminados. Há também a norma ABNT/NBR 3871 que estabelece orientação para o manuseio, embalagem, rotulação, armazenagem e transporte de PCBs para transformadores e capacitores, níveis de contaminação permitidos em equipamentos novos, equipamentos em operação, além de valores para manutenção e descarte dos fluidos e equipamentos elétricos que contenham PCBs. (PENTEADO; VAZ, 2001). 


\section{Capítulo I I - Revisão bibliográfica}

\section{Bifenilas policloradas (PCBs)}

\subsection{Estrutura química dos $\mathrm{PCBs}$}

Embora o benzeno seja um composto muito estável, seu aquecimento a temperaturas muito elevadas pode romper as ligações carbono hidrogênio. Tal fato é explorado comercialmente quando o benzeno é aquecido até cerca de $750^{\circ} \mathrm{C}$ em presença de óxido de chumbo como catalisador para formar bifenila, uma molécula na qual dois anéis de benzeno encontram-se unidos por uma ligação simples formada entre dois carbonos que perderam seus átomos de hidrogênio, como mostra a figura 1 :
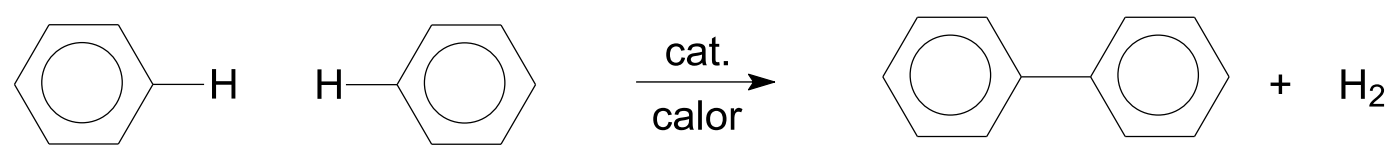

bifenila

Figura 1- Reação de formação da bifenila.

Como no caso do benzeno, se a bifenila reage com cloro na presença de cloreto férrico como catalisador, alguns de seus átomos de hidrogênio são substituídos por cloro. Quanto maior a quantidade de cloro inicialmente presente e quanto mais tempo for dado para o transcurso da reação, maior será a extensão (em média) da cloração da molécula de bifenila. Os produtos resultantes são bifenilas policloradas, ou, para abreviar, PCBs. A reação de bifenila com cloro produz uma mistura de muitos dos 209 congêneres da família dos PCBs; as proporções exatas dependem da razão de cloro para bifenila e do tempo e temperatura de reação. Embora muitos PCBs sejam sólidos, as misturas são normalmente líquidas ou sólidas, com baixos 
pontos de fusão. Compostos puros da família dos PCBs não foram isolados com finalidade comercial; eles são vendidos sob a forma de misturas parcialmente separadas, nas quais o teor médio de cloro varia de 21 a $68 \%$ nos diferentes produtos ( Tabela 1) (BAIRD, 2003).

Tabela 1 - Composição e grau de cloração de misturas comerciais de PCBs.

\begin{tabular}{|c|c|c|c|c|c|c|c|c|c|c|c|c|}
\hline & & & \multicolumn{10}{|c|}{ Percentagem de congêneres } \\
\hline & & & & & úme & $\mathrm{od}$ & áton & os & $\mathrm{clo}$ & & & \\
\hline $\begin{array}{l}\text { Produto } \\
\text { Comercial }\end{array}$ & $\%$ & & 1 & 2 & 3 & 4 & 5 & 6 & 7 & 8 & 9 & 10 \\
\hline PCB & Cloro & $\begin{array}{l}\text { Número de possíveis } \\
\text { isômeros }\end{array}$ & 3 & 12 & 23 & 42 & 46 & 42 & 24 & 12 & 3 & 1 \\
\hline $\begin{array}{c}\text { Aroclor } \\
1232 \\
\end{array}$ & 32 & & 26 & 29 & 24 & 14 & & & & & & \\
\hline $\begin{array}{c}\text { Aroclor } \\
1016 \\
\end{array}$ & 41 & & 2 & 19 & 57 & 22 & & & & & & \\
\hline $\begin{array}{c}\text { Aroclor } \\
1242 \\
\end{array}$ & 42 & & 3 & 13 & 28 & 30 & 22 & 4 & & & & \\
\hline $\begin{array}{c}\text { Aroclor } \\
1248\end{array}$ & 48 & & & 2 & 18 & 40 & 36 & 4 & & & & \\
\hline $\begin{array}{c}\text { Aroclor } \\
1254 \\
\end{array}$ & 54 & & & & & 11 & 49 & 34 & 6 & & & \\
\hline $\begin{array}{c}\text { Aroclor } \\
1260 \\
\end{array}$ & 60 & & & & & & 12 & 38 & 41 & 8 & 1 & \\
\hline
\end{tabular}

Fonte: http://www.chem.unep.ch/pops/pops inc/proceedings/bangkok/FIEDLER1.html

\subsubsection{Estruturas químicas de congêneres do Aroclor 1242}
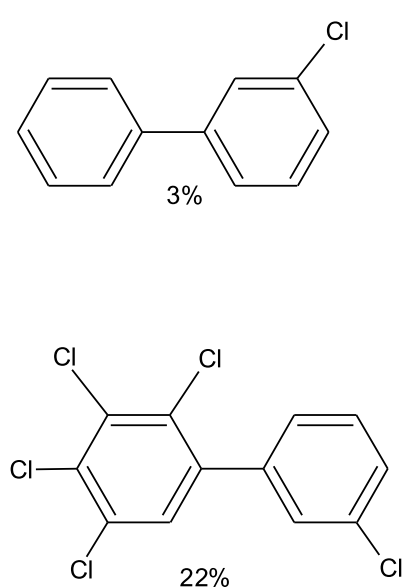
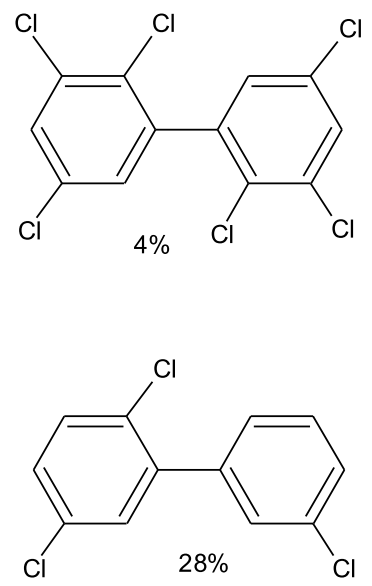
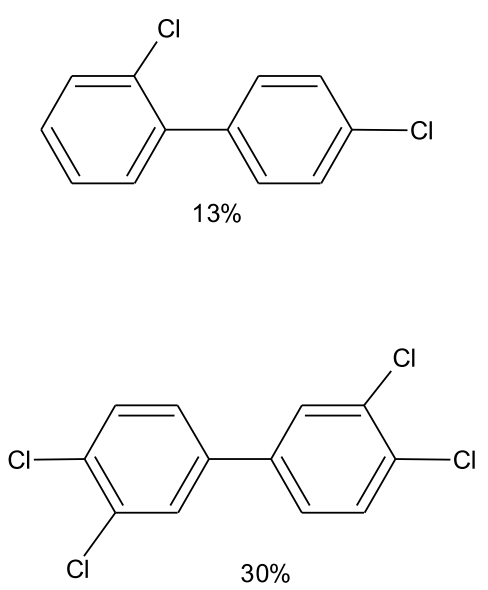

Figura 2 - Mostra as estruturas químicas de congêneres do Aroclor 1242, com as possíveis percentagens de átomos de cloro.

Fonte: HUTZINGER, O.; SAFE,S.; ZITKO, V. The Chemistry of PCBs; New York, CRC Press, 1974. 


\subsubsection{Estruturas químicas de congêneres do Aroclor 1254}<smiles>Clc1ccc(-c2c(Cl)cc(Cl)c(Cl)c2Cl)c(Cl)c1Cl</smiles><smiles>Clc1ccc(-c2ccc(Cl)c(Cl)c2)cc1Cl</smiles><smiles>Clc1cc(Cl)c(Cl)c(-c2cc(Cl)cc(Cl)c2Cl)c1</smiles><smiles>Clc1cccc(-c2cc(Cl)c(Cl)c(Cl)c2Cl)c1</smiles>

Figura 3 - Mostra as estruturas químicas de congêneres do Aroclor 1254, com as possíveis percentagens de átomos de cloro.

Fonte: HUTZINGER, O.; SAFE,S.; ZITKO, V. The Chemistry of PCBs; New York, CRC Press, 1974.

\subsubsection{Estruturas químicas de congêneres do Aroclor 1260}

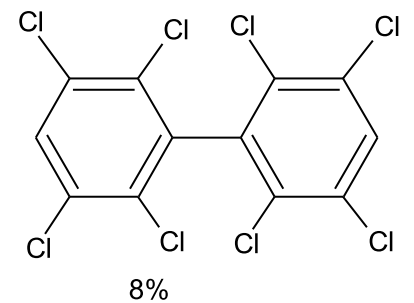

$8 \%$<smiles>Clc1cc(Cl)c(Cl)c(-c2c(Cl)c(Cl)c(Cl)c(Cl)c2Cl)c1Cl</smiles>

$1 \%$
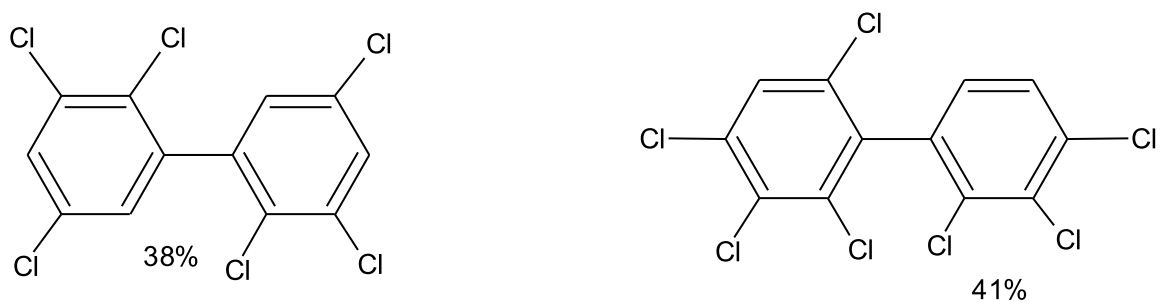

Figura 4 - Mostra as estruturas químicas de congêneres do Aroclor 1242, com as possíveis percentagens de átomos de cloro.

Fonte: HUTZINGER, O.; SAFE,S.; ZITKO, V. The Chemistry of PCBs; New York, CRC Press, 1974. 


\subsection{Classificação de congêneres de PCBs proposta por Ballschmiter e Zell}

A nomenclatura utilizada para os PCBs segue as regras propostas pela União Internacional para Química Pura e Aplicada (International Union for Pure and Applied Chemistry - IUPAC) conforme Tabela 2. Entretanto, devido à dificuldade de classificação destes compostos através do método proposto por este órgão, Ballschmiter e Zell (1980) propuseram uma nova sistemática onde os congêneres seriam numerados de 1 a 209 (Pereira, 2002). Para exemplificar as duas classificações, o congênere $2,2^{\prime}, 3,3^{\prime}, 4,4^{\prime}, 5,5^{\prime}$-octaclorobifenila passaria a ser o PCB194 pela classificação proposta por Ballschmiter e Zell (1980). 
Tabela 2 - Nomenclatura de homólogos de PCBs de acordo com a IUPAC (BALLSCHMITER; ZELL 1980).

\begin{tabular}{|c|c|c|c|c|c|c|c|}
\hline $\mathbf{N}^{\circ}$ & Estrutura & $\mathbf{N}^{0}$ & Estrutura & $\mathbf{N}^{0}$ & Estrutura & $\mathbf{N}^{0}$ & Estrutura \\
\hline \multicolumn{2}{|c|}{ Monoclorobifenila } & \multicolumn{2}{|c|}{ Tetraclorobifenila } & \multicolumn{2}{|c|}{ Pentaclorobifenila } & \multicolumn{2}{|r|}{ Hexaclorobifenila } \\
\hline 1 & 2 & 52 & $2,2^{\prime}, 5,5^{\prime}$ & 107 & $2,3,3^{\prime}, 4^{\prime}, 5$ & 161 & $2,3,3^{\prime}, 4,5^{\prime}, 6$ \\
\hline 2 & 3 & 53 & $2,2^{\prime}, 5,6^{\prime}$ & 108 & $2,3,3^{\prime}, 4,5^{\prime}$ & 162 & $2,3,3^{\prime}, 4^{\prime}, 5,5^{\prime}$ \\
\hline \multirow[t]{2}{*}{3} & 4 & 54 & $2,2^{\prime}, 6,6^{\prime}$ & 109 & $2,3,3,4,6$ & 163 & $2,3,3^{\prime}, 44^{\prime}, 5,6$ \\
\hline & & 55 & $2,3,3^{\prime}, 4$ & 110 & $2,3,3^{\prime}, 4^{\prime}, 6$ & 164 & $2,3,3^{\prime}, 4^{\prime}, 5^{\prime}, 6$ \\
\hline \multicolumn{2}{|c|}{ Diclorobifenila } & 56 & $2,3,3^{\prime}, 4^{\prime}$ & 111 & $2,3,3^{\prime}, 5,5^{\prime}$ & 165 & $2,3,3,5,5$ ', 6 \\
\hline 4 & $2,2^{\prime}$ & 57 & $2,3,3^{\prime}, 5$ & 112 & $2,3,3,5,6$ & 166 & $2,3,4,4,5,6$ \\
\hline 5 & 2,3 & 58 & $2,3,3^{\prime}, 5^{\prime}$ & 113 & $2,3,3^{\prime}, 5^{\prime}, 6$ & 167 & $2,3^{\prime}, 4,4^{\prime}, 5,5^{\prime}$ \\
\hline 6 & 2,3 " & 59 & $2,3,3^{\prime}, 6$ & 114 & $2,3,4,4,, 5$ & 168 & $2,3^{\prime}, 4,4^{\prime}, 5^{\prime}, 6$ \\
\hline 7 & 2,4 & 60 & $2,3,4,4^{\prime}$ & 115 & $2,3,4,4,, 6$ & 169 & $3,3^{\prime}, 4,4^{\prime}, 5,5^{\prime}$ \\
\hline 8 & $2,4^{\prime}$ & 61 & $2,3,4,5$ & 116 & $2,3,4,5,6$ & & \\
\hline 9 & 2,5 & 62 & $2,3,4,6$ & 117 & $2,3,4,5,6$ & \multicolumn{2}{|c|}{ Heptaclorobifenila } \\
\hline 10 & 2,6 & 63 & $2,3,4^{\prime}, 5$ & 118 & $2,3^{\prime}, 4,4^{\prime}, 5$ & 170 & $2,2^{\prime}, 3,3^{\prime}, 4,4^{\prime}, 5$ \\
\hline 11 & $3,3^{\prime}$ & 64 & $2,3,4^{\prime}, 6$ & 119 & $2,3,4,4^{\prime}, 6$ & 171 & $2,2^{\prime}, 3,3^{\prime}, 4,4^{\prime}, 6$ \\
\hline 12 & 3,4 & 65 & $2,3,5,6$ & 120 & $2,3^{\prime}, 4,5,5^{\prime}$ & 172 & $2,2^{\prime}, 3,3^{\prime}, 4,5,5^{\prime}$ \\
\hline 13 & $3,4^{\prime}$ & 66 & $2,3^{\prime}, 4,4^{\prime}$ & 121 & $2,3^{\prime}, 4,5^{\prime}, 6$ & 173 & $2,2^{\prime}, 3,33^{\prime}, 4,5,6$ \\
\hline 14 & 3,5 & 67 & $2,3,4,5$ & 122 & $2^{\prime}, 3,3,3^{\prime}, 4,5$ & 174 & $2,2^{\prime}, 3,3^{\prime}, 4,5,6^{\prime}$ \\
\hline \multirow[t]{2}{*}{15} & $4,4^{\prime}$ & 68 & $2,3^{\prime}, 4,5^{\prime}$ & 123 & $2,3,4,4^{\prime}, 5$ & 175 & $2,2^{\prime}, 3,3^{\prime}, 4,5^{\prime}, 6$ \\
\hline & & 69 & $2,3,4,6$ & 124 & $2^{\prime}, 3,4,5,5^{\prime}$ & 176 & $2,2^{\prime}, 3,3^{\prime}, 4,6,6^{\prime}$ \\
\hline \multicolumn{2}{|c|}{ Triclorobifenila } & 70 & $2,3^{\prime}, 4^{\prime}, 5$ & 125 & $2^{\prime}, 3,4,5,6^{\prime}$ & 177 & $2,2^{\prime}, 3,3^{\prime}, 4^{\prime}, 5,6$ \\
\hline 16 & $2,2 ', 3$ & 71 & $2,3,4^{\prime}, 6$ & 126 & $3,3^{\prime}, 4,4^{\prime}, 5$ & 178 & $2,2^{\prime}, 3,3^{\prime}, 5,5^{\prime}, 6$ \\
\hline 17 & $2,2 ', 4$ & 72 & $2,3^{\prime}, 5,5^{\prime}$ & 127 & $3,3^{\prime}, 4,5,5^{\prime}$ & 179 & $2,2^{\prime}, 3,3^{\prime}, 5,6,6^{\prime}$ \\
\hline 18 & $2,2^{\prime}, 5$ & 73 & $2,3^{\prime}, 5^{\prime}, 6$ & & & 180 & $2,2^{\prime}, 3,4,4^{\prime}, 5,5^{\prime}$ \\
\hline 19 & $2,2^{\prime}, 6$ & 74 & $2,4,4$ ', 5 & \multicolumn{2}{|c|}{ Hexaclorobifenila } & 181 & $2,2^{\prime}, 3,4,4^{\prime}, 5,6$ \\
\hline 20 & $2,3,3^{\prime}$ & 75 & $2,4,4^{\prime}, 6$ & 128 & $2,2^{\prime}, 3,3^{\prime}, 4,4^{\prime}$ & 182 & $2,2^{\prime}, 3,4,4^{\prime}, 5,6^{\prime}$ \\
\hline 21 & $2,3,4$ & 76 & $2^{\prime}, 3,4,5$ & 129 & $2,2^{\prime}, 3,3^{\prime}, 4,5$ & 183 & $2,2^{\prime}, 3,4,4^{\prime}, 5^{\prime}, 6$ \\
\hline 22 & $2,3,4^{\prime}$ & 77 & $3,3^{\prime}, 4,4^{\prime}$ & 130 & $2,2^{\prime}, 3,3^{\prime}, 4,5^{\prime}$ & 184 & $2,2,3,4,4^{\prime}, 6,6^{\prime}$ \\
\hline 23 & $2,3,5$ & 78 & $3,3^{\prime}, 4,5$ & 131 & $2,2^{\prime}, 3,3^{\prime}, 4,6$ & 185 & $2,2,3,4,5,5,6$ \\
\hline 24 & $2,3,6$ & 79 & $3,3^{\prime}, 4,5^{\prime}$ & 132 & $2,2^{\prime}, 3,3^{\prime}, 4,6^{\prime}$ & 186 & $2,2,3,4,5,6,6^{\prime}$ \\
\hline 25 & $2,3^{\prime}, 4$ & 80 & $3,3^{\prime}, 5,5^{\prime}$ & 133 & $2,2^{\prime}, 3,3^{\prime}, 5,5^{\prime}$ & 187 & $2,2^{\prime}, 3,4^{\prime}, 5,5^{\prime}, 6$ \\
\hline 26 & $2,3^{\prime}, 5$ & 81 & $3,4,4^{\prime}, 5$ & 134 & $2,2^{\prime}, 3,3^{\prime}, 5,6$ & 188 & $2,2^{\prime}, 3,4^{\prime}, 5,6,6^{\prime}$ \\
\hline 27 & $2,3,6$ & & & 135 & $2,2^{\prime}, 3,3^{\prime}, 5,6^{\prime}$ & 189 & $2,3,3^{\prime}, 4,4^{\prime}, 5,5^{\prime}$ \\
\hline 28 & $2,4,4^{\prime}$ & \multicolumn{2}{|c|}{ Pentaclorobifenila } & 136 & $2,2^{\prime}, 3,3^{\prime}, 6,6^{\prime}$ & 190 & $2,3,3^{\prime}, 4,4^{\prime}, 5,6$ \\
\hline 29 & $2,4,5$ & 82 & $2,2^{\prime}, 3,3^{\prime}, 4$ & 137 & $2,2^{\prime}, 3,4,4^{\prime}, 5$ & 191 & $2,3,3^{\prime}, 4,4^{\prime}, 5^{\prime}, 6$ \\
\hline 30 & $2,4,6$ & 83 & $2,2^{\prime}, 3,3,3^{\prime}, 5$ & 138 & $2,2,3,4,4^{\prime}, 5^{\prime}$ & 192 & $2,3,3,4,5,5,6$ \\
\hline 31 & $2,4^{\prime}, 5$ & 84 & $2,2^{\prime}, 3,3^{\prime}, 6$ & 139 & $2,2^{\prime}, 3,4,4^{\prime}, 6$ & 193 & $2,3,3$ ', 4 ", 5,5', 6 \\
\hline 32 & $2,4^{\prime}, 6$ & 85 & $2,2^{\prime}, 3,4,4^{\prime}$ & 140 & $2,2^{\prime}, 3,4,4^{\prime}, 6^{\prime}$ & & \\
\hline 33 & $2 ', 3,4$ & 86 & $2,2,3,4,5$ & 141 & $2,2,3,4,5,5^{\prime}$ & \multicolumn{2}{|c|}{ Octaclorobifenila } \\
\hline 34 & $2,3,5$ & 87 & $2,2^{\prime}, 3,4,5^{\prime}$ & 142 & $2,2,3,4,5,6$ & 194 & $2,2^{\prime}, 3,3^{\prime}, 4,4^{\prime}, 5,5^{\prime}$ \\
\hline 35 & $3,3^{\prime}, 4$ & 88 & $2,2,3,4,6$ & 143 & $2,2,3,4,5,6^{\prime}$ & 195 & $2,2^{\prime}, 3,3^{\prime}, 4,4^{\prime}, 5,6$ \\
\hline 36 & $3,3^{\prime}, 5$ & 89 & $2,2^{\prime}, 3,4,6^{\prime}$ & 144 & $2,2^{\prime}, 3,4,5^{\prime}, 6$ & 196 & $2,2^{\prime}, 3,3^{\prime}, 4,4^{\prime}, 5^{\prime}, 6$ \\
\hline 37 & $3,4,4^{\prime}$ & 90 & $2,2 ', 3,4,5$ & 145 & $2,2,3,4,6,6^{\prime}$ & 197 & $2,2^{\prime}, 3,3^{\prime}, 4,4^{\prime}, 6,6^{\prime}$ \\
\hline 38 & $3,4,5$ & 91 & $2,2^{\prime}, 3,4^{\prime}, 6$ & 146 & $2,2^{\prime}, 3,4^{\prime}, 5,5^{\prime}$ & 198 & $2,2^{\prime}, 3,3^{\prime}, 4,5,5^{\prime}, 6$ \\
\hline \multirow[t]{2}{*}{39} & $3,4^{\prime}, 5$ & 92 & $2,2^{\prime}, 3,5,5^{\prime}$ & 147 & $2,2^{\prime}, 3,4^{\prime}, 5,6$ & 199 & $2,2,3,3^{\prime}, 4^{\prime}, 5,5^{\prime}, 6$ \\
\hline & & 93 & $2,2^{\prime}, 3,5,6$ & 148 & $2,2,3,4,5,6^{\prime}$ & 200 & $2,2^{\prime}, 3,3^{\prime}, 4,5,6,6^{\prime}$ \\
\hline \multicolumn{2}{|c|}{ Tetraclorobifenila } & 94 & $2,2^{\prime}, 3,5,6^{\prime}$ & 149 & $2,2^{\prime}, 3,4^{\prime}, 5^{\prime} 6$ & 201 & $2,2^{\prime}, 3,3^{\prime}, 4,5^{\prime}, 6,6^{\prime}$ \\
\hline 40 & $2,2^{\prime}, 3,3^{\prime}$ & 95 & $2,2^{\prime}, 3,5^{\prime}, 6$ & 150 & $2,2^{\prime}, 3,4^{\prime}, 6,6^{\prime}$ & 202 & $2,2^{\prime}, 3,3^{\prime}, 5,5^{\prime}, 6,6^{\prime}$ \\
\hline 41 & $2,2 ', 3,4$ & 96 & $2,2^{\prime}, 3,6,6^{\prime}$ & 151 & $2,2^{\prime}, 3,5,5^{\prime}, 6$ & 203 & $2,2^{\prime}, 3,4,4^{\prime}, 5,5^{\prime}, 6$ \\
\hline 42 & $2,2^{\prime}, 3,4^{\prime}$ & 97 & $2,2^{\prime}, 3^{\prime}, 4,5$ & 152 & $2,2,3,5,6,6$ & 204 & $2,2^{\prime}, 3,4,4,5,6,6^{\prime}$ \\
\hline 43 & $2,2 ', 3,5$ & 98 & $2,2 ', 3,4,6$ & 153 & $2,2^{\prime}, 4,4^{\prime}, 5,5^{\prime}$ & 205 & $2,3,3^{\prime}, 4,4^{\prime}, 5,5^{\prime}, 6^{\prime}$ \\
\hline 44 & $2,2,3,5^{\prime}$ & 99 & $2,2^{\prime}, 4,4^{\prime}, 5$ & 154 & $2,2,4,4,5,6^{\prime}$ & & \\
\hline 45 & $2,2^{\prime}, 3,6$ & 100 & $2,2^{\prime}, 4,4^{\prime}, 6$ & 155 & $2,2^{\prime}, 4,4,6,6^{\prime}$ & \multicolumn{2}{|r|}{ Nonaclorobifenila } \\
\hline 46 & $2,2^{\prime}, 3,6^{\prime}$ & 101 & $2,2^{\prime}, 4,5,5^{\prime}$ & 156 & $2,3,3^{\prime}, 4,4^{\prime}, 5$ & 206 & 2,2 ', 3,3', 4,4 ', 5,5', 6 \\
\hline 47 & $2,2,4,4^{\prime}$ & 102 & $2,2^{\prime}, 4,5,6^{\prime}$ & 157 & $2,3,3^{\prime}, 4,4^{\prime}, 5^{\prime}$ & 207 & $2,2^{\prime}, 3,3^{\prime}, 4,4^{\prime}, 5,6,6^{\prime}$ \\
\hline 48 & $2,2^{\prime}, 4,5$ & 103 & $2,2^{\prime}, 4,5^{\prime}, 6$ & 158 & $2,3,3^{\prime}, 4,4^{\prime}, 6$ & 208 & $2,2^{\prime}, 3,3^{\prime}, 4,5,5^{\prime}, 6,6^{\prime}$ \\
\hline 49 & $2,2^{\prime}, 4,5^{\prime}$ & 104 & $2,2^{\prime}, 4,6,6^{\prime}$ & 159 & $2,3,3,4,5,5^{\prime}$ & & \\
\hline 50 & $2,2^{\prime}, 4,6$ & 105 & $2,3,3,4,4$ & 160 & $2,3,4,4,5,6$ & \multicolumn{2}{|r|}{ Decaclorobifenila } \\
\hline 51 & $2,2^{\prime}, 4,6^{\prime}$ & 106 & $2,3,3,4,5$ & & & 209 & $2,2^{\prime}, 3,3^{\prime}, 4,4^{\prime}, 5,5^{\prime}, 6,6^{\prime}$ \\
\hline
\end{tabular}

Fonte: http://www.chem.unep.ch/pops/pops inc/proceedings/bangkok/FIEDLER1.htm 


\subsection{Propriedades físico-químicas dos PCBs}

As propriedades físicas e químicas dos Arocloros (PCBs) estão resumidos na Tabela 3. Uma propriedade importante dos PCBs é a sua inércia; resistem ácidos e álcalis e tem estabilidade térmica. Isso faz com que eles sejam úteis em uma ampla variedade de aplicações, incluindo fluidos dielétricos em transformadores e capacitores, fluidos de transferência de calor, e lubrificantes (AFGHAN; CHAU, 1989). Em geral, os PCBs são relativamente insolúveis em água, a solubilidade diminui com o aumento da cloração (Tabela 3). São também muito solúveis em solventes orgânicos apolares e lipídios biológicos (EPA 1980). PCBs são combustíveis líquidos e os produtos da combustão podem ser mais perigosos do que o próprio material. Subprodutos da combustão incluem cloreto de hidrogênio, dibenzodioxinas policloradas (PCDD) e os dibenzofuranos policlorados (PCDF) (NFPA, 1994).

Tabela 3 - Propriedades físico - químicas de alguns Arocloros (PCBs).

\begin{tabular}{|c|c|c|c|c|c|}
\hline $\begin{array}{l}\text { Composto } \\
\text { Arocloro }\end{array}$ & $\begin{array}{l}\text { Solubilidade } \\
\text { em água } \\
\text { (mg/l) } 25^{\circ} \mathrm{C}\end{array}$ & $\begin{array}{l}\text { Pressão de } \\
\text { Vapor (torr) } \\
25^{\circ} \mathrm{C}\end{array}$ & $\begin{array}{l}\text { Densidade } \\
\left(\mathrm{g} / \mathrm{cm}^{3}\right) \\
25^{\circ} \mathrm{C}\end{array}$ & Aparência & $\begin{array}{l}\text { Ponto de } \\
\text { Ebulição } \\
\left({ }^{\circ} \mathrm{C}\right) \text { a } 750 \\
\text { torr }\end{array}$ \\
\hline 1016 & 0.42 & $4.0 \times 10^{-4}$ & 1.33 & Óleo claro & $325-356$ \\
\hline 1221 & 0.59 & $6.7 \times 10^{-3}$ & 1.15 & Óleo claro & $275-320$ \\
\hline 1232 & 0.45 & $4.1 \times 10^{-3}$ & 1.24 & Óleo claro & $290-325$ \\
\hline $\begin{array}{l}1242 \\
1248\end{array}$ & $\begin{array}{c}0.24 \\
0.054\end{array}$ & $\begin{array}{l}4.1 \times 10^{-3} \\
4.9 \times 10^{-4}\end{array}$ & $\begin{array}{l}1.35 \\
1.41\end{array}$ & $\begin{array}{l}\text { Óleo claro } \\
\text { Óleo claro }\end{array}$ & $\begin{array}{l}325-366 \\
340-375\end{array}$ \\
\hline 1254 & 0.021 & $7.7 \times 10^{-5}$ & 1.50 & $\begin{array}{l}\text { Óleo viscoso } \\
\text { amarelo claro }\end{array}$ & $365-390$ \\
\hline 1260 & 0.0027 & $4.0 \times 10^{-5}$ & 1.58 & $\begin{array}{c}\text { Resina viscosa } \\
\text { amarelo claro }\end{array}$ & 385 \\
\hline
\end{tabular}

Fonte: IARC (1978), WHO/EURO (1987). 


\subsection{Nomenclatura}

A nomenclatura para os 209 congêneres de PCBs, adotada pela IUPAC (International Union of Pure and Applied Chemistry) conforme mostrado na Figura 5 considera a posição relativa dos átomos de cloro na estrutura bifenila, sendo a posição 1 reservada para a ligação entre os anéis. A partir desta, no anel da esquerda, as posições são numeradas em ordem crescente no sentido anti-horário. No outro anel as posições são numeradas da mesma forma, mas em sentido horário, adicionando-se um índice para diferenciar do outro anel (BALLSCHIMITER, 1980).
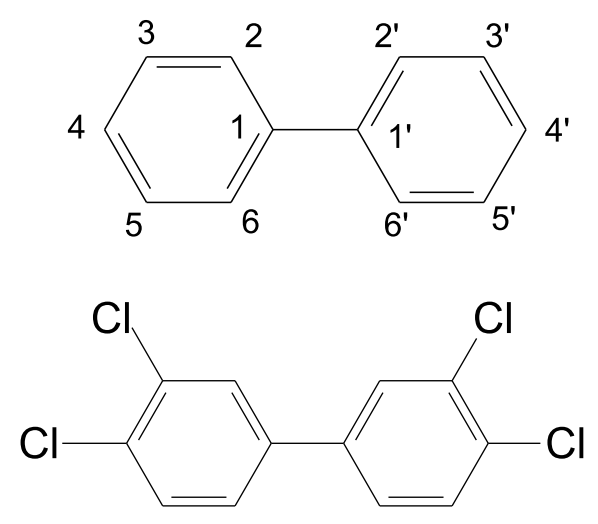

\section{3,3',4,4'-tetraclorobifenil}

Figura 5- Estrutura química da bifenila policlorada (PCB).

\subsection{Produção e usos}

Todos os PCBs são praticamente insolúveis em água, mas são solúveis em meios hidrofóbicos, tais como substâncias gordurosas ou oleosas. Do ponto de vista comercial, eles tornaram-se atrativos porque são líquidos quimicamente inertes e difíceis de queimar, têm pressões de vapor baixas, sua produção não é cara e são excelentes isolantes elétricos. Por essas propriedades, foram extensivamente 
empregados como fluidos refrigerantes em transformadores e capacitores elétricos. Mais tarde, foram também utilizados como plastificantes, isto é, agentes usados para conseguir uma maior flexibilidade em outros materiais, como o PVC; em papel copiativo "sem carbono"; como solvente sem coloração para reciclagem de papel de jornal; como fluidos de transferência de calor em maquinaria; como agentes de impermeabilização, entre várias outras aplicações. Seu uso está demonstrado na Tabela 4 (HUTZINGER,1974).

Tabela 4 - Uso dos PCBs classificados de acordo com o tipo de Arocloro (HUTZINGER, O., 1974).

Uso de PCBs

Capacitores Elétricos

Transformadores Elétricos

Bombas de Vácuo

Turbinas de Transmissão de Gás

Fluidos Hidráulicos

Resinas Plastificantes

Adesivos

Plastificante para Borracha

Sistema de Transferência de Calor

Aditivo antichama

Óleos de corte, lubrificantes

Pesticida $^{a}$

Papel Carbono
Tipo de Arocloro 1221,1254

$1242,1254,1260$

1248,1254

1221,1242

$1232,1242,1248,1254,1260$

$1248,1254,1260,1262,1268$

$1221,1232,1242,1248,1254$

$1221,1232,1242,1248,1254,1268$

1242

1254,1260

1254,1260

1254

1242

${ }^{a}$ utilizados como conservantes de pesticidas 
Entre 1929 e 1977, cerca de 700.000 toneladas de PCBs foram fabricados nos Estados Unidos, 625.000 toneladas foram utilizadas em nível nacional e 75.000 toneladas foram exportadas. Utilização de PCB em 1970, atingiu 42.500 toneladas anuais. A "Environmental Protection Agency" (EPA) estima que mais da metade do PCB vendido nos Estados Unidos foram eliminados antes da promulgação da regulamentação federal em 1976. Embora os PCBs já não sejam comercialmente fabricados e sua disposição proveniente de equipamentos industriais existentes é fortemente regulamentada, existem várias fontes potenciais para a continuação no meio ambiente. Essas fontes incluem: (1) uso continuado e a eliminação de PCB dos produtos que os contenham, tais como transformadores, capacitores e outros equipamentos elétricos que foram fabricados antes de 1977, (2) combustão de materiais contendo PCBs (3), reciclagem de produtos contaminados com PCBs, tais como papel autocopiativo, e (4) PCBs em armazenamento, eliminação de resíduos de bens de consumo usados e lixo doméstico que também podem conter PCBs cuja utilização e eliminação não sejam regulamentados. O banco de dados da EPA para registro de transformadores elétricos (EPA, 2000) mostra que, a partir de 1998, 18.714 transformadores relacionados continham um total de cerca de 54.000 toneladas de PCBs e, a partir de 1988, 141.000 toneladas de PCBs permaneceram em serviço em equipamentos elétricos. Devido à longa vida útil dos equipamentos, quantidades consideráveis de PCBs podem ainda permanecer em uso por muitos anos (BAIRD, 2003).

\subsection{Ocorrência no Ambiente}

Quando os produtos contendo PCBs se decompõem, ou são destruídos pelo fogo, quantidades significativas de PCBs ainda permanecem, devido à sua alta 
estabilidade. Durante incinerações em ambientes com pouco oxigênio, e onde as moléculas de PCBs são quebradas, compostos altamente tóxicos como os dibenzofuranos policlorados, podem ser formados e liberados. Já ocorreram também descargas acidentais de PCBs e contaminantes associados ao ambiente, através do vazamento de líquidos durante a operação de transformadores e capacitores, e da eliminação inadequada de equipamentos ou produtos (ASCH, 1997).

\subsection{Exposição ocupacional e efeitos}

Os seres humanos absorvem PCBs por ingestão, inalação e através da pele, embora mais de $90 \%$ de exposição seja através dos alimentos (THEELEN et al. 1993). A gordura animal é a principal fonte de PCBs. Uma vez absorvidos, podem equilibrar entre os compartimentos de lipídios no corpo inteiro, devido à sua elevada afinidade aos triglicérides e ésteres de colesterol e sua baixa afinidade por fosfolipídeos e colesterol (LANTING et al., 1998). No fígado, os PCBs interferem em sistemas enzimáticos importantes na desintoxicação (MATTHEWS ; ANDERSON, 1975).

\subsection{Mecanismos de ação}

Os PCBs são compostos lipofílicos que são facilmente absorvidos pelo trato gastrointestinal. Enquanto os PCBs em muitos casos, entram no meio ambiente através de formulações comerciais contendo uma mistura relativamente definida de congêneres de PCBs específicos, a acumulação e retenção desses congêneres em várias matrizes ambientais, fauna e seres humanos não refletem diretamente o perfil das misturas comerciais de PCBs. Portanto, é importante considerar o destino biológico e da atividade dos congêneres dos PCBs individualmente, ao avaliar o risco que os PCBs possam ter para a saúde humana. Embora os PCBs sejam 
encontrados em todos os tecidos analisados até o momento, eles estão armazenados em alta concentração no tecido adiposo, uma vez que são lipofílicos. Congêneres de PCBs, são metabolizados no fígado pelos citocromos P-450 microssomal para metabólitos menos lipofílicos que podem sofrer conjugação com a glutationa ou ácido glucurônico. A taxa de metabolismo do congênere é altamente dependente do padrão de substituição do cloro no anel bifenila. Fortes evidências sugerem que o mecanismo de toxicidade para os congêneres de dioxina está relacionada com a melhora da expressão genética desencadeada pela ligação inicial ao mesmo receptor Ah (Proteína citosólica) envolvidos na toxicidade do 2,3,7,8TCDD. O mecanismo de toxicidade para outros grupos de congêneres de PCBs, como aqueles que mostram a atividade estrogênica ou neurotóxicos, e o mecanismo de carcinogenicidade PCB ainda não foi elucidado. Da mesma forma, a perturbação da função de neutrófilos e homeostase do cálcio parecem ser mediados por outros mecanismos além do receptor Ah. A perturbação na homeostase do hormônio tireoideano ocorre através de mecanismos que vão além dos grupos congêneres de PCBs (Agency for Toxic Substances and Disease Registry (ATSDR),2000).

\section{Interação elétron doador- aceptor (Transferência de carga)}

A presença de grupos deficientes de elétrons como as quinonas e um doador rico em elétrons (por exemplo, nitrogênio ou anéis aromáticos ativados), em $\mathrm{SP}_{\mathrm{HS}}$ (ácidos húmicos em fase sólida) e a existência de poluentes orgânicos que possuem as mesmas características, fornecem a possibilidade de uma interação baseada entre os sistemas "doador-aceptor" ou "transferência de carga" de um poluente orgânico adequado e os grupos funcionais estruturais do HS (ácidos húmicos) (SUFFET; MACCARTHY,1989). 
A ocorrência entre os diversos complexos de compostos orgânicos (por exemplo, pesticidas e herbicidas), PAHs e bifenilas policloradas (PCBs), e as fases de $\mathrm{SP}_{\mathrm{HS}}$ foram postulados por diversos autores (SENESI ; TESTINI,1983a).

Estudos de ressonância paramagnética eletrônica (EPR), (SENESI et al.,1987) confirmaram a abordagem do mecanismo de interação elétron aceptordoador, mostrando que as concentrações de radicais livres aumentaram na interação de produtos entre um número de s-triazinas e HA de diferentes origens (SENESI,N.; TESTINI,C.,1983b).Este efeito foi explicado admitindo que estruturas elétron-deficientes como da quinona e na molécula de HA são capazes de retirar elétrons da amina rica em elétrons doadores ou átomos de nitrogênio heterocíclico das moléculas de triazina.

Senesi e Testini (1983a) e Senesi et al. (1987), mostraram por ressonância paramagnética eletrônica (EPR) que a interação de HA (ácidos húmicos) de diferentes origens com um número de herbicidas com uréia substituídas por processos de elétron aceptor-doador, envolve radicais livres orgânicos que levam à formação de complexos de transferência de carga. As estruturas químicas e propriedades dos herbicidas uréias substituídas influenciam na extensão da formação de sistemas de elétron aceptor-doador com HA. Uréias substituídas são, de fato, esperadas na atuação como doadores de elétrons de átomos de nitrogênio (ou oxigênio) para sítios aceptores de elétrons na quinona ou de unidades similares em moléculas de HÁ (ácidos húmicos). 
A importância da transferência de carga e as interações na química do HA nas condições vigentes em sistemas aquosos sólido, tem sido enfatizada e confirmada por espectroscopia UV. Interações específicas de transferência de carga entre as estruturas polinucleares de PAHs e PCBs com as moléculas de HA também têm sido sugeridas e confirmadas pelos estudos de dissipação (quenching) da fluorescência (GAUTHIER et al.,1987).

\section{Remediação das bifenilas policloradas}

As bifenilas policloradas (PCBs) foram produzidas por cloração catalítica de bifenilas para produzir misturas complexas, cada uma contendo 60 a 90 espécies diferentes de PCBs moleculares ou congêneres. Nos Estados Unidos, as misturas de PCBs foram fabricadas pela Monsanto sob a marca Aroclor e eram amplamente utilizadas como fluidos dielétricos em capacitores e transformadores entre 1929 e 1978. Os PCBs são contaminantes generalizados de sedimentos aquáticos, e continuam a ser um foco de preocupação ambiental, pois eles tendem a se acumular na biota e são potencialmente tóxicos. As técnicas de biorremediação mais eficazes aplicadas aos PCBs em vários ambientes contaminados, são:

\subsection{Degradação aeróbica}

A degradação aeróbica na faixa de temperatura mesofílica de 18 a $35^{\circ} \mathrm{C}$ dos sedimentos do rio contaminado por PCBs foi relatada por vários autores (SENESI et al.,1986), a bactéria de degradação Alcaligenes eutrophus H850 foi isolada por (BEDARD ; QUENSEN,1995) em materiais contaminados por PCBs através de dragagem da parte superior do rio Hudson. Essa bactéria tem uma especificidade particularmente ampla ao congênere de $\mathrm{PCB}$, quando comparada com muitas outras 
bactérias isoladas na parte superior do rio Hudson e outros locais (BEDARD et al.,1986). Além da degradação de PCBs por bactérias isoladas, in situ, a degradação microbiana aeróbica de PCBs foi demonstrada em um local contaminado por PCBs no rio Hudson (HARKNESS at al., 1993). (FISH ; PRINCIPE,1994) e (FISH, 1996) também descreveram a degradação microbiana aeróbica de PCB por declorinação anaeróbica de Aroclor 1242 em microcosmos de PCBs contaminados na parte superior do sedimento do rio Hudson.

Em contraste, (WILLIAMS ; MAY,1997) investigaram à baixa temperatura $\left(4^{\circ} \mathrm{C}\right)$ a degradação microbiana aeróbica dos PCBs presentes em sedimentos do rio Hudson. Eles relataram a depleção específica dos di- e tricloro-bifenilas na camada superficial de sedimentos contaminados com PCBs. A perda de congêneres dos PCBs específicos do sedimento foi indicativo de degradação microbiana aeróbica de PCBs e demonstraram que essa degradação pode ocorrer em amostras de sedimentos a baixas temperaturas.

\subsection{Declorinação redutiva}

A descoberta de que a declorinação microbiana do PCB estava ocorrendo em muitos sedimentos aquáticos mostrou que este processo é um meio natural de recuperação. A declorinação diminui o potencial de bioacumulação de PCBs, tornando-os mais biodegradáveis esperando-se, assim, diminuir a toxicidade potencial dos PCBs. A declorinação redutiva dos PCBs é importante porque reduz a sua toxicidade e persistência. A declorinação em situ de PCBs atribuída a microorganismos em sedimentos anaeróbios tem sido documentada no rio Hudson, Silver Lake (MA), o St. Lawrence River (NY), e Porto de New Bedford (MA) (BROWN JUNIOR et al.,1987). 
A declorinação redutiva é o mecanismo de biodegradação apenas conhecido por congêneres clorados dos PCBs, como a maioria dos congêneres de PCBs encontrada nos Aroclors 1254 e 1260. Tem sido bem estabelecido que a declorinação microbiana do Aroclor 1260 pode ocorrer tanto no ambiente quanto em condições de laboratório (YOUNG, L. Y.; CERNIGLIA, C. E.,1995). Alguns estudos também quantificaram o grau de declorinação do octa- e nona-clorobifenilas em Aroclor 1260 (VAN DORT et al.,1997) . No entanto, devido à complexidade de ambos a partir da mistura Aroclor 1260 e da mistura de produtos formados, é impossível identificar os produtos característicos e vias de degradação para os congêneres específicos na mistura geral.

Vários estudos têm investigado a declorinação de congêneres de PCBs em condições anaeróbicas (VAN DORT; BEDARD,1991), mas estas foram todas voltadas para PCBs com seis ou menos cloro substituintes. A dehalogenação do decaclorobifenila ao longo do tempo também tem sido relatada (HARTKAMPCOMMANDEUR et al.,1996 ), no entanto, os produtos só foram tentativamente identificados e não quantificados.

Bedard e May (1995), utilizaram cromatografia gasosa na análise de congêneres específicos utilizando detecção por captura de elétrons e detecção por espectrometria de massa para determinar PCBs nos sedimentos da Lagoa Woods (Lennox, MA). As distribuições dos congêneres de todas as amostras apresentaram o hexa, hepta, e octaclorobifenilas características de Aroclor 1260, mas, principalmente o hexa e hepta-BC diminuiram em até $45 \%$ em relação ao Aroclor 1260, e o tri-, tetra- e penta-BC aumentaram. A análise por GC-MS revelou incomum tetra, penta e hexa-BC, muitos anéis contendo 2,4 - e 2,4,6-cloro-fenila, que são incomuns em Arocloros superiores, indicando forte evidência da declorinação. 


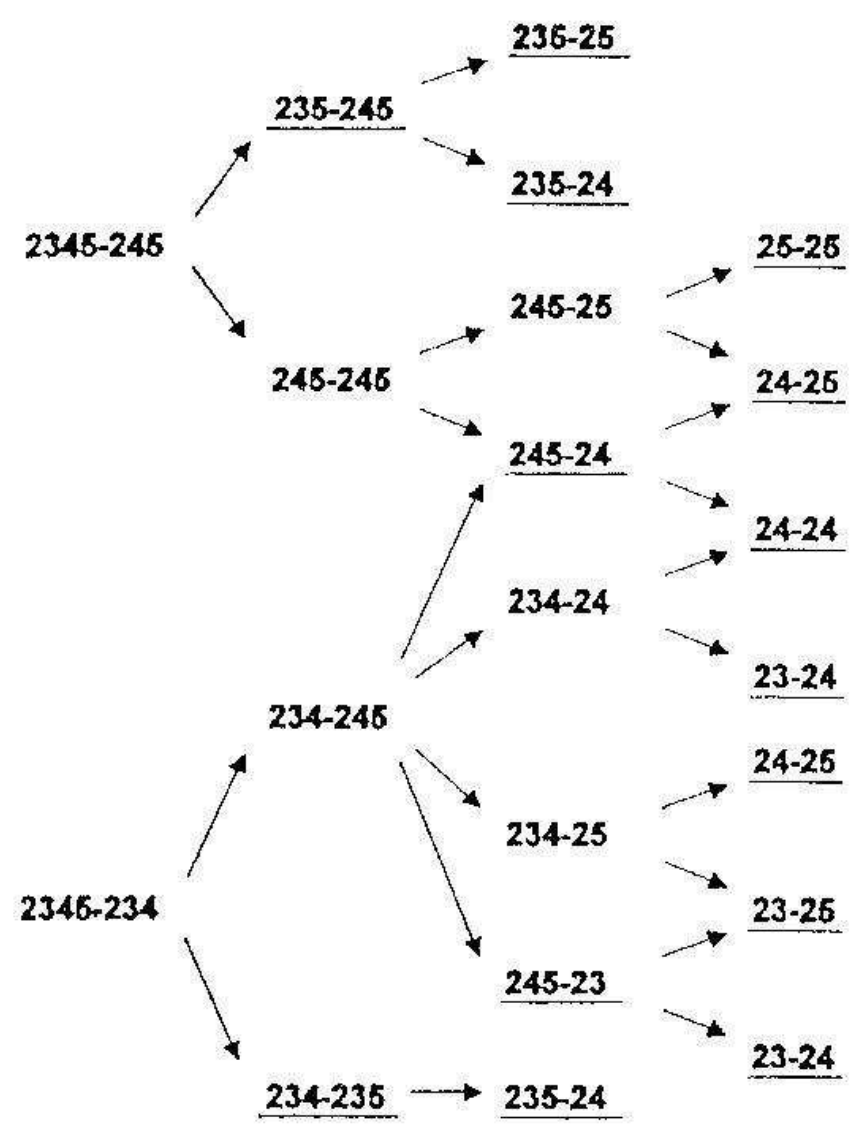

Figura 6 - Rotas propostas por (BROWN JUNIOR,1994) para os principais componentes e hexa-hepta-CB de Aroclor 1260.

As rotas propostas de declorinação para os principais componentes e hexa-hepta$\mathrm{CB}$ de Aroclor 1260 mostradas na Figura 6, indicam o seguinte (BROWN JUNIOR,1994):

Congêneres que foram elevados no sedimento em relação ao Aroclor 1260 estão sublinhados. Um suposto produto de declorinação, 235-24-CB, apresenta comigração com o isômero, 245-25-CB. O PCB total mostrou pouca alteração em relação ao Aroclor 1260, mas a situação mudou a partir de 245 2'5'-CB e, principalmente, a 235-2'4'-CB. 


\section{Compostos tóxicos no meio ambiente}

Cerca de 70.000 compostos sintéticos são utilizados em todo o mundo e entram nos cursos de água ou na atmosfera, sendo desta forma dispersos no ambiente (FENT, 1996). Apenas uma fração desses compostos pode provocar efeitos, agudos ou crônicos, adversos nos organismos, com os últimos a despertar especial atenção, uma vez que são mais sutis e só reconheciveis após longos períodos de exposição. Tais compostos têm três propriedades críticas:
a) Elevada atividade biológica com correspondente elevada toxicidade;
b) Elevada persistência e mobilidade no ambiente;
c) Tendência para se bioacumularem, com reflexos na cadeia alimentar.

Os principais fatores que estão subjacentes à toxicidade dos micropoluentes são a dosagem e a sensibilidade dos organismos, exercendo efeitos crônicos em todos os níveis biológicos. Por exemplo, micropoluentes como os metais pesados, pesticidas, hidrocarbonetos poliaromáticos, organoestanhosos, alquilfenóis, etc. têm ação:

a) a nível molecular, podendo provocar mutações, tumores ou inibições enzimáticas;

b) a nível da célula, afetando as membranas;

c) nos organismos, afetando os órgãos, o crescimento e desenvolvimento, a imunidade ou o aparelho reprodutivo, e causando alterações de comportamento.

Consequentemente, há um reflexo a nível das populações e ecossistemas incidindo na composição e densidade das espécies (FENT, 1996). 
$\mathrm{Na}$ década de 70 , do século $\mathrm{XX}$, alguns organismos dos Estados Unidos da América (EUA), liderados pela Environmental Protection Agency (EPA), elaboraram uma lista de 65 compostos tóxicos e uma lista mais abrangente contendo 129 compostos prioritários no sentido de avaliar as suas concentrações nos efluentes descarregados pelas diferentes atividades industriais (KEITH ; TELLIARD, 1979). Este problema surge porque a exposição humana aos compostos tóxicos pode ocorrer de forma direta ou indireta, esta última forma bastante mais silenciosa e geralmente involuntária, cuja trajetória mais comum será a contaminação do ar ou água, passando para ervas e plantas, e posteriormente em toda a cadeia alimentar.

Existe um conjunto de compostos orgânicos que são muito estáveis e quimicamente pouco reativos às condições ambientais comuns, pelo que são considerados Poluentes Orgânicos Persistentes - POP (JONES ; VOOGT, 1999). Os compostos deste grupo são utilizados como herbicidas, pesticidas, fungicidas e como matérias-primas na produção de outros compostos químicos. A UNEP - United Nations Environment Programme considera doze compostos pertencentes a esta categoria, que são: Aldrin, Hexaclorobenzeno, Clordano, Mirex, Dieldrin, Toxafeno, DDT, Endrin, Heptacloro, a família das Bifenilas policloradas (PCBs) das Dioxinas e dos Furanos (FISHER, 1999). Estes dois últimos grupos de compostos resultam da incineração de outros produtos químicos ou são produtos secundários de várias reações químicas (WITTICH, 1998).

Os compostos referidos anteriormente são lipofílicos, essencialmente não voláteis e extremamente difíceis de degradar, tendendo-se a bioacumular na biosfera. Em ambientes aquáticos e nos solos, tendem a ficar fortemente sorvidos nos sólidos, predominantemente mais ricos em matéria orgânica, evitando a fase aquosa. Nos organismos, a sua afinidade pelas fases orgânicas estimula a 
acumulação nos tecidos adiposos. Consideram-se persistentes porque têm tempos de meia-vida longos em solos, sedimentos, ar e organismos em geral, apesar de não haver consenso sobre a definição de "persistente". Na prática, considera-se que estes compostos podem ter tempos de meia-vida de vários anos em solos ou sedimentos e de vários dias na atmosfera (UNIDO, 2003).

\section{Sorção de compostos orgânicos}

A sorção é um processo que ocorre naturalmente ou é induzido de maneira a controlar a distribuição dos poluentes no ambiente. Neste capítulo faz-se uma abordagem aos aspectos teóricos que definem este processo, dando-se especial atenção à sorção de poluentes em solução aquosa, apresentando-se os seus princípios de cinética e de equilíbrio, os mecanismos de retenção envolvidos e as propriedades dos sistemas que condicionam a extensão da sorção. Dentro destas propriedades destacam-se a importância da matéria orgânica, a química da superfície, bem como as propriedades texturais do sorvente e as propriedades químicas dos solutos.

\subsection{Definições}

O termo sorção é utilizado para descrever a acumulação de uma substância dissolvida (soluto), em partículas sólidas (sorvente), a partir de uma solução líquida - solvente. A adsorção e a absorção são duas categorias do fenômeno de sorção, que diferem pelo grau de interação da superfície com o soluto e a facilidade que este tem de migrar pela fase sólida. No primeiro caso, a acumulação do soluto é geralmente restringida à superfície do sólido ou à interface deste com o solvente, enquanto na absorção, o soluto é transferido para a fase sólida e interpenetra o seio 
do sólido. Frequentemente, a absorção é definida como a partição do soluto entre a solução e a fração orgânica, especificamente em sistemas que envolvem sorção em solos (WEBER JUNIOR et al., 1991).

A sorção de um composto de uma solução num sólido ocorre como resultado de uma de duas características num dado sistema, ou a combinação de ambas. A primeira força impulsionadora pode ser consequência da falta de afinidade do composto para o solvente, lipofilicidade, enquanto a segunda deve-se à maior afinidade do soluto para o sólido. Na maioria das situações existe uma combinação das duas forças (WEBER JUNIOR, 1972). Embora existam vários fatores que afetam de forma determinante a intensidade da sorção, a solubilidade do soluto é o mais significativo na situação em que a força impulsionadora é a falta de compatibilidade entre o soluto e o solvente (WEBER JUNIOR, 1972).

O soluto estabelece ligações com os grupos funcionais da superfície sólida por atrações eletroestáticas, de van der Waals (físicas) ou de natureza química, (VOICE; WEBER JUNIOR, 1983). Distinguem-se, portanto, três tipos principais de adsorção: a troca iônica, a adsorção física e a adsorção química.

As forças interferentes no estabelecimento das ligações químicas, covalentes e pontes de hidrogênio, são as mais intensas ficando os átomos muito próximos entre si, comparativamente com as interações dipolo-dipolo, dipolo-dipolo induzido ou dipolo instantâneo-dipolo induzido, características da adsorção física (WEBER JUNIOR et al., 1991). Esta situação é característica da interação de moléculas hidrofóbicas, apolares, com as superfícies. Quando há uma falha de simetria eletrônica à volta do núcleo é criado um momento de dipolo. Em termos médios e ao 
longo do tempo, a distribuição eletrônica é simétrica, mas, instantaneamente, não é, induzindo a formação de dipolos instantâneos ou quadrupolos instantâneos. Um momento de dipolo na molécula do soluto induz o momento de dipolo nos átomos ou moléculas à superfície, e a interação destes dois momentos de dipolo induz à formação de forças atrativas (COONEY, 1998). Essas forças são definidas como as forças de dispersão de London e resultam da rápida flutuação dos momentos dos polos das moléculas. Globalmente, as forças envolvidas na adsorção física de moléculas à superfície sólida são consideradas as forças de van der Waals, que englobam as de dispersão de London e forças eletroestáticas entre dipolos permanentes (RUTHVEN, 1984).

Além das forças de atração existem também forças de repulsão entre as moléculas, as quais se tornam desprezíveis a partir de uma distância muito pequena entre elas, distância essa correspondente ao raio de van der Waals, $1 / r^{12}$. A soma das forças atrativas e repulsivas leva à determinação do potencial energético, $\Psi_{L J}$, entre um par de moléculas separadas por uma distância $2 r$, definido como o potencial Lennard-Jones (RUTHVEN, 1984). A Equação 2.1 permite calcular esse potencial, em que $\varepsilon$ representa o nível mínimo de energia para o qual as forças atrativas correspondem a um potencial negativo e $\sigma$ à metade da distância entre as moléculas quando $\Psi_{L J}$ é igual a zero (WEBER JUNIOR et al., 1991).

$$
\Psi_{\mathrm{LJ}}=4 \varepsilon\left[(\sigma / \mathrm{r})^{12}-(\sigma / \mathrm{r})^{6}\right] \quad \text { Equação } 2.1
$$

A magnitude da energia envolvida na adsorção física pode ser quantificada através da medição do diferencial de calores de sorção, entalpia da reação, 
correspondendo a valores entre 1 e $2 \mathrm{kcal} / \mathrm{mol}$ para as interações de dispersão de London (WEBER JUNIOR et al., 1991).

Nos processos de sorção física de moléculas apolares, embora as energias envolvidas sejam muito fracas, são normalmente amplificadas uma vez que existem gradientes termodinâmicos repulsivos entre o soluto e a solução em que está dissolvido. Esta combinação entre as interações do tipo dispersivas com a superfície e repulsivas com o solvente designam-se especificamente de ligações hidrofóbicas (WEBER JUNIOR et al., 1991).

A troca iônica está associada a forças de maior energia uma vez que estão envolvidas espécies permanentemente carregadas. Possuem calores de sorção muito superiores aos referidos para a sorção física e a energia envolvida é definida pela lei de Coulomb (Equação 2.2).

$$
\Psi_{\mathrm{C}}=\mathrm{E} \frac{\zeta 1-\zeta 2}{\mathrm{r}^{2}}
$$

A energia envolvida nestas ligações é proporcional às cargas das duas espécies envolvidas, $\zeta 1$ e $\zeta 2$, e à constante $E$ que depende das propriedades do solvente e é inversamente proporcional ao quadrado da distância entre os íons, $r$ (WEBER JUNIOR et al., 1991).

Finalmente, as interações associadas a valores de energia mais elevados, 15$50 \mathrm{kcal} / \mathrm{mol}$ (VOICE ; WEBER JUNIOR, 1983) são as correspondentes à sorção química, havendo alteração química da molécula pela formação de ligações fortes 
com os grupos da superfície. Como já foi mencionado anteriormente, estabelecemse ligações químicas de hidrogênio e covalentes resultando em calores de sorção elevados, com as energias podendo ser avaliadas pela relação de Morse (Equação 2.3).

$$
\Psi_{M}=D_{M}\left[1-e^{-m\left(r-r_{e}\right)}\right]^{2} \quad \text { Equação } 2.3
$$

Nessa equação, o termo $D_{m}$ corresponde à energia mínima, $r_{\mathrm{e}}$ é a distância entre as moléculas no equilíbrio e $m$ é uma constante (WEBER JUNIOR et al., 1991). Estas reações podem envolver energias de ativação e são favorecidas por temperaturas elevadas, de forma geral, as reações químicas ocorrem mais rapidamente a temperaturas elevadas que a temperaturas reduzidas (WEBER JR, 1972).

Globalmente, os vários fenômenos de sorção são combinações das três formas de sorção, não sendo fácil distinguir entre sorção física ou química. Por exemplo, as interações entre compostos aromáticos com grupos nitro ou hidroxila em carvão ativado podem ser consideradas como resultado de um processo específico de adsorção devido à formação de complexos doador receptor do soluto com os grupos carbonila da superfície, com a adsorção contínua após a exaustão destes centros com a complexação com os anéis do plano basal das cristalites (pequenos cristais) do carvão (WEBER JUNIOR, 1972).

\subsection{Equilíbrio de sorção}

A sorção em superfícies sólidas ocorre com solutos que estejam nos três estados da matéria: gases, líquidos ou sólidos (dissolvidos) e com o solvente na fase gasosa ou líquida. Mas os diferentes conceitos que vão ser apresentados estão 
englobados no âmbito do tratamento de efluentes líquidos pelo que se dá especial atenção a esta vertente de sorção de solutos dissolvidos de matrizes aquosas.

O equilíbrio do soluto entre as duas fases presentes ocorre através da absorção pelo sorvente ou pela adsorção no sorvente. O primeiro resulta da necessidade de ser estabelecido o equilíbrio nas fases de forma a diminuir as energias livres no seu interior, enquanto na adsorção a força que impulsiona o processo está relacionada com a diminuição da energia à superfície. Isto é, a tensão à superfície pode ser visualizada por uma gota de um líquido numa superfície sólida que resiste a espalhar-se pela superfície mantendo a forma esférica, minimizando assim a energia à superfície da gota. A presença de solutos orgânicos sorvidos na interface reduz a tensão interfacial no equilíbrio, diminuindo desta forma a concentração do soluto no seio da fase líquida (WEBER JUNIOR et al., 1991).

No que diz respeito ao processo de absorção, a distribuição entre as fases no equilíbrio, ou partição, pode ser expressa como a razão das concentrações na fase sólida $\left(C_{s}\right)$ e na fase líquida $\left(C_{L}\right)$, assumindo o mesmo estado padrão do soluto no sólido e no líquido, em concentrações muito diluídas. Este coeficiente de partição, $K_{p}$, é então representado pela Equação 2.4 .

$$
K_{p}=\frac{C_{S}}{C_{L}} \quad \quad \text { Equação } 2.4
$$

A distribuição no equilíbrio é normalmente representada por uma equação que exprime a quantidade de soluto na fase sólida, $q_{e}$, como função da concentração final do soluto na fase líquida, $C_{e}$, à temperatura constante. Uma vez que esta 
equação é determinada à temperatura constante é designada de isoterma. Estes sistemas normalmente envolvem solutos com solubilidade limitada no solvente, considerando-se por isso que a isoterma está completa quando o soluto atingir o seu valor de saturação no solvente (GILES et al., 1974a).

A construção de isotermas e sua interpretação foi amplamente estudada por físicos e químicos, principalmente na última metade do século XX (GILES et al., 1974b). A classificação das suas formas é importante uma vez que são condicionadas pelos mecanismos de adsorção e podem, portanto, ser utilizadas como diagnóstico da natureza da adsorção (GILES et al., 1974a). Mas é importante frisar que uma isoterma é uma característica integral de um sistema concreto onde toda a informação deduzida relaciona-se apenas com um sorvente e um soluto específico (DABROWSKI, 2001).

\subsection{Sistema de classificação do processo de sorção}

Uma classificação da adsorção de moléculas de soluto em superfícies divide as isotermas em quatro classes principais, de acordo com o seu declive inicial. Estes

grupos correspondem às classes S, L (de Langmuir), H (“high affinity" - elevada afinidade) e C ("constant partition" - partição constante), e são ainda subdivididas em vários grupos , 1, 2, 3, 4 e max, resultantes de algumas variações nos modelos (GILES et al., 1974a). Os referidos modelos estão representados na Figura 7. 


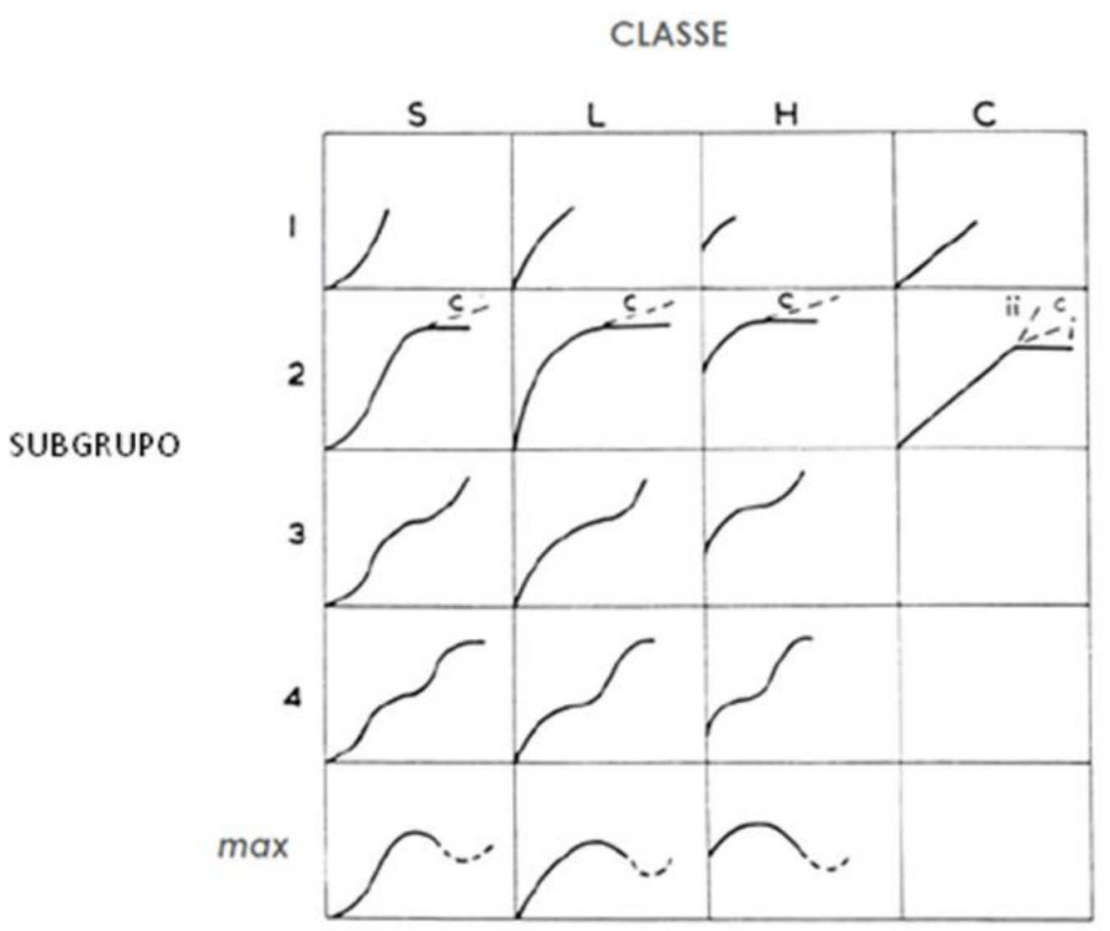

Figura 7 - Sistema de classificação de isotermas (Adaptado de GILES et. al;, 1974a).

$\mathrm{Na}$ maioria dos casos, a curva $\mathrm{S}$ indica "adsorção cooperativa" com as moléculas do soluto adsorvidas de forma bastante organizada em linhas ou agrupamentos notadamente com distribuição face a face, perpendicularmente à superfície. Difere da situação representada pela classe L, uma vez que, neste caso, as moléculas ficam distribuídas mais estendidas ao longo da superfície e há competição do solvente ou de outras impurezas pelos centros ativos do sorvente (GILES et al., 1974b).

As isotermas classe $\mathrm{H}$ resultam de sistemas em que o soluto e o sorvente apresentam elevada afinidade, como por exemplo, solutos iônicos a adsorver em superfícies carregadas com carga oposta. Os patamares de saturação longos demonstram a dificuldade de formação de uma segunda camada devido à repulsão das cargas entre moléculas adjacentes (GILES et al, 1974b). 
Relativamente à classe $\mathrm{C}$, estas curvas são atributo de sistemas de adsorção de sólidos dissolvidos e a sua característica principal relaciona-se com uma maior afinidade do soluto para a superfície sólida do que para o solvente (GILES et al., 1974a). A isoterma linear é consistente com as condições nas quais os centros ativos permanecem constantes na faixa de concentração de soluto estudada até à saturação. O contrário é visível nas curvas das classes $\mathrm{S}$ e L. O declive da isoterma em qualquer ponto pode ser encarado como uma medida da facilidade com que a molécula do soluto encontra centros ativos vazios à superfície. Na curva $L$, o declive vai diminuindo com o aumento da concentração porque à medida que o processo de adsorção decorre, os sítios vazios são cada vez mais difíceis de encontrar. No caso da curva S, o declive primeiro aumenta com a concentração devido à adsorção cooperativa, promovendo o aumento dos sítios capazes de reter as moléculas do soluto. Em qualquer dos casos, é sempre provável que o declive torne-se nulo, com a formação de um patamar no final, quando todos os centros ativos do sorvente estão ocupados (GILES et al., 1974a).

Os subgrupos apresentados na Figura 7 estão relacionados com a capacidade do sorvente estabelecer várias camadas de soluto. O subgrupo 1 representa sistemas nos quais a monocamada no sorvente ainda não está completa, ao contrário do representado pelo subgrupo 2 podendo identificar-se o patamar de saturação. Os subgrupos subsequentes representam o desenvolvimento da segunda camada de soluto à superfície do sorvente, estando completa no subgrupo 4 . $\mathrm{Na}$ situação especial do sub-grupo max existe um máximo que corresponde à concentração a partir da qual as interações de van der Waals entre as moléculas de soluto intensificam-se relativamente às ligações soluto sorvente, de forma que algum 
soluto é dessorvido da superfície até ser atingido novo equilíbrio (GILES et al., 1974a).

Existem vários modelos matemáticos referidos na literatura, conceituais ou empíricos, para descrever o comportamento de sorção. Esses modelos enquadramse no sistema de classificação apresentado.

\subsection{Modelos de equilíbrio de sorção}

Inicialmente, estes estudos foram desenvolvidos com substâncias gasosas em que o efeito da temperatura é muito significativo relativamente às suas propriedades físicas e químicas. Em meios líquidos, particularmente aquosos, a diferença de temperatura dos ensaios pode não ser condicionante para a obtenção de resultados significativamente diferentes.

A utilização eficiente de um sorvente requer que as condições de operação sejam tais que se utilize por completo a capacidade de equilíbrio, no mínimo, se não for possível a capacidade total de saturação (WEBER JUNIOR, 1972).

O modelo mais simples descreve a acumulação de soluto na fase sólida diretamente proporcional à concentração de equilíbrio na solução, a isoterma linear, apresentada na Equação 2.5.

$$
q_{e}=K_{d} \cdot C_{e}
$$

Equação 2.5

A equação 2.5 é semelhante à Equação 2.4, no fundo representando a partição do soluto entre as fases, com $K_{d}$ desta equação a ter um significado 
semelhante mas denominado coeficiente de distribuição, uma vez que a fase sorvente não é uma fase pura. Desta forma, este modelo linear descreve os processos de absorção e é adequadamente aplicada para descrever a adsorção de solutos em concentrações muito baixas, nas quais as energias são uniformes com o aumento da concentração, ou em materiais sólidos com baixo potencial de sorção (WEBER JUNIOR et al., 1991). Algum cuidado deve presidir à modelação de sistemas com esta equação uma vez que em gamas de concentrações diferentes das estudadas para a obtenção do modelo, este pode não ser aplicável.

Pelo desenvolvimento dos conceitos termodinâmicos subjacentes ao equilíbrio da sorção e através de considerações cinéticas, Langmuir (1918) desenvolveu um modelo que corresponde à formação de uma monocamada à superfície do sorvente, representada pela concentração de saturação, $\mathrm{C}_{\mathrm{s}}$ (Figura 8). Esse modelo é previsto com base nos pressupostos de que a energia de sorção de cada molécula é igual e independente do grau de cobertura da superfície e que a sorção ocorre apenas em locais específicos não envolvendo interações entre as moléculas sorvidas. A expressão matemática resultante é:

$$
q_{e}=\frac{Q^{\circ} b C_{e}}{1+C_{e}}
$$

O parâmetro $Q^{0}$ representa a concentração máxima de soluto sorvido correspondente à formação total da monocamada, quantidade de soluto sorvido por unidade de massa de sorvente, e $b$ é o coeficiente de sorção relacionado com a entalpia de sorção, $\Delta H=\left(b \propto e^{-\Delta H / R T}\right)$. 


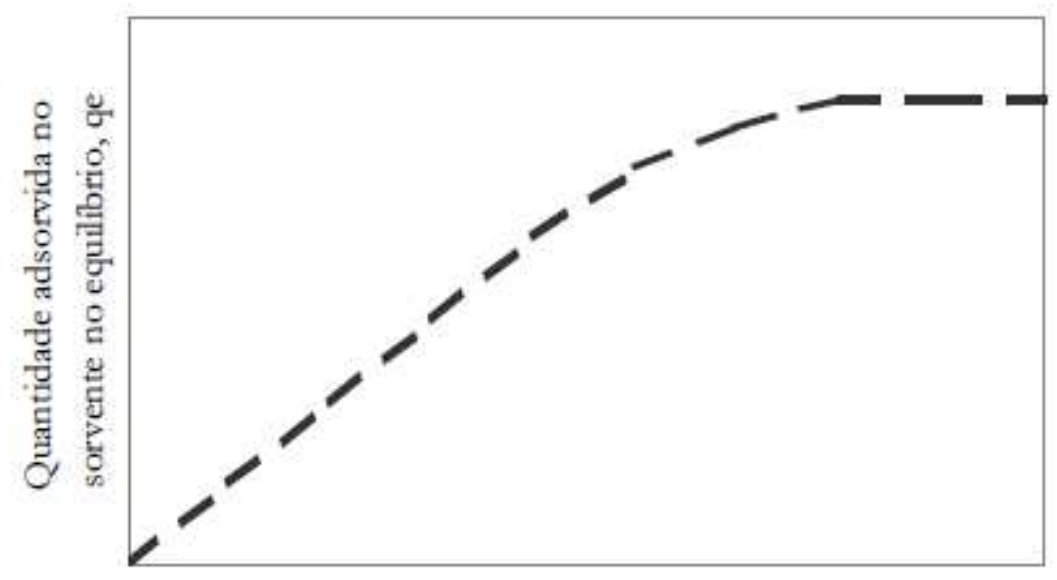

Conoentração de equilibrio na fase líquida, $\mathrm{Ce}$

Figura 8 - Representação esquemática da isoterma de Langmuir.

A obtenção dos parâmetros para um dado sistema passa pela linearização do modelo de Langmuir, havendo duas formas apresentadas nas equações 2.7 e 2.8, que podem ser utilizadas dependendo da gama e dispersão dos dados para cada sistema em estudo (WEBER JUNIOR, 1972).

$$
\begin{aligned}
& \frac{C_{e}}{q_{e}}=\frac{1}{b Q^{\circ}}+\frac{C_{e}}{Q^{\circ}} \\
& \frac{1}{q_{e}}=\frac{1}{Q^{\circ}}+\frac{1}{b Q^{\circ}} \frac{1}{C_{e}}
\end{aligned}
$$

Quando a sorção é muito reduzida, isto é, quando o termo $b C_{e}$ é muito inferior a um, a sorção específica no equilíbrio é proporcional à concentração do soluto em solução, obtendo a relação linear. Por outro lado, quando a sorção é intensa $q_{e}$ é equivalente a $Q^{\circ}$.

Uma variação deste modelo foi proposto por Bruner, Emmet e Teller (1938), isoterma BET, assumindo que existe a formação de várias camadas de soluto à 
superfície e que a equação de Langmuir aplica-se a cada uma dessas camadas (Figura 9). O referido modelo representa convenientemente a adsorção física de vapores e gases em superfícies secas de vários materiais, sendo utilizada normalmente para a determinação da área superficial desses materiais, mas não ajusta dados experimentais resultantes de interações eletrostáticas de íons a superfícies heterogêneas em sistemas aquosos (WEBER JUNIOR et al., 1991).

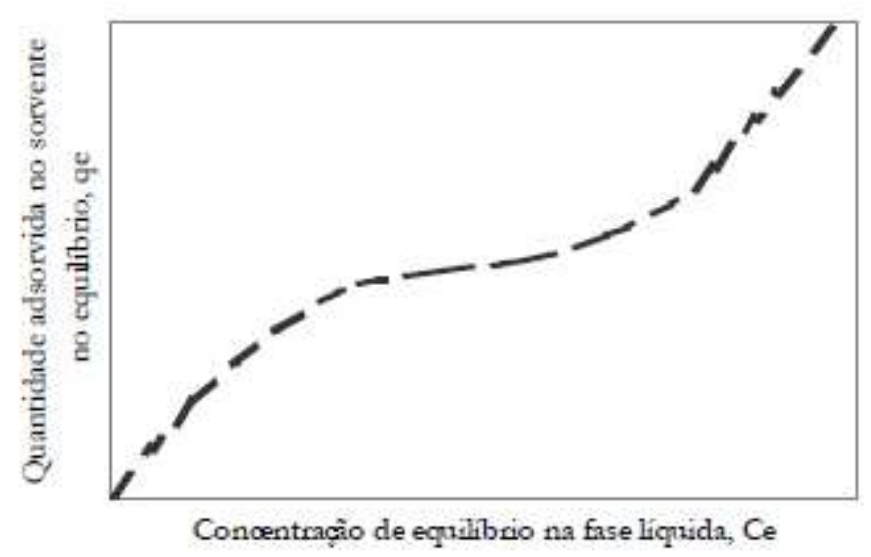

Figura 9 - Representação esquemática da isoterma BET.

Um pressuposto inerente ao modelo representado pela Equação 2.9, é que o início da formação de uma nova camada não implica a completa formação da anterior, ou seja, as condições de equilíbrio envolvem vários tipos de superfícies que correspondem a camadas de diferente número de moléculas, mas associadas a iguais energias de sorção.

$$
q_{e}=\frac{B Q^{\circ} C_{e}}{\left(C_{e}-C_{e}\right)\left[1+(B-1)\left(C_{e} / C_{s}\right)\right]}
$$


$\mathrm{Na}$ Equação 2.9, $C_{s}$ é a concentração de saturação de soluto na solução no equilíbrio, $B$ é uma constante que exprime a interação energética das moléculas com a superfície, tendo os restantes símbolos o mesmo significado do modelo de Langmuir. Em sistemas reais de tratamento de efluentes com matéria orgânica, raramente $Q^{\circ}$ representa a verdadeira capacidade de uma monocamada, mas reveste-se de bastante utilidade pois indica a capacidade limite para a sorção.

Em linha com o desenvolvido anteriormente, relativamente ao fato dos solutos não polares diminuírem a tensão interfacial da água, Gibbs propôs um modelo cuja equação é assim definida:

$$
\Gamma_{i}=-\frac{a_{i}}{R T} \frac{d \gamma}{d a_{i}}
$$

Nessa equação, $\Gamma_{i}$ é o excesso do componente $i$ na superfície (acima do existente no seio do fluido), a é a atividade do componente $i$, e $\gamma$ é a tensão superficial. Esta equação não é diretamente aplicável a sistemas de sorção ambientais devido à dificuldade e à incerteza das medições requeridas e pelas violações aos princípios básicos em que assenta (VOICE ; WEBER JUNIOR,1983).

Embora estes modelos conceituais tenham uma base teórica bem fundamentada, normalmente não se mostram adequados a descrever dados experimentais de sorção. O contrário é verdade para o modelo de Freundlich (1926). Empiricamente, Freundlich verificou que os dados experimentais frequentemente eram melhor descritos pela seguinte relação: 


$$
q_{e}=K_{F} C_{e}^{1 / n}
$$

\section{Equação 2.11}

Na equação $2.11 K_{F}$ relaciona-se com a capacidade de sorção e $n$ com a sua intensidade, refletindo o grau ao qual a extensão da sorção é dependente da concentração (IGLESIAS-JIMÉNEZ et al., 1997). Embora a sua base seja empírica, o modelo mostra-se bastante rigoroso na descrição de sistemas em que a sorção ocorre em superfícies heterogêneas. A determinação dos parâmetros empíricos da equação de Freundlich é conseguida aplicando os dados experimentais ao modelo na forma linearizada, de acordo com a Equação 2.12.

$$
\log q_{e}=\log K_{F} \frac{1}{n} \log C_{e}
$$

Dependendo do valor do coeficiente $n$, a isoterma de Freundlich toma diferentes significados (Figura 10). Quando $n>1$, considera-se o desenvolvimento de uma isoterma favorável, classe $\mathrm{L}$, em que a constante de sorção, $K_{F}$, diminui com a concentração da solução à medida que os centros ativos de maior energia ficam ocupados. Ao contrário, em sistemas representados por uma isoterma desfavorável, pertencendo à classe $\mathrm{S}$, com $n<1, K_{F}$ aumenta com o aumento da concentração da solução, provavelmente refletindo um aumento do caráter hidrofóbico da superfície após a formação da primeira camada. Quando o valor de $n$ é igual a 1, a isoterma torna-se linear, o que representa normalmente fenômenos de absorção ou fenômenos de partição de solutos orgânicos em matéria orgânica. 


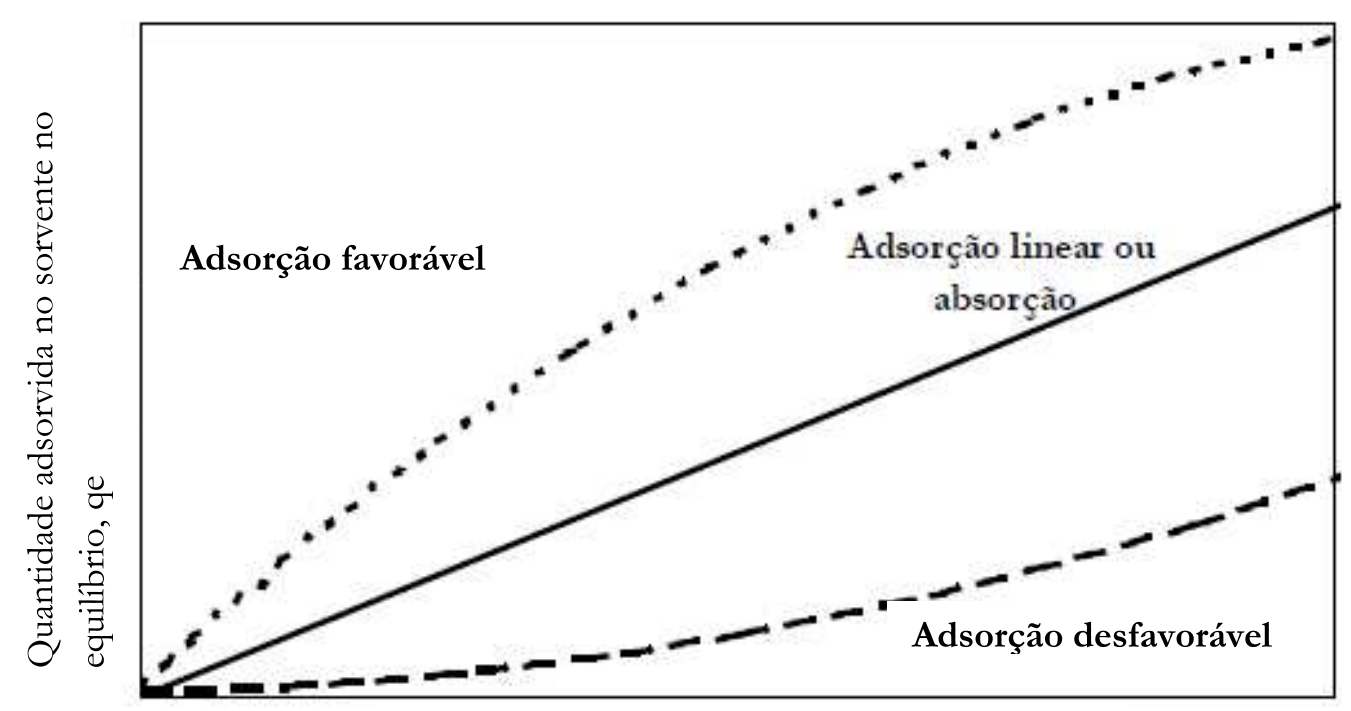

Concentração de equilíbrio na fase líquida, Ce

Figura 10 - Representação esquemática da isoterma de Freundlich.

Existem sistemas onde a aplicação da isoterma de Freundlich e a de Langmuir podem simultaneamente descrever matematicamente fenômenos de adsorção não linear, isto em gamas de concentrações limitadas. Esta situação já não é válida quando as concentrações de trabalho são muito amplas e, principalmente, quando essas concentrações são elevadas (WEBER JUNIOR et al., 1991).

De acordo com Voice e Weber Junior (1983), todos os modelos reduzem-se ao modelo linear em condições especiais, designadamente em sistemas cujo soluto está presente em concentrações bastante baixas, excetuando-se o modelo de Freundlich, cuja principal desvantagem é que não se aproxima da Lei de Henry para concentrações baixas (WEBER JUNIOR et al., 1991). Além dos modelos já referidos, existem outros que são referidos por diferentes autores para descrever a sorção de compostos orgânicos, especificamente clorofenóis, de água residual, que não são 
mais que variações dos modelos já apresentados. Na Tabela 5 estão definidos esses modelos que, no fundo, são restritos na sua aplicação pelos pressupostos assumidos em cada sistema. Destes modelos, os respectivos autores definem que a isoterma de Radke-Prausnitz é aplicável em sistemas onde o soluto está presente numa concentração diluída e que a isoterma de Redlich- Peterson mostrou-se adequada a descrever o equilíbrio do sorvente com um soluto único.

Tabela 5 - Modelos matemáticos para a representação do equilíbrio de adsorção em vários tipos de sorventes

\begin{tabular}{|c|c|c|c|}
\hline Modelo & Equações & Parâmetros & Referências \\
\hline $\begin{array}{l}\text { Langmuir- } \\
\text { Freundlich }\end{array}$ & $\mathrm{q}_{\mathrm{e}}=\mathrm{K} \mathrm{Q}^{\circ} \mathrm{Ce}^{1 / \mathrm{n}} /\left(1+\mathrm{KCe}^{1 / \mathrm{n}}\right), 0<1 / \mathrm{n} \delta 1$ & $\mathrm{~K}, \mathrm{Q}^{\circ}, 1 / \mathrm{n}$ & Calace et al., 2002 \\
\hline Hill & $\mathrm{q}_{\mathrm{e}}=\mathrm{K} \mathrm{Q}^{\circ} \mathrm{Ce}^{1 / \mathrm{n}} /\left(1+\mathrm{KCe}^{1 / \mathrm{n}}\right), 1 / \mathrm{n}>1$ & $\mathrm{~K}, \mathrm{Q}^{\circ}, 1 / \mathrm{n}$ & Calace et al., 2002 \\
\hline $\begin{array}{l}\text { Redlich- } \\
\text { Peterson }\end{array}$ & $\mathrm{q}_{\mathrm{e}}=\mathrm{K}_{\mathrm{RP}} \mathrm{Ce} /\left(1+\mathrm{a}_{\mathrm{RP}} \mathrm{Ce}^{\beta}\right)$ & $\mathrm{K}_{\mathrm{RP}}, \mathrm{aRP}_{\mathrm{RP}} \beta$ & Aksu et al., 2002 \\
\hline $\begin{array}{l}\text { Radke- } \\
\text { Prausnitz }\end{array}$ & $\mathrm{q}_{\mathrm{e}}=\mathrm{K}_{\mathrm{R}} \mathrm{Ce}^{\alpha} /\left(1+\mathrm{aR}_{\mathrm{R}} \mathrm{Ce}^{\alpha-1}\right)$ & $K_{R}, \alpha, a_{R}$ & Mollah et al., 1996 \\
\hline $\begin{array}{l}\text { Fritz- } \\
\text { Schlunder }\end{array}$ & $\mathrm{q}_{\mathrm{e}}=\mathrm{K}_{\mathrm{FS}} \mathrm{Ce}^{\delta} /\left(1+\mathrm{a}_{\mathrm{FS}} \mathrm{Ce}^{\delta 1}\right)$ & $\mathrm{K}_{\mathrm{FS},}, \delta$, aFs, $\left.\gamma 1\right)$ & Mollah et al., 1996 \\
\hline $\begin{array}{l}\text { Dubinin- } \\
\text { Astakhov }\end{array}$ & $\mathrm{qe}=\mathrm{Q}^{\circ} \exp \left[-\left(\mathrm{A} / \mathrm{E}^{\prime}\right)^{\mathrm{n} 1}\right]$ & $Q^{\circ}, E^{\prime}, n 1, A$ & Subramani, 2002 \\
\hline
\end{tabular}

\subsection{Cinética do processo de sorção}

Para avaliar a aplicação de um modelo de equilíbrio na representação dos dados experimentais é necessário definir o tempo para o qual, no sistema, não se 
verificam alterações da concentração na fase sólida e na fase líquida. A dependência da sorção com o tempo denomina-se a cinética de sorção, que pode ser regida por etapas como:

a) difusão das moléculas através do filme que rodeia as partículas sólidas, chamada difusão externa;

b) difusão das moléculas à superfície do sólido, a difusão superficial;

c) difusão das moléculas nos poros do sólido, a difusão interna;

d) processo de sorção e interação nos centros ativos, o processo elementar.

A velocidade em que estes mecanismos ocorrem determina a cinética total da sorção, sendo a mais relevante a velocidade que apresentar o processo mais lento. Normalmente, para sólidos porosos é determinante a difusão das moléculas nos poros para a avaliação da cinética total, enquanto para sólidos pouco porosos ou com macroporosidade a difusão interna é normalmente negligenciada. Neste caso, a cinética é determinada pela difusão externa e pela sorção nos centros ativos que se encontram à superfície (DABROWSKI, 2001).

Para processos em que a limitação da velocidade esteja associada com a sorção na superfície exterior do sólido ou pela transferência de massa no filme exterior, a velocidade deve variar inversamente com o diâmetro das partículas para uma dada massa de sorvente. Por outro lado, a difusão do soluto nos poros de uma partícula varia com o inverso de uma potência superior do diâmetro da partícula. Outra forma de avaliar se a sorção à superfície é o passo limitante da sorção em sólidos pouco porosos relaciona-se com a comparação da cinética para diferentes concentrações. Se esta situação se verificar, a velocidade tenderá a ser proporcional 
à concentração, o que não é verificado quando o passo limitante da sorção é a difusão no interior dos poros (WEBER JUNIOR, 1972).

Interessa formular expressões para a velocidade de sorção de maneira que seja possível estudar estas variáveis e de que modo afetam o fenômeno. De fato, a velocidade de uma reação é determinante na avaliação da dimensão de um reator ou no tempo necessário para ser atingida uma conversão desejada. Muitos modelos, como o de difusão homogênea à superfície, o de difusão nos poros e o de difusão heterogênea já foram aplicados em sistemas descontínuos, mas a sua complexidade matemática torna-os, muitas vezes, poucos práticos. A grande complexidade das superfícies dos sorventes, com grupos carboxilas, carbonilas, hidroxilas, éter, quinonas, lactonas ou anidridos, abrangem um sem número de interações entre o soluto e o sorvente. Pelo que, qualquer representação cinética deve ser olhada do ponto de vista global (TSENG et al., 2003).

A velocidade da sorção, ou seja, a acumulação de soluto na matriz sólida com o tempo, $d q / d t$, relaciona-se com uma constante cinética, $k$, e com a força motriz que induz a progressão da reação, a diferença entre $q_{e}$, a quantidade de soluto sorvido no equilíbrio por unidade de massa de sorvente, e q, a quantidade de soluto sorvido por unidade de massa de sorvente em qualquer instante $t$ (Equação 2.13).

$$
\frac{d q}{d t}=k\left(q_{e}-q\right)^{\alpha_{1}}
$$

O resultado da integração desta relação matemática varia de acordo com a ordem da reação, a qual não é mais que o expoente da força motriz da sorção, $\alpha_{1}$. Por esta razão, dependendo da ordem da reação, a constante cinética terá diferentes unidades. 
Em sorção, as leis cinéticas mais comuns são a de $1^{\text {a }}$ ordem, com $\alpha_{1}$ igual a 1 e de $2^{\mathrm{a}}$ ordem, onde $\alpha_{1}$ toma o valor 2 , embora modelos mais complicados possam ser adequados para definir alguns sistemas. Após a integração entre $t=0$ e $t$, para $q=0$ e $q$, a equação de $1^{\mathrm{a}}$ ordem resulta na equação de Lagergran (Equação 2.14), a partir da qual é possível avaliar o valor da constante cinética (TSENG et al, 2003).

$$
-\ln \left(1-\frac{q}{q_{e}}\right) k t
$$

A determinação do valor de $k$ pressupõe o conhecimento da quantidade sorvida no equilíbrio, $q_{e}$, pelo que a forma mais adequada de fazer esta avaliação seja a aplicação dos resultados experimentais à equação não linear (Equação 2.15) e determinar simultaneamente os dois parâmetros, $k$ e $q_{e}$, onde $k$ está em min $^{-1}$.

$$
q=q_{e}[1-\exp (-k t)] \quad \text { Equação } 2.15
$$

A integração da equação de $2^{\mathrm{a}}$ ordem para os mesmos limites resulta na Equação 2.16, que após a sua linearização (Equação 2.17) pode ajustar os dados experimentais obtendo desta forma $k$ e $q_{e}$.(TSENG et al., 2003).

$$
\begin{gathered}
q=q_{e} \frac{k q_{e} t}{1+k q_{e} t} \\
\frac{t}{q}=\frac{1}{k q_{e}^{2}}+\frac{1}{q_{e}} t
\end{gathered}
$$


O inverso da ordenada na origem da reta que lineariza o modelo de $2^{a}$ ordem

$$
h=k q_{e}^{2}
$$

representa a velocidade de sorção inicial (mg/(g.min)) (ÖZACAR; ŞENGIL, 2005). Em reações com cinética de $2^{\mathrm{a}}$ ordem, $k$ tem como unidades $\mathrm{g} /(\mathrm{mg} \cdot \mathrm{min})$.

Outros modelos são também propostos na literatura para ajustar os pontos experimentais e que permitem avaliar o mecanismo de sorção. É o exemplo do modelo que descreve os sistemas cujo passo limitante da sorção é a transferência de massa no filme que rodeia as partículas. Se a transferência de massa externa for o passo limitante, deve ser encontrada a dependência de soluto sorvido com o tempo de acordo com a Equação 2.19, em particular na fase inicial da curva de sorção.

$$
-\ln \left(1-\frac{m_{\text {sorvente }}}{C_{0} V_{\text {solução }}}\right)=\frac{3 m_{\text {sorvente }}}{R \rho V_{\text {solução }}} k_{L} t
$$

$\mathrm{Na}$ equação anterior, $C_{0}$ representa a concentração inicial do soluto, $R$ o raio médio da partícula esférica do sorvente $(\mathrm{cm}), \rho$ a massa volúmica aparente do sorvente $(\mathrm{g} / \mathrm{cm})$, e $\mathrm{kL}$ é o coeficiente de transferência de massa no filme. Se $\mathrm{V}_{\text {solução }}$ tiver unidades de $\mathrm{cm}^{3}$ e $\mathrm{m}_{\text {sorvente }}$ estiver em gramas, com o tempo em minutos, o coeficiente virá em unidades de $\mathrm{cm} / \mathrm{min}$. Conhecendo todos os parâmetros, pelo declive da reta pode estimar-se o valor de $\mathrm{kL}$. 
Por outro lado, se a etapa determinante for a difusão do soluto no interior do sorvente, os dados deverão ser representados pela Equação 2.20 , que modela a transferência de massa num sólido esférico, homogêneo e amorfo de raio $R$, sendo $D$ a difusividade intraparticular do soluto (COONEY, 1998).

$$
\frac{q}{q_{e}}=1-\frac{6}{n^{2}} \sum_{n=1}^{\infty}\left(\frac{1}{n^{2}}\right) \exp \left(-\frac{D n^{2} n^{2} t}{R^{2}}\right) \quad \text { Equação } 2.20
$$

Este é o modelo de difusão homogênea no sólido, que para tempos de ensaio pequenos, ou mais precisamente para $q / q_{e}<0,3$, a sua solução pode ser aproximada pela Equação 2.21 .

$$
q=q_{e} \frac{6 D^{1 / 2}}{n^{1 / 2 R}} t^{1 / 2}
$$

Se ocorrer difusão interna, então q versus $t^{1 / 2}$ deverá ser linear e se passar na origem, portanto, o processo limitante é apenas a difusão intraparticular. Caso contrário, outros mecanismos podem estar envolvidos (NAMASIVAYAM ; KAVITHA, 2003). A partir do declive, conhecendo o tamanho médio das partículas e o valor de $\mathrm{q}_{\mathrm{e}}$, (que é estimado através da curva experimental), determina-se o valor de $\mathrm{D}$ $\left(\mathrm{cm}^{2} / \mathrm{s}\right)$ para as condições do ensaio.

Embora na literatura sejam encontradas referências a outros modelos cinéticos que representam sistemas específicos, a grande maioria aplica-se a carvão ativado. 
Deve-se perceber que isotermas de adsorção são meramente descrições de dados macroscópicos e não como prova definitiva de um mecanismo de reação. Os mecanismos devem ser elucidados a partir de investigações moleculares (como por exemplo, o uso de técnicas espectroscópicas). Assim, a conformidade dos dados experimentais de adsorção de uma isoterma em particular, não indica que é uma descrição única dos dados experimentais, e que somente a adsorção está em operação. (ABOUL-KASSIM; SIMONEIT, 2001).

\subsection{Fatores que afetam a sorção}

Como já foi referido anteriormente, o soluto tende a deixar a solução por uma de duas razões, ou pela baixa afinidade para o solvente ou pela elevada afinidade para o sorvente. Desta forma, os fatores que influenciam a extensão de sorção prendem-se com as propriedades dos dois meios onde o soluto se distribui. Por um lado, são importantes as características da superfície: a área superficial específica e as propriedades químicas, principalmente o teor de matéria orgânica, a sua acidez e/ou cargas elétricas, por outro lado são determinantes as características da solução: a solubilidade do soluto, a temperatura, o pH ou a salinidade.

\subsection{Características da solução}

Uma vez que os fenômenos de sorção são normalmente exotérmicos, os valores das constantes de equilíbrio usualmente diminuem com o aumento da temperatura (WEBER JUNIOR, 1972). Mas, as variações de entalpia são da mesma ordem de grandeza das reações de condensação ou cristalização, não se esperando por tal motivo que pequenas variações de temperatura, nomeadamente na gama esperada em efluentes líquidos, tenham grandes efeitos no processo de sorção. 
Relativamente ao caráter químico do meio, pode ressaltar-se que $\circ \mathrm{pH}$ é determinante no processo de sorção. Este efeito pode sentir-se a nível do soluto ou a nível da superfície do sorvente. No que concerne ao soluto, esta característica é importante em compostos que sejam ionizáveis, afetando, por exemplo, a sorção de ácidos ou bases orgânicas uma vez que influenciam a sua solubilidade. A nível da superfície, a alteração do $\mathrm{pH}$ condiciona a sua carga superficial. Esta propriedade faz-se sentir sobretudo em superfícies anfóteras, uma vez que podem apresentar comportamentos antagônicos a diferentes valores de $\mathrm{pH}$, exibindo carga negativa ou positiva com afinidades para solutos com cargas elétricas opostas. Em geral, a sorção de poluentes orgânicos de água aumenta com a diminuição do $\mathrm{pH}$, como resultado da neutralização das cargas negativas à superfície do sorvente com o aumento da concentração do próton $\mathrm{H}^{+}$, reduzindo o impedimento à difusão do soluto e tornando a superfície do sorvente mais ativa (WEBER JUNIOR, 1972).

É também evidente que o $\mathrm{pH}$ controla a solubilidade do soluto, solubilidade essa que é determinante na extensão da sorção, com especial importância para solutos ionizáveis com o pKa conhecido. De acordo com a Regra de Traube, a sorção aumenta com a diminuição da solubilidade do soluto no solvente. Esta relação pode ser compreendida em relação à quebra das ligações estabelecidas entre o soluto e o solvente, isto é, quanto maior for a solubilidade mais fortes são as ligações soluto-solvente. Geralmente, a solubilidade dos compostos orgânicos em água diminui com o aumento do comprimento da cadeia do composto, ou pela sua aromaticidade ou, ainda, pela presença de substituintes e a sua posição. Um parâmetro utilizado como indicador da apolaridade dos compostos é o coeficiente de partição octanol-água, Kow (MORENO-CASTILLA, 2004). 
O tamanho da molécula, bem como a sua forma, para além de condicionarem a solubilidade do composto têm importância na velocidade da sorção e na sua extensão em sólidos porosos, isto se a velocidade for controlada pelo transporte intraparticular. Nesta situação e para moléculas da mesma família de compostos, a reação decorre tanto mais rapidamente quanto menor for a molécula do soluto (WEBER JUNIOR, 1972).

Ainda relacionada com a solubilidade, a presença de matéria orgânica ou de solventes orgânicos solúveis em água pode promover o aumento da solubilidade de um soluto de características apolares, diminuindo a extensão da sorção (NZENGUN et al., 1996). E o mesmo pode acontecer pela presença de outros solutos em solução. As águas residuais são normalmente uma mistura de compostos, que podem mutuamente melhorar a sorção ou inibi-la pela competição pelos centros ativos. A extensão desta ação depende do tamanho relativo das moléculas, das suas afinidades para o sorvente e das suas concentrações relativas (WEBER JUNIOR, 1972). A presença de sais inorgânicos dissolvidos, por sua vez, poderá ter um efeito contrário, uma vez que o aumento da força iônica do meio tende a diminuir a solubilidade dos compostos orgânicos (TURNER, 2003).

\section{8. Área superficial do sorvente}

A sorção é um fenômeno de superfície diretamente relacionado com a área superficial disponivel, de tal forma que aumentando a área a sorção sofrerá um incremento. A área específica é a porção da área superficial total que está disponível para a sorção, por unidade de massa de sorvente. Portanto, a extensão da sorção conseguida é maior em sólidos mais finamente divididos ou mais porosos (WEBER JUNIOR, 1972). 
A capacidade de sorção de um sólido não poroso também deve variar com o inverso do diâmetro da partícula, enquanto para sorventes muito porosos esta capacidade será relativamente independente da dimensão do sólido. Tanto a velocidade como a extensão da sorção em partículas de iguais dimensões devem variar de forma aproximadamente linear com a dosagem de sorvente numa gama de valores que não resulte em grandes diferenças na concentração do soluto remanescente na solução.

Relativamente à textura do sorvente, principalmente na estrutura dos poros, deve ser tal que, a molécula do soluto entre no poro e seja apenas sorvida na sua superfície interior. Se as moléculas têm dimensões superiores às do poro, a extensão da sorção ficará largamente condicionada devido a impedimentos estéricos (GRAHAM, 1955). Desta forma é relevante fazer a caracterização dos sólidos no que diz respeito à dimensão dos seus poros. De acordo com a IUPAC (International Union of Pure and Applied Chemistry) a porosidade total é classificada em três grupos: microporos, mesoporos e macroporos com a largura dos poros até $2 \mathrm{~nm}$, de 2 a $50 \mathrm{~nm}$ e superiores a $50 \mathrm{~nm}$, respectivamente.

\subsection{Propriedades químicas do sorvente}

As interações envolvidas nos fenômenos de sorção estão normalmente divididas em forças fracas, no caso da sorção física, e forças mais intensas, no caso da sorção química. Outro aspecto determinante relaciona-se com o teor de matéria orgânica do sorvente, especificamente em sistemas em que o soluto é um composto orgânico, sendo esta propriedade tanto mais importante quanto maior for a hidrofobicidade do soluto. 
No caso dos materiais de carbono, considera-se que a química da superfície dos sorventes depende essencialmente do seu teor em heteroátomos, sobretudo do seu teor em oxigênio. Esta característica determina a carga à superfície do material, a sua hidrofobicidade e a densidade eletrônica (MORENO-CASTILLA, 2004). Quando um sólido é colocado numa solução tem tendência a adquirir uma carga à superfície resultante da dissociação dos grupos superficiais ou da adsorção de íons da solução. Os carvões ativados são classificados como materiais anfóteros, adquirindo características básicas ou ácidas dependendo do $\mathrm{pH}$ do meio aquoso em contato (RODRIGUEZ- REINOSO et al., 1998).

A carga negativa resulta da dissociação dos átomos de oxigênio superficiais com caráter ácido como os que estão presentes nos grupos carboxila e hidroxila, com a libertação do próton e permanência da carga negativa à superfície (MORENO-CASTILLA, 2004). Além destes grupos, também as lactonas (ésteres cíclicos) e os anidridos têm o mesmo comportamento, sendo estes últimos facilmente hidrolisados a ácidos em solução aquosa (PINE, 1987).

Por outro lado, algumas moléculas orgânicas consideradas neutras eletricamente, são de fato compostas por átomos com diferentes eletronegatividades, formando entre si uma ligação polar. Uma característica importante relacionada com o grupo carbonila é a sua polaridade que pode ser explicada recorrendo à estrutura eletrônica. A ligação do átomo oxigênio ao átomo de carbono, induz maior densidade eletrônica próximo do átomo de oxigênio. Esta polaridade depende dos grupos ou átomos que se encontram ligados ao carbono, isto é, quando comparando a polaridade do grupo carbonila nas cetonas ou nos aldeídos, verifica-se que este último possui maior polaridade porque o átomo de 
carbono ao qual se encontra ligado é mais pobre em elétrons (PINE, 1987). São estas estruturas que aceitam prótons da solução aquosa que asseguram à superfície do carvão ativado um caráter básico (MORENO-CASTILLA, 2004).

Em materiais anfóteros, a presença de diferentes grupos funcionais condiciona a carga superficial, dependendo do $\mathrm{pH}$. Existe um valor de $\mathrm{pH}$ para o qual à superfície existem tantos grupos carregados positivamente como os carregados negativamente considerando-se, neste ponto, que a superfície tem carga nula. Este valor de $\mathrm{pH}$ é considerado o ponto isoelétrico ou o ponto de carga nula do material, $\mathrm{pH}_{\mathrm{PCN}}$ (RODRIGUEZ-REINOSO et al., 1998). Este aspecto é relevante na definição das condições de ativação dos carvões, podendo controlar-se desta forma a predominância dos grupos de superfície que terão o comportamento desejado relativamente aos compostos que se deseja tratar na água.

A presença de átomos de oxigênio à superfície dos materiais de carbono afeta a densidade eletrônica das superfícies o que, consequentemente, afeta as interações dispersivas entre a superfície e as moléculas do soluto (MORENOCASTILLA, 2004). O teor de oxigênio nos grupos funcionais superficiais dos sorventes está relacionado com o caráter hidrofóbico que estes apresentam, sendo tanto mais acentuado quanto menor for o teor de oxigênio (MORENO-CASTILLA, 2004).

Em linha com o referido anteriormente, a sorção de compostos orgânicos de soluções aquosas resulta majoritariamente de ligações hidrofóbicas entre o soluto e o sorvente. Assim sendo, pode compreender-se a importância do teor de matéria orgânica do sorvente. Este parâmetro tem tido maior atenção em sistemas naturais onde materiais como os solos ou plantas funcionam como sorventes. No primeiro 
caso, o teor de carbono orgânico é considerado o fator mais importante que influencia a sorção de compostos orgânicos, onde apenas teores muito baixos de matéria orgânica podem eclipsar os efeitos da área superficial em diferentes solos (WEBER JUNIOR et al., 1983). Relativamente às plantas, alguns estudos têm indicado que as frações de lipídeos ou de lenhina são determinantes na sorção de solutos hidrofóbicos (SIMONICH ; HITES, 1995; TRAPP et al., 2001).

\subsection{Sorção em materiais orgânicos}

Materiais orgânicos naturais (SIMONICH ; HITES,1995) apresentam a fração lipídica como a responsável pela acumulação de poluentes em materiais orgânicos naturais, especialmente na vegetação, servindo mesmo como indicadores de poluição atmosférica. Essa fração lipídica não será mais que o conjunto de cadeias longas alifáticas de ácidos graxos, reforçando, desta forma, a importância dos compostos alifáticos na sorção de compostos orgânicos não polares (SEVERTSON ; BENERJEE, 1996).

As espumas de poliuretano derivadas de óleo de mamona, têm sido um material que desperta bastante interesse na sorção de diferentes solutos, principalmente orgânicos, Devido à fração de cadeias longas alifáticas de ácidos graxos destes materiais, com a sua rede polimérica tridimensional complexa.

\section{Poliuretano derivado de óleo de mamona}

O termo poliuretano se aplica à classe de polímeros que contém ligação uretana, mesmo que existam outras ligações presentes. Diferentes de outros polímeros, que são polímeros de unidades monoméricas, os poliuretanos não 
contêm unidades uretanas repetidas de modo regular e não têm uma fórmula empírica que seja representativa de um todo. Um poliuretano típico, além dos grupos uretano, pode conter hidrocarbonetos alifáticos e aromáticos, grupos éster, éter, uréia, amida, etc. No poliuretano, duas estruturas básicas podem ser diferenciadas: segmentos poliéster ou poliéter longos, moderadamente flexíveis e segmentos curtos, relativamente rígidos, compreendendo os grupos uretano e aromáticos. A razão entre estes dois segmentos pode ser variada dentro de amplos limites, alterando, significativamente, as propriedades dos poliuretanos obtidos.

As reações de formação dos uretanos foram propostos por WURTZ em 1849, mas somente nas décadas de 30 e 40, BAYER e colaboradores, encontraram uso comercial para o produto de reação de grupos hidroxila e isocianatos. Desde então, a quantidade de materiais desenvolvidos a partir deste tipo de polimerização aumentou enormemente, a ponto de abranger diferentes segmentos de aplicação. Durante a $2^{\mathrm{a}}$ Guerra Mundial, na Alemanha, os poliuretanos foram extensivamente empregados e desenvolveu-se uma excelente indústria baseada em diisocianatos, com aplicações em fibras, cerdas, revestimentos, adesivos, espumas e elastômeros (CANGEMI, 2006).

Alguns desses trabalhos, pioneiros na síntese de poliuretanos, usaram o óleo da mamona como poliol. Entretanto, com o aparecimento dos polióis poliéteres, no final da década de 50, tendo como principal característica o seu baixo custo por ser um subproduto derivado do petróleo, foi delegado ao segundo plano as pesquisas com os poliuretanos derivados de óleo de mamona, ficando estas restritas ao desenvolvimento de materiais mais nobres. 
A tendência mundial à procura de materiais biodegradáveis, não poluentes e derivados da biomassa fez com que as pesquisas com poliuretanos derivados de óleo de mamona se tornassem um tema atual, abrindo, assim, novas perspectivas para seu desenvolvimento (ARAÚJO, 1998).

A partir disto, o emprego do óleo de mamona como poliol (só ou modificado) vem se tornando cada vez mais difundido, mas ainda existem poucas referências sobre as propriedades estruturais dos poliuretanos obtidos a partir dele.

Embora os poliuretanos tenham se desenvolvido recentemente, se comparados a outros polímeros, sua versatilidade em se obter materiais com propriedades diferentes fez com que esses se tornassem um dos principais polímeros deste século.

\subsection{Reação de polimerização}

O produto da reação química entre um grupo hidroxila e um grupo isocianato, é conhecido como uretano.

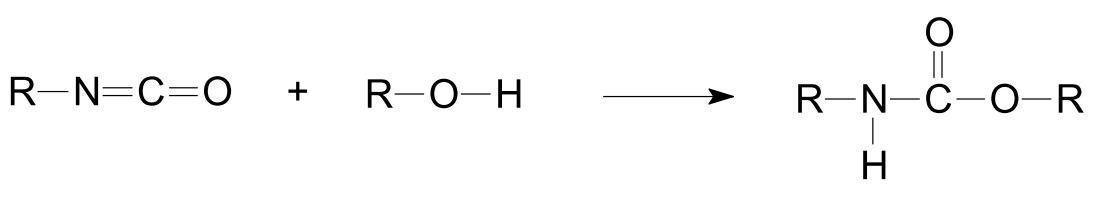

Isocianato Hidroxila Uretano

Figura 11 - Reação de formação do uretano.

A polimerização dos poliuretanos ocorre quando um composto com dois ou mais isocianatos reage em uma estrutura com um poliol, ou seja, um álcool polifuncional. 


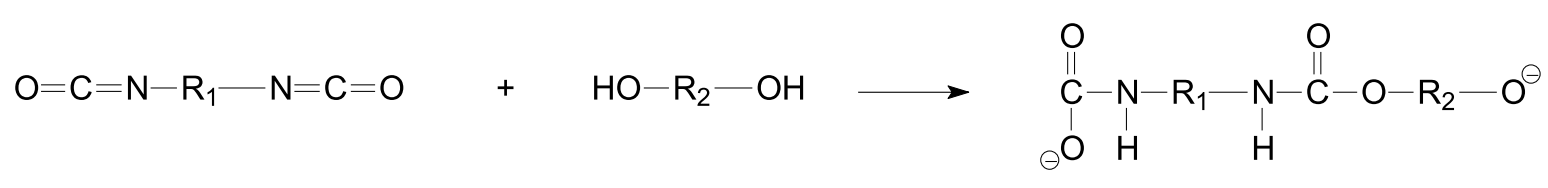

$\begin{array}{lll}\text { Diisocianato Poliol Poliuretano } & \text { Pol }\end{array}$

Figura 12 - Reação de formação do poliuretano.

Quando se usam reagentes difuncionais, são produzidos poliuretanos lineares. Se a funcionalidade (número de hidroxilas por moléculas disponíveis para reagir com grupos isocianatos) do composto dihidroxilado ou do isocianato for aumentada para três ou mais, são formados polímeros ramificados ou entrecruzados.

A reação é exotérmica e sua velocidade depende tanto da estrutura do isocianato como do poliol. A reatividade do isocianato é dependente da influência dos grupos vizinhos e da configuração da molécula.

Os poliuretanos se caracterizam devido a sua versatilidade: o entrecruzamento; a flexibilidade das cadeias mais as forças intermoleculares, podem ser largamente variados, obtendo-se estruturas que variam de lineares e flexíveis, a rígidas altamente entrecruzadas.

Devido à alta reatividade dos compostos contendo grupos isocianatos, geralmente é feita uma pré-polimerização que consiste da reação de um di ou poliisocianato com um poliol, nas proporções previamente determinadas para a obtenção do teor de isocianato livre desejado. A reação de polimerização ocorre pela mistura do pré-polímero com o poliol final conforme mostrado na Figura 13, gerando um poliuretano de alto peso molecular. 

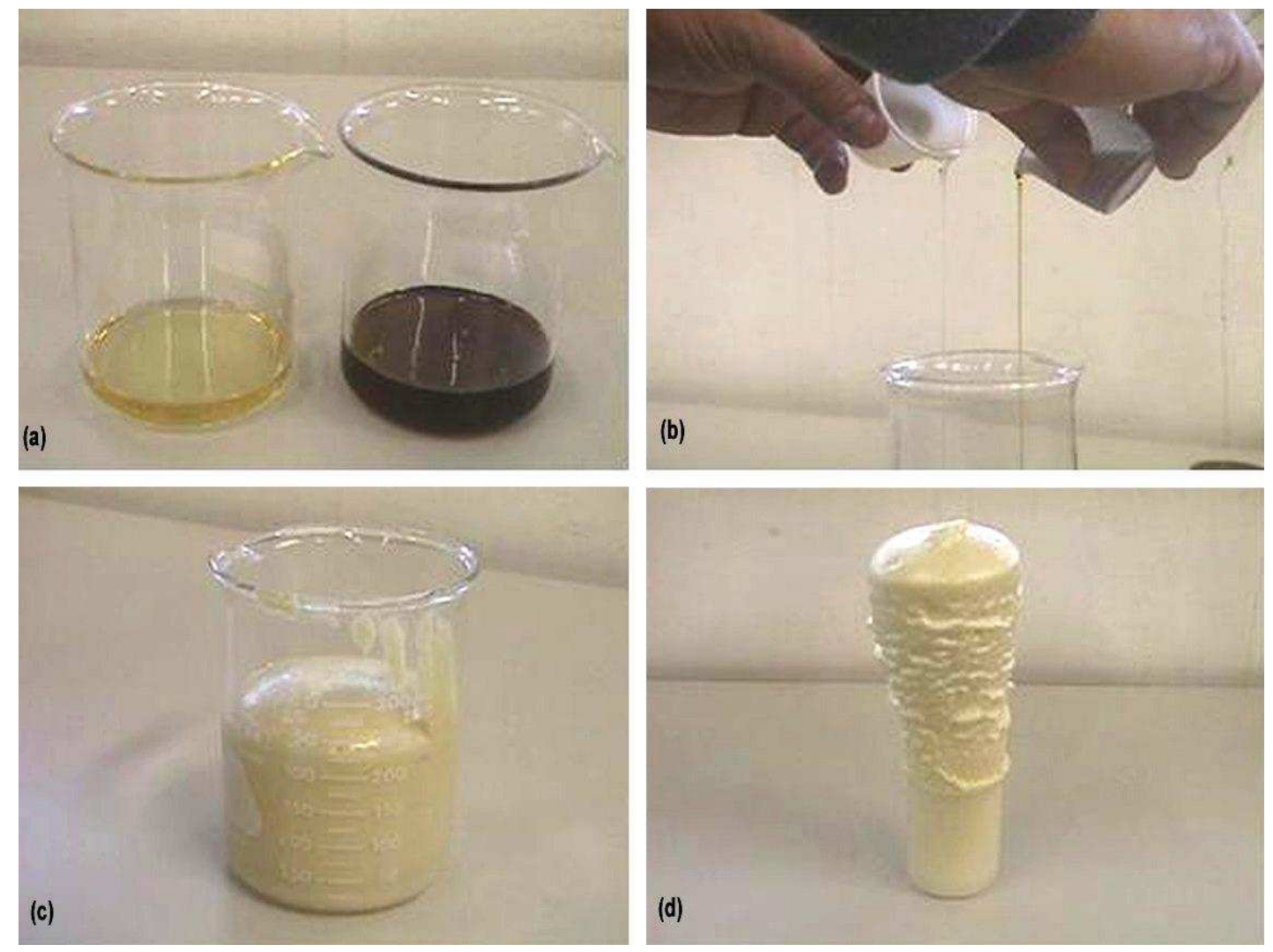

Fonte: QUÍMICA NOVA NA ESCOLA Vol. 31, N³, AGOSTO 2009

Figura 13 - Etapa de síntese de espuma de poliuretano (a) poliol e pré-polímero; (b) durante a mistura; (c) início da formação da espuma; (d) espuma depois de pronta.

\subsection{Poliol, pré-polímero e óleo de mamona}

\subsubsection{Poliol}

Juntamente com os isocianatos, os compostos hidroxilados (polióis) são componentes importantes na síntese dos poliuretanos. Uma grande variedade de polióis é utilizada na manufatura de poliuretanos, desde compostos naturais como o óleo de mamona, que contém três grupos hidroxila e produzem polímeros entrecruzados, até polióis sintéticos, especialmente preparados para a produção de polímeros com características específicas. 
A maioria dos polióis é encontrada na forma de poliéteres ou de poliésteres. A massa molecular e a funcionalidade são fatores principais na determinação das propriedades do polímero, mas a estrutura do poliol também é importante. Um poliéster produz poliuretanos que têm propriedades térmicas e tolerância a substâncias corrosivas diferentes das produzidas com poliéter. Os poliuretanos derivados de poliéster são mais estáveis e menos facilmente oxidáveis (VILAR, 1993).

Os polióis são desenvolvidos com estrutura molecular e funcionalidade necessária para reagir com um pré-polímero ou um diisocianato comercial podendo gerar poliuretanos com propriedades específicas. A escolha do poliol, especialmente pelo tamanho e flexibilidade de sua estrutura molecular e sua funcionalidade controla, em grande parte, o grau de entrecruzamento obtido no polímero formado na reação do poliol com o isocianato (PLEPIS, 1991). O poliol utilizado neste trabalho é um poliéster derivado do ácido ricinoleico.

\subsubsection{Pré- polímero}

Conforme estudo anterior, devido à alta reatividade dos compostos contendo grupos isocianatos, geralmente, embora não seja uma regra, é feita uma prépolimerização com um poliol conforme mostrado na Figura 14, aumentando sua massa molecular, deixando uma porcentagem de isocianato livre para reagir com o poliol final. 
$\mathrm{O}=\mathrm{C}=\mathrm{N}-\mathrm{R}_{1}-\mathrm{N}=\mathrm{C}=\mathrm{O}+\mathrm{HO}=\mathrm{R}_{2}-\mathrm{OH} \longrightarrow$

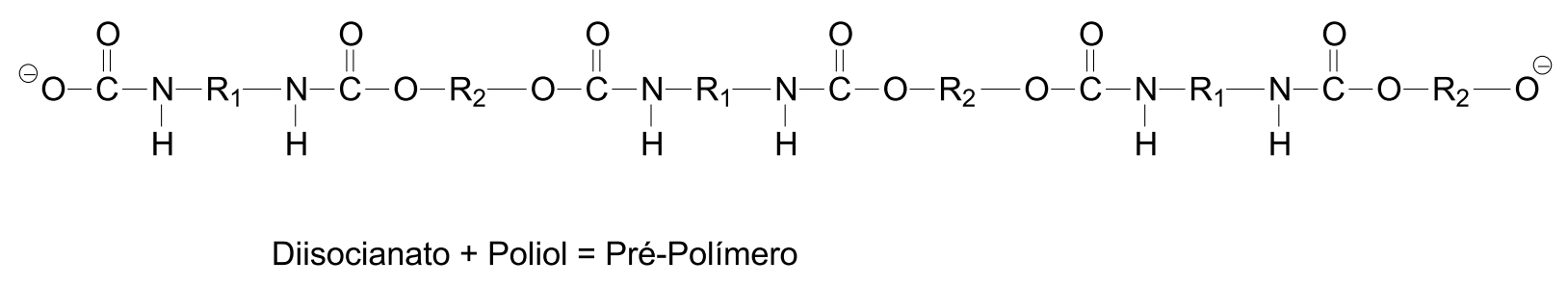

Figura 14 - Reação de formação do pré-polímero.

Os compostos contendo grupos isocianatos são encontrados em duas classes distintas: aromáticos, em que os mais utilizados são o difenilmetano diisocianato (MDI), e o tolueno diisocianato (TDI); alifáticos, sendo mais utilizado o hexametileno diisocianato (HDI) e o isofurona diisocianato (IPDI). O pré-polímero utilizado neste trabalho foi sintetizado a partir do MDI e de um poliol derivado de óleo de mamona (CLARO NETO, 1997).

\subsection{3. Óleo de mamona}

O óleo de mamona é obtido da semente da planta Ricinus Communis que é encontrada em regiões tropicais e subtropicais, sendo muito abundante no Brasil.

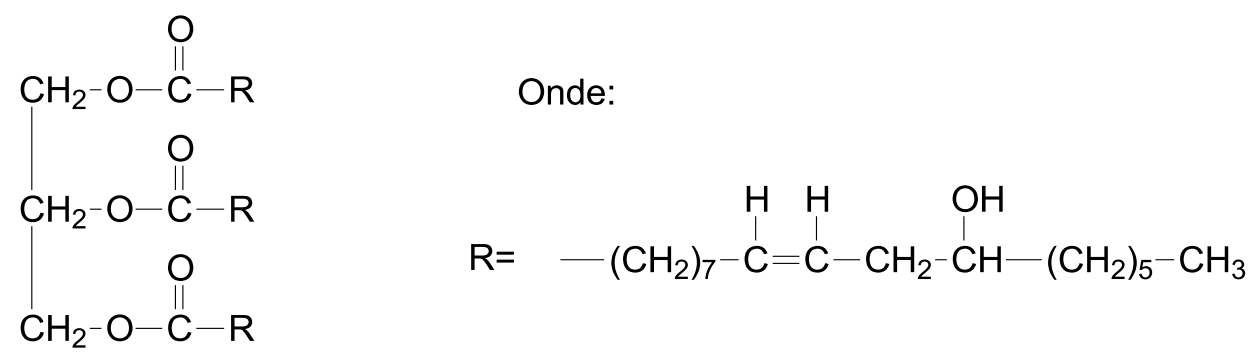

Figura 15 - Estrutura química do óleo de mamona.

Cerca de $90 \%$ do ácido graxo presente na composição dos triglicerídeos do óleo de mamona é o ácido ricinoleico, sendo os restantes $10 \%$ constituídos de 
ácidos graxos não hidroxilados como os ácidos oleicos e linoleicos. O que difere o ácido ricinoleico da grande maioria dos ácidos graxos presentes na natureza é a presença em sua estrutura molecular do grupo hidroxila no carbono 12. Esta particularidade é que faz da triglicéride do ácido ricinoleico um poliol natural trifuncional. A composição média do óleo de mamona é mostrada na Tabela 6.

Tabela 6 - Composição média do óleo de mamona.

\begin{tabular}{lc}
\hline \multicolumn{1}{c}{ Componente } & Percentagem \\
\hline Ácido ricinoleico & 89,5 \\
Ácido palmítico & 1,0 \\
Ácido linoleico & 4,2 \\
Ácido linolênico & 0,3 \\
Ácido dihidroxiesteárico & 0,7 \\
Ácido estereático & 1,0 \\
Ácido oleico & 3,0 \\
Ácido eicosanoico & 0,3 \\
\hline
\end{tabular}

Fonte: PLEPIS (1991).

A presença do ácido ricinoleico confere ao óleo de mamona, propriedades únicas e versatilidade não comum que surge devido aos grupos $\mathrm{OH}$ e a ligação dupla, que são sítios distintos de reação para a preparação de vários derivados industriais. As reações podem ser efetuadas isoladamente ou em combinação, resultando em muitas possibilidades de obtenção de derivados. Devido à presença de grupos hidroxila na porção ricinoleico, o óleo exibe características de solubilidade diferentes dos outros óleos vegetais. Ele é solúvel apenas em quantidades limitadas de éter e outros solventes similares, mas forma sistemas de duas fases com grandes 
quantidades destes solventes. É muito mais solúvel em álcool e tem maior viscosidade ( viscosidade/ Gardner U-V a $25^{\circ} \mathrm{C}$ ) que outros óleos vegetais.

Segundo (VILAR ,1998), a funcionalidade do óleo de mamona é de cerca de 2,7. O seu valor de hidroxilas é de $163 \mathrm{mg} \mathrm{KOH/g}$ (miligramas de hidróxido de potássio por grama). Portanto, o produto com grande pureza, é indicado para emprego em poliuretanos.

\subsection{Características do poliuretano derivado de óleo de mamona}

O poliuretano apresenta-se na forma bicomponente, constando de um poliol e um pré-polímero. O poliol foi sintetizado a partir do óleo de mamona. O pré-polímero foi sintetizado a partir do difenilmetano diisocianato (MDI) e pré-polimerizado com um poliol também derivado de óleo de mamona, permanecendo com um percentual de isocianato livre para posterior reação.

O GQATP (Grupo de Química Analítica e Tecnologia de Polímeros) do Instituto de Química de São Carlos (IQSC-USP), que estuda a aplicação de poliuretanos obtidos a partir do óleo de mamona na medicina, como cimento ósseo, material para a recuperação de falhas ósseas e material para a confecção de próteses. O GQATP, em junho de 2003, recebeu a aprovação da Food and Drug Administration (FDA), agência do governo norte americano responsável pela liberação de novos alimentos e medicamentos. O GQATP forneceu para este trabalho o pré-polímero, denominado 253 , e o poliol para espuma rígida. 0 poliuretano é preparado, misturando-se o pré-polímero e o poliol. A relação estequiométrica para o poliuretano é de 1:0,7 (pré-polímero e poliol, respectivamente). Após a cura, o poliuretano tem, aproximadamente, uma massa específica de $0,0440 \mathrm{~g} / \mathrm{cm}^{3}$ e um tamanho de poro igual a $0,7 \mu \mathrm{m}$. 


\section{Microscopia eletrônica de varredura (MEV)}

A microscopia eletrônica de varredura constitui-se em uma técnica útil neste trabalho, já que as imagens produzidas são tridimensionais e apresentam alta profundidade de foco, o que significa obter diferentes relevos da superfícies da amostra simultaneamente. A Figura 16 mostra as micrografias da espuma de poliuretano derivada de óleo de mamona em ampliações de 500 vezes e de 1000 vezes após a amostra ser submetida à trituração em moinho, com o objetivo de conseguir-se uma maior superfície de contato na adsorção dos PCBs.
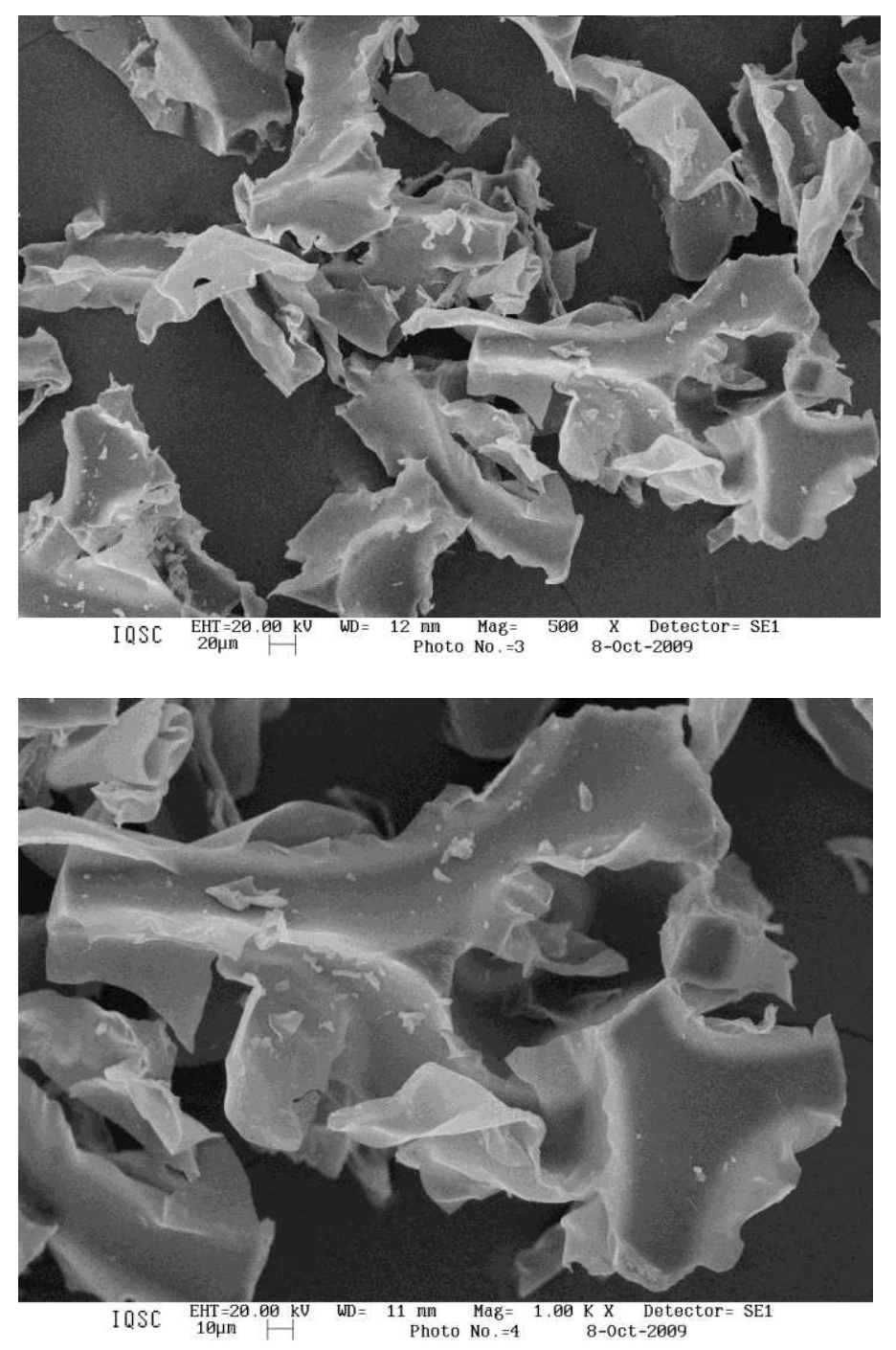

Figura 16 - Micrografias das espumas de poliuretânicas derivadas de óleo de mamona (500X e 1000X). 


\section{Capítulo III - Parte Experimental}

\section{Procedimentos Analíticos}

Os métodos atuais de análise são divididos em dois grandes grupos: PCBs específicos e PCBs não específicos. Em geral, os métodos não específicos são mais rápidos e menos caros do que os métodos específicos. As técnicas mais utilizadas são fluorescência de raios $\mathrm{X}$, métodos colorimétricos e eletroquímicos. Métodos específicos utilizam algum tipo de cromatografia para separar congêneres de PCBs e compostos interferentes, no entanto, não é simplesmente o caso de encontrar um composto facilmente quantificável, mas quantificar uma mistura complexa de compostos. Dos três tipos principais de cromatografia: cromatografia em fase gasosa (CG), cromatografia de camada delgada (CCD) e de líquidos (CLAE), a cromatografia em fase gasosa é a preferida e mais amplamente utilizada. O método mais utilizado para detecção é o detector por captura de elétrons (DCE) (GRAY, 2004).

\subsection{Normas ASTM-D4059 e ABNT NBR 13882}

Nestes métodos, os óleos minerais isolantes, diluídos com o solvente apropriado, são tratados com ácido (ASTM-D4059) e / ou um adsorvente para remover as interferências, e em seguida analisados por cromatografia gasosa utilizando-se detector de captura de elétrons, CG - DCE. O método utilizado nos experimentos foi o ABNT NBR 13882,2005. 


\subsection{Procedimentos para óleos minerais isolantes}

O procedimento para óleos minerais isolantes foi realizado segundo o método ABNT NBR 13882 que utiliza solvente para diluição em cartucho SPE (Agilent Sampliq Florisil), no processo clean-up anterior à determinação por cromatografia gasosa em detector por captura de elétrons. O procedimento prevê que a composição dos $\mathrm{PCBs}$ presentes nos óleos utilizados em transformadores e capacitores estejam em concentrações próximas àquelas presentes nos padrões de PCBs.

\subsection{Amostragem}

A amostragem do óleo mineral isolante, foi realizada de acordo com a norma ABNT NBR 8840.

\subsection{Adsorção de PCBs}

A adsorção dos PCBs presentes no óleo mineral isolante, foi realizada por percolação em coluna de vidro termostatizada mostrada na Figura 17, utilizando-se um banho ultratermostatizado modelo MA-184 Marconi, contendo espuma poliuretânica derivada de óleo de mamona, com massa conhecida, prensada na forma de pó entre dois discos de espuma sólida contendo dois milímetros de espessura. Os teores de PCBs foram medidos antes e após eluição de $50 \mathrm{~mL}$ de óleo pela espuma, nas temperaturas de $25^{\circ} \mathrm{C}, 40^{\circ} \mathrm{C}$ e $60^{\circ} \mathrm{C}$. 


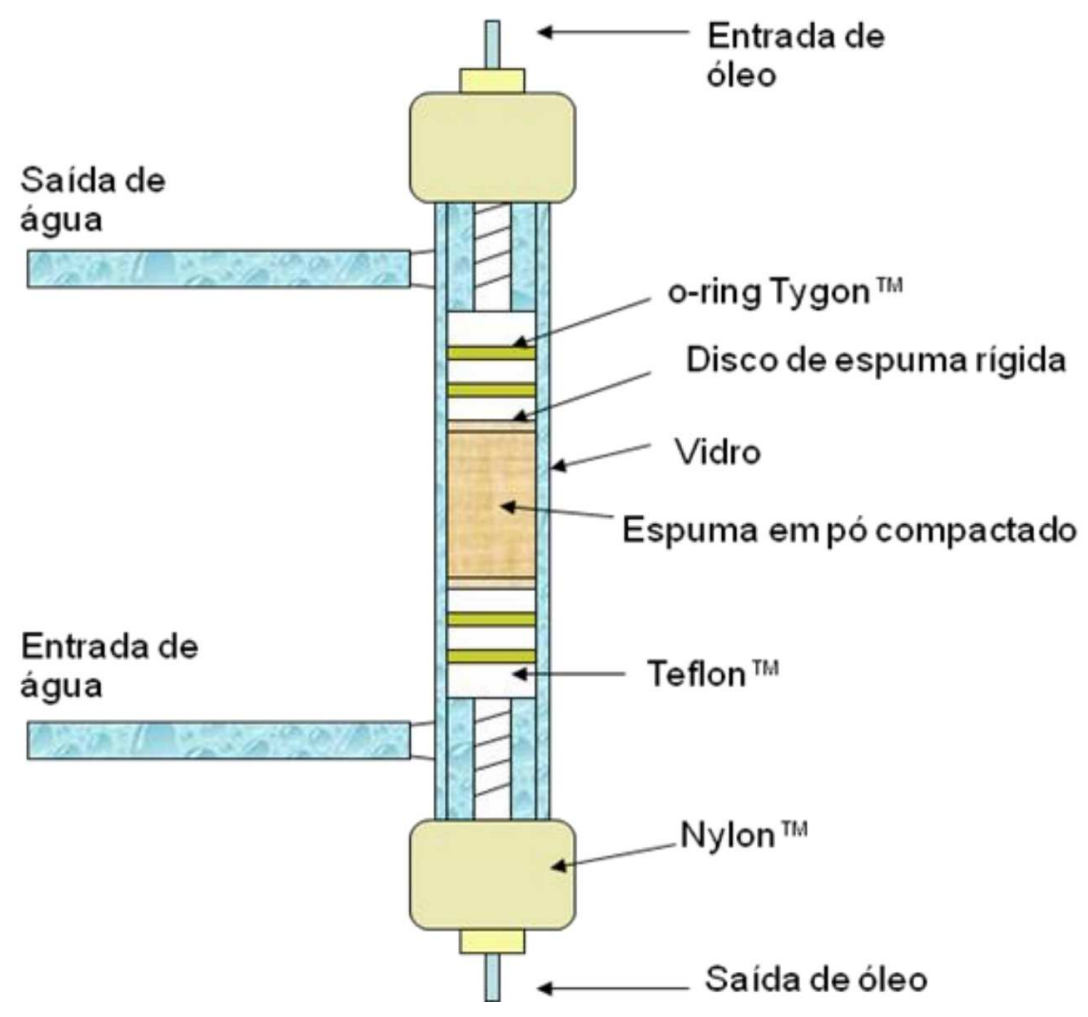

Figura 17 - Coluna de vidro termostatizada, contendo espuma poliuretânica derivada de óleo de mamona.

\subsection{Extração de PCBs}

PCBs são compostos orgânicos semivoláteis não polares, altamente solúveis em solventes não polares como o n-hexano e somente levemente solúveis em solventes polares como a água. Desta forma, os PCBs quando dissolvidos em matriz não polar, como óleos minerais isolantes, o processo de extração torna-se muito difícil (ERICKSON, 1997). Preparou-se, portanto, a extração dos PCBs presentes em óleo utilizando uma relação 1:20 (v/v) de óleo e n-hexano, valor sugerido pela (norma ABNT NBR 13882). Essa relação permitiu que o solvente entrasse inteiramente em contato com a amostra de óleo extraindo os PCBs com eficiência.

\subsection{Clean-up}

O clean-up é um procedimento analítico que remove compostos 
interferentes na determinação de analitos específicos como os PCBs. Um volume de $2 \mathrm{~mL}$ de óleo foram eluidos por gravidade em cartucho SPE Florisil $($ adquiridos da Agilent Technologies. A fração eluida foi diluida em n-hexano, em seguida injetada em triplicata em CG-DCE, através de sistema automatizado, reduzindo, portanto, a possibilidade de erros do volume injetado na quantificação dos PCBs.

\subsection{Cromatografia Gasosa}

As análises de cromatografia gasosa foram realizadas em um cromatógrafo GC-2010 Shimadzu equipado com detector por captura de elétrons (DCE). Utilizouse uma coluna capilar RTX5MS, 30m de comprimento, 0,25 mm diâmetro interno, $0,25 \mu \mathrm{m}$ de espessura de filme, $5 \%$ Difenil, $95 \%$ Dimetil polisiloxano. As condições do método de análise cromatográfica foram: Temp. coluna : $170^{\circ} \mathrm{C}\left(1 \mathrm{~min}\right.$.) $5^{\circ} \mathrm{C} / \mathrm{min}$. até $200^{\circ} \mathrm{C}\left(0,0 \mathrm{~min}\right.$.) $10^{\circ} \mathrm{C} / \mathrm{min}$. até $300^{\circ} \mathrm{C}(5 \mathrm{~min}$.). Temp.; detector DCE: 300 ${ }^{\circ} \mathrm{C}$;Temp. injetor: $280^{\circ} \mathrm{C}$; Vol. Injeção: $1,5 \mu \mathrm{L}$; Pressão: $64,6 \mathrm{Kpa}$;Fluxo total: 13,3 mL/min.;Fluxo Coluna: 0,94 mL / min.;Fluxo Purga: 3,0 mL / min.;Split: 1:10; Gás de arraste: $\mathrm{N}_{2}$.

\subsection{Soluções - padrão (Arocloros 1242 , 1254 e 1260)}

As soluções dos padrões dos Arocloros 1242, 1254 e 1260 de concentração $1000 \mu \mathrm{g} / \mathrm{g}$ foram obtidas da Supelco USA. Inicialmente foram preparadas separadamente conforme mostrado nas Figuras 18, 19 e 20, em seguida, utilizandose uma mistura dos três padrões conforme mostrado na Figura 21. A partir de cada ampola do padrão foram retirados $100 \mu \mathrm{L}$ para um balão volumétrico (cap.10mL), completando-se o volume com n-hexano, obtendo-se a concentração final de $30 \mathrm{mg}$ $\mathrm{kg}^{-1}$ em seguida preparou-se 6 vials adicionado-se respectivamente os volumes de $50 \mu \mathrm{L}, 100 \mu \mathrm{L}, 125 \mu \mathrm{L}, 200 \mu \mathrm{L}, 250 \mu \mathrm{L}$ e $500 \mu \mathrm{L}$ da solução padrão $\left(30 \mathrm{mg} \mathrm{kg}^{-1}\right)$, 
completando-se o volume de cada vial para $1500 \mu \mathrm{L}$ com n-hexano. Obtendo-se as concentrações finais de $1 \mathrm{mg} \mathrm{kg}^{-1}, 2 \mathrm{mg} \mathrm{kg}^{-1}, 2,5 \mathrm{mg} \mathrm{kg}^{-1}, 4 \mathrm{mg} \mathrm{kg}^{-1}, 5 \mathrm{mg} \mathrm{kg}^{-1}$ e 10 $\mathrm{mg} \mathrm{kg}^{-1}$.

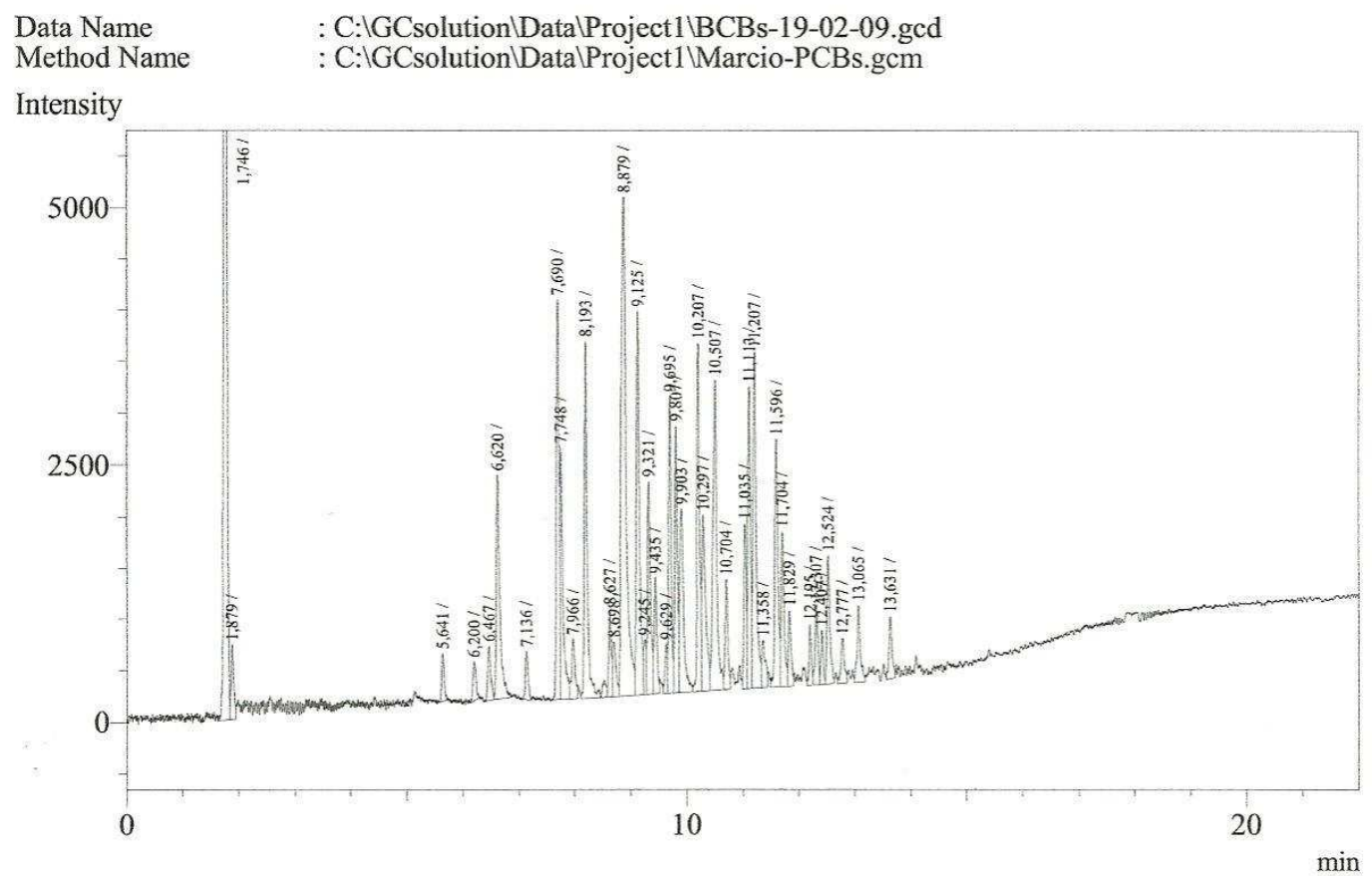

Figura 18 - Cromatograma típico da solução padrão Arocloro 1242.

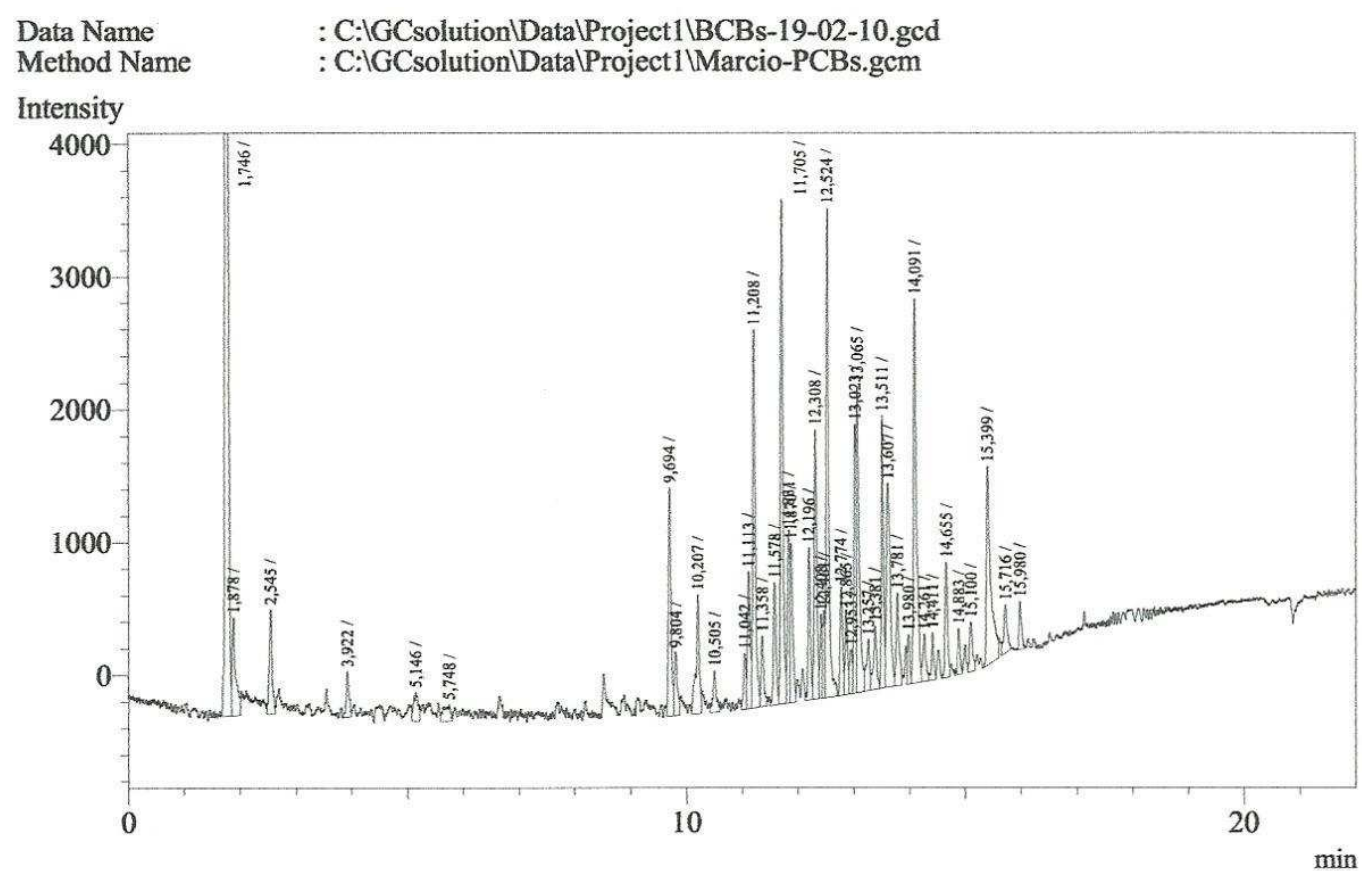

Figura 19 - Cromatograma típico da solução padrão Arocloro 1254. 


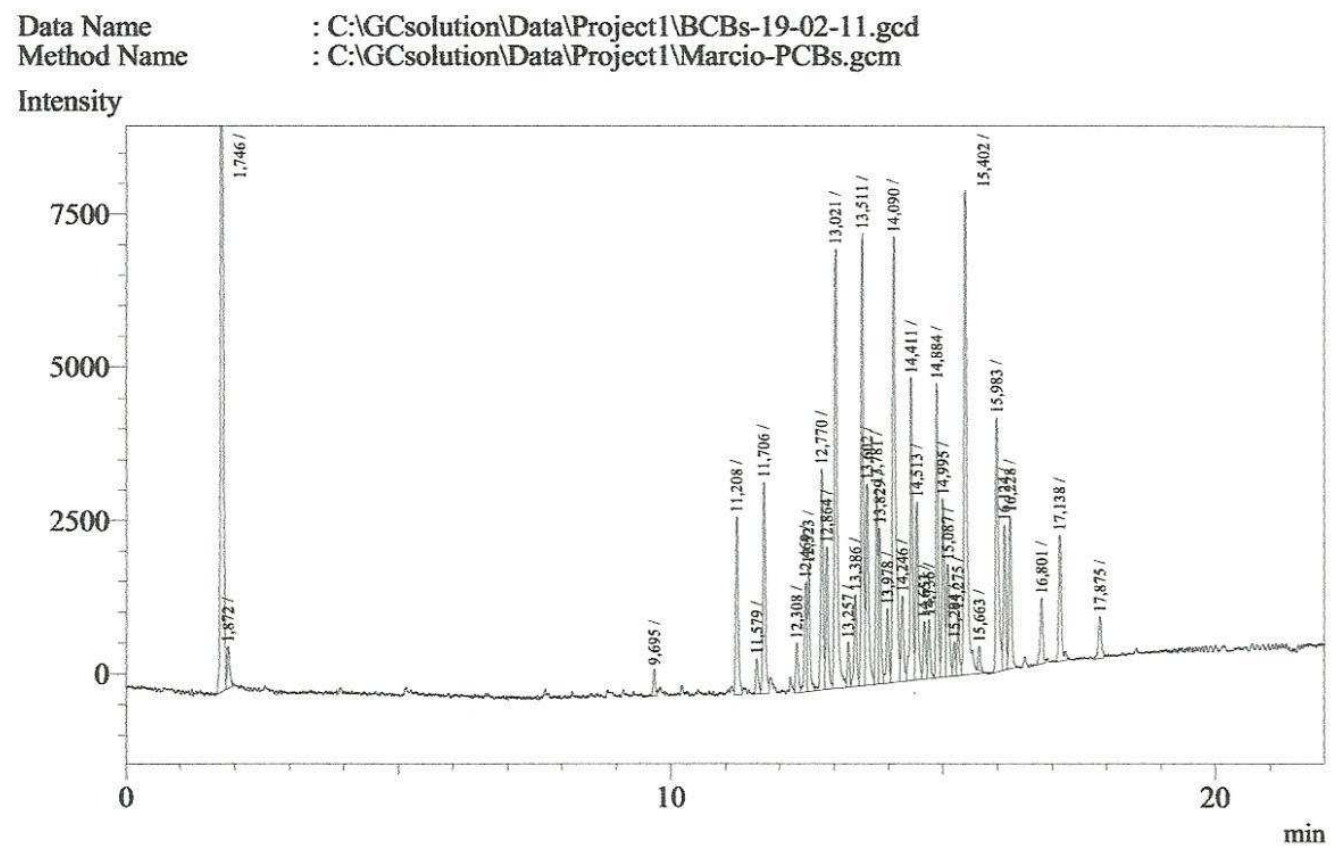

Figura 20 - Cromatograma típico da solução padrão Arocloro 1260.

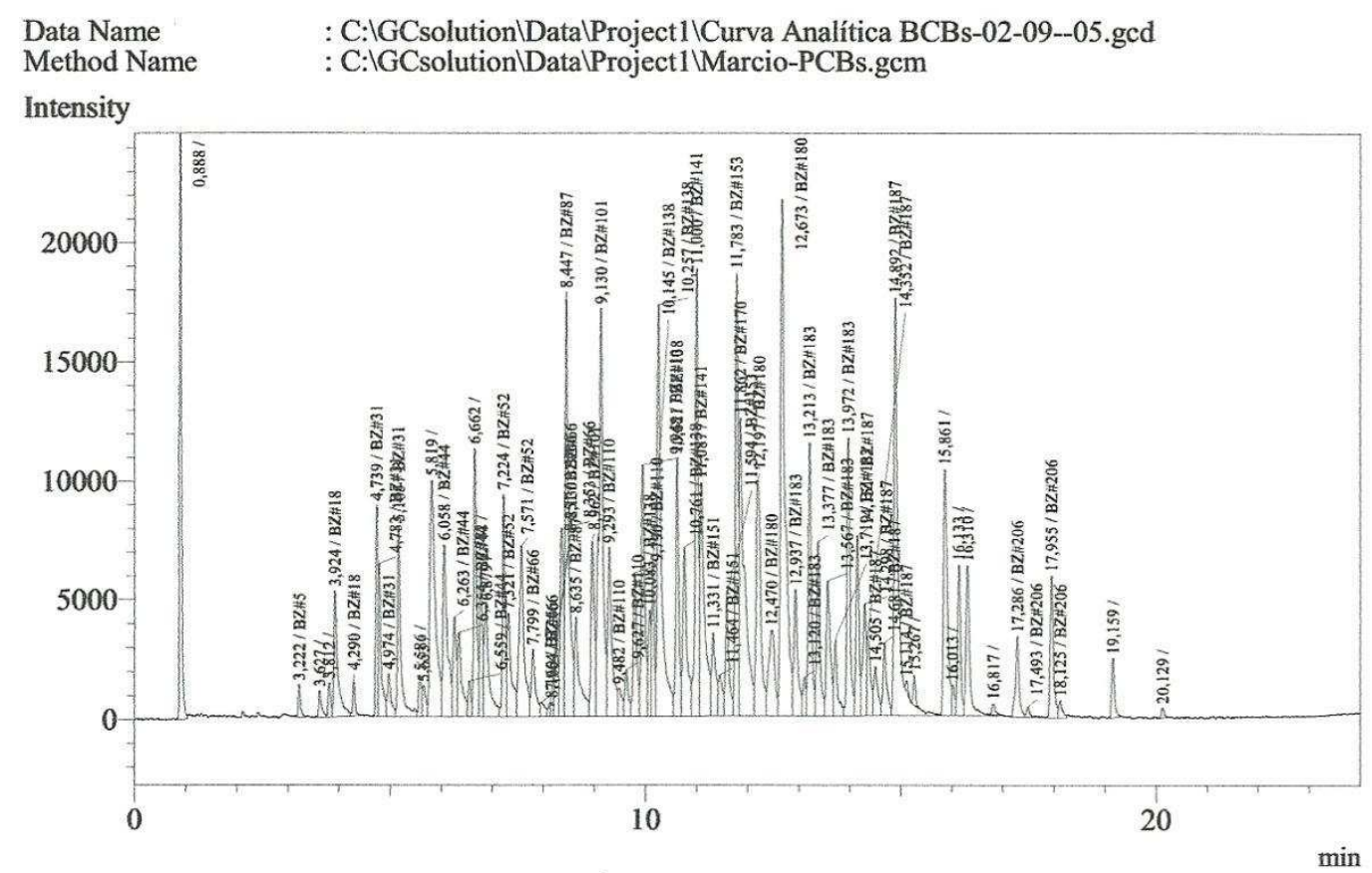

Figura 21 - Cromatograma típico da mistura da solução padrão de

Arocloros 1242,1254 e 1260. 


\subsection{Curva analítica}

A curva analítica mostrada na Figura 22 foi preparada através de injeção em triplicata utilizando uma mistura dos três padrões nas seguintes concentrações:1 mg $\mathrm{kg}^{-1}, 2 \mathrm{mg} \mathrm{kg}^{-1}, 2,5 \mathrm{mg} \mathrm{kg}^{-1}, 4 \mathrm{mg} \mathrm{kg}^{-1}, 5 \mathrm{mg} \mathrm{kg}^{-1}$ e $10 \mathrm{mg} \mathrm{kg}^{-1}$.

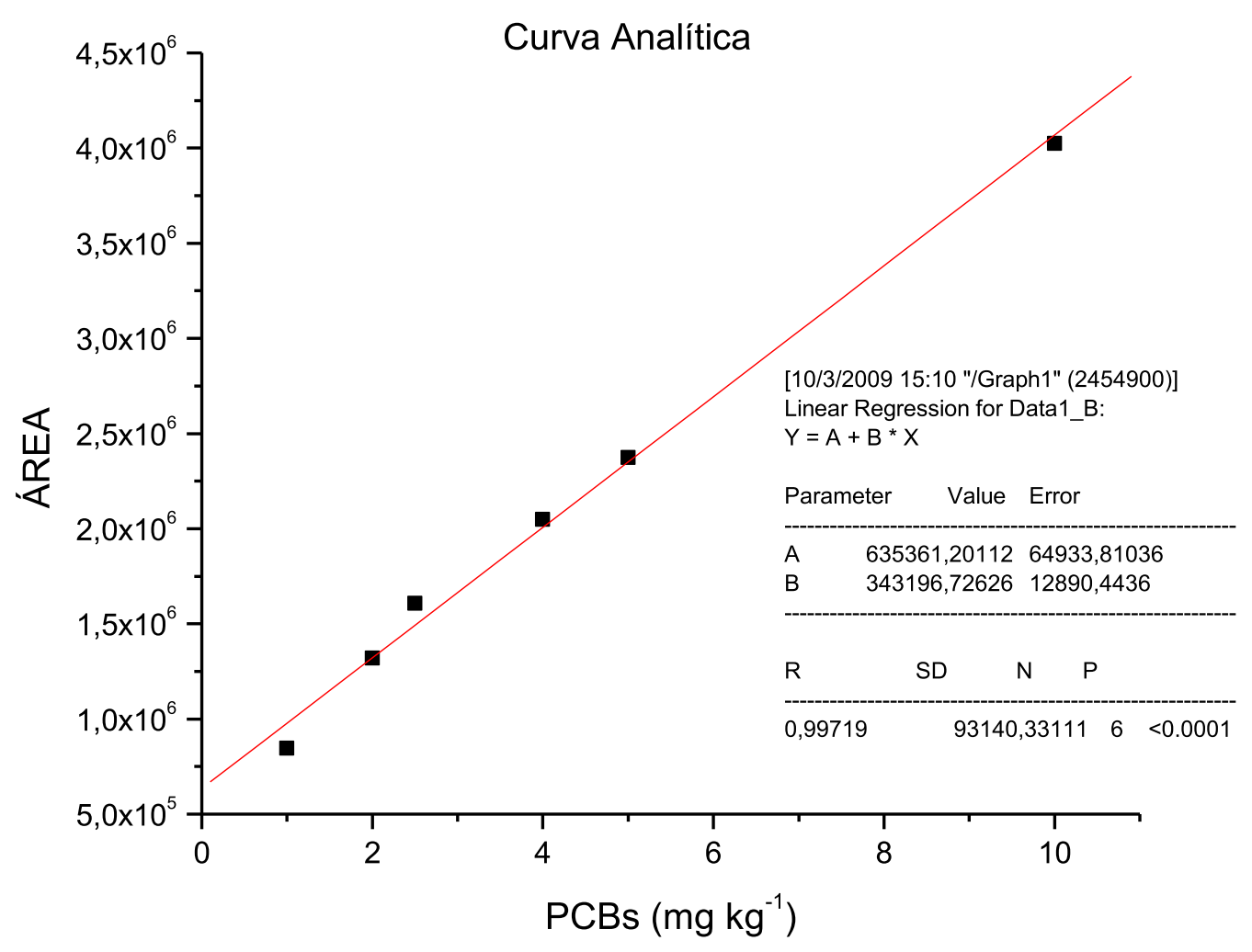

Figura 22 - Curva analítica preparada utilizando uma mistura dos três padrões nas seguintes concentrações: $1 \mathrm{mg} \mathrm{kg}^{-1}, 2 \mathrm{mg} \mathrm{kg}^{-1}, 2,5 \mathrm{mg} \mathrm{kg}^{-1}$, $4 \mathrm{mg} \mathrm{kg}^{-1}, 5 \mathrm{mg} \mathrm{kg}^{-1}$ e $10 \mathrm{mg} \mathrm{kg}^{-1}$. 


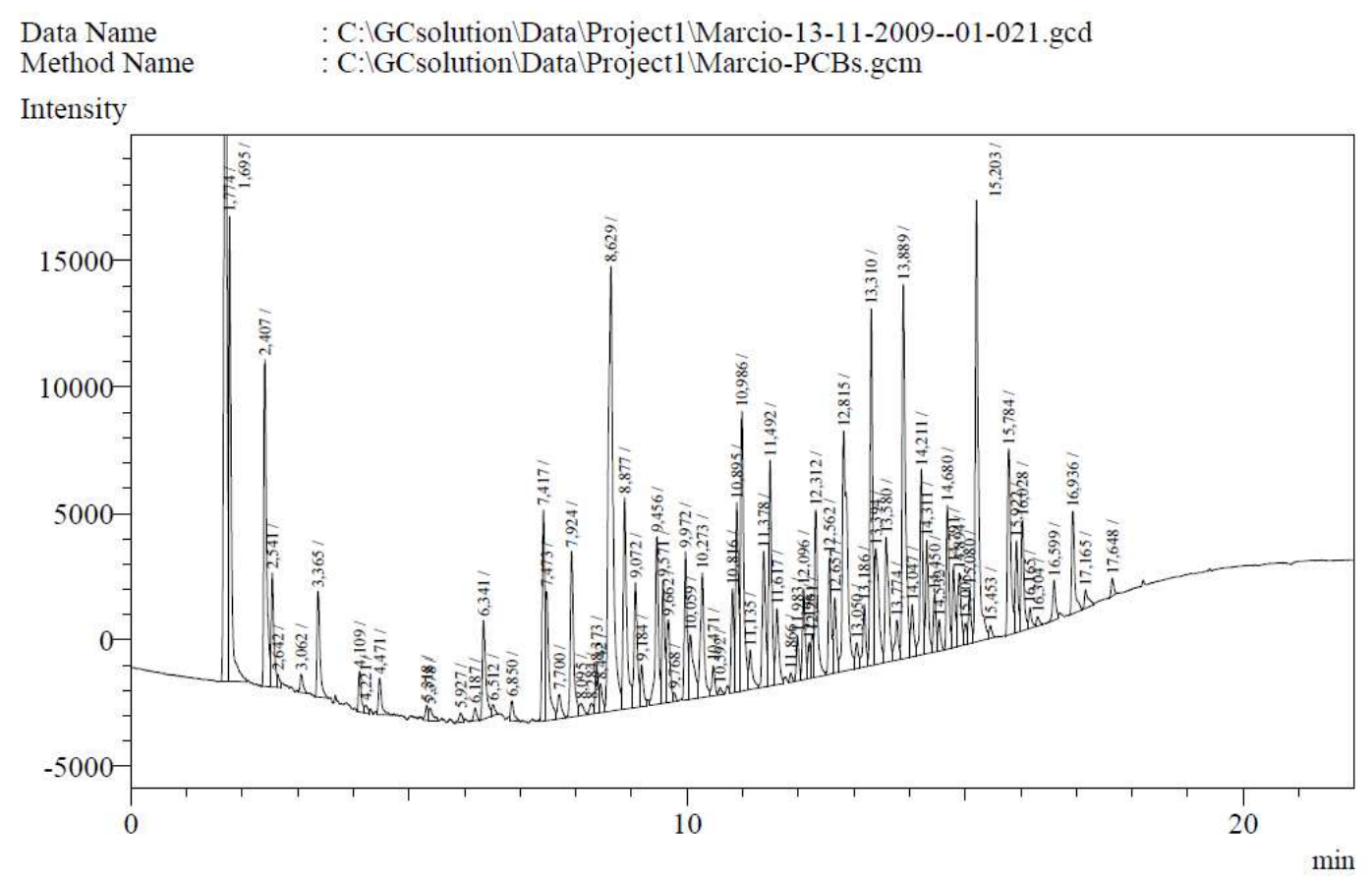

Figura 23 - Cromatograma típico de uma amostra de óleo mineral isolante contendo PCBs

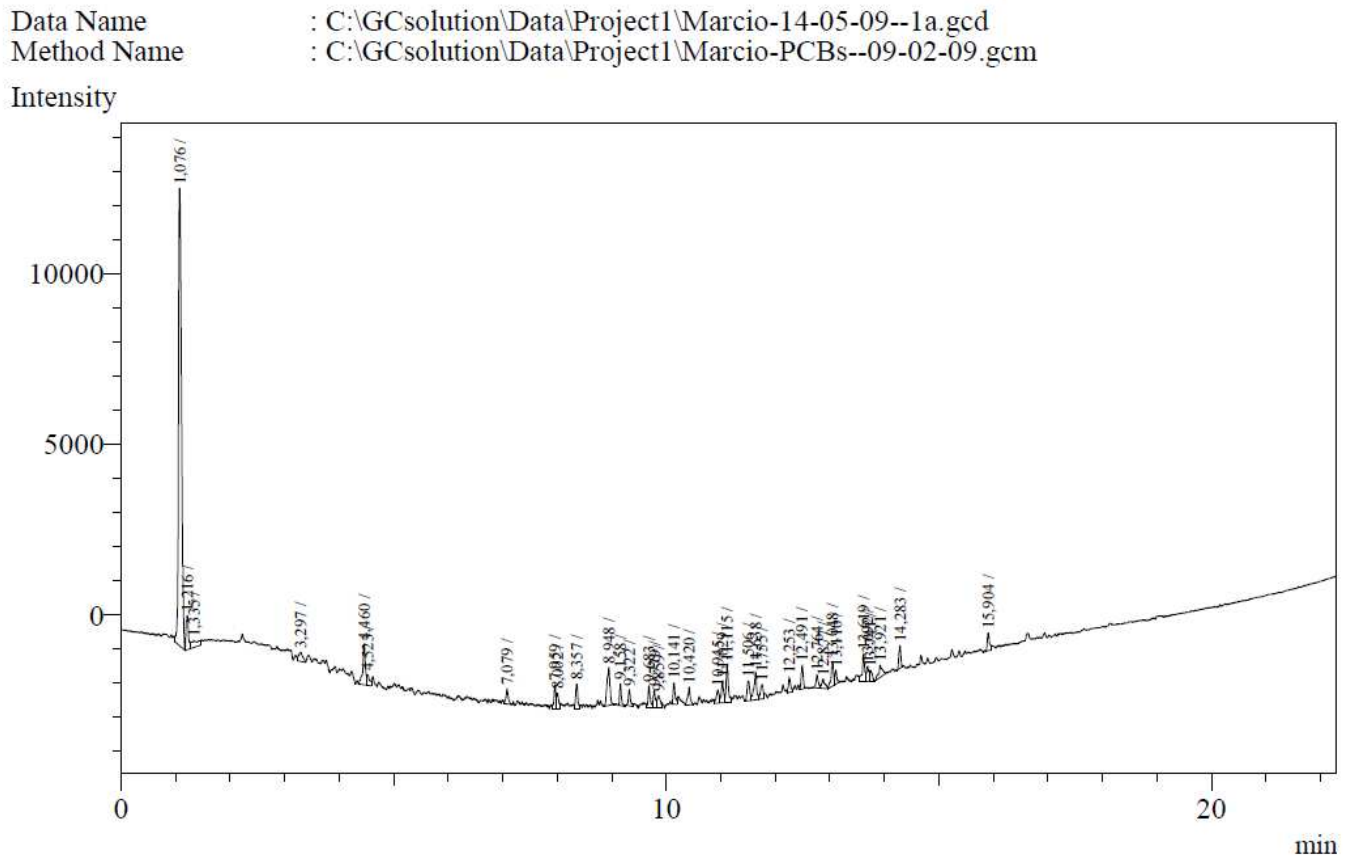

Figura 24 - Cromatograma típico de uma amostra de óleo mineral isolante isento de PCBs 


\subsection{Determinação de PCBs em óleo mineral isolante}

O método utilizado na determinação de $\mathrm{PCBs}$ em óleo mineral isolante, propõe a comparação da área total denominada "região de arocloro" conforme mostrados nas Figuras 18, 19, 20 e 21 obtida na amostra, com a área total obtida pela curva analítica. As Figuras 23 e 24 mostram respectivamente um cromatograma típico de uma amostra de PCBs em óleo mineral isolante e um cromatograma de um óleo isento de PCBs. Esse método tem sido recomendado principalmente para análise de óleo utilizado em transformadores (BELLAR; LICHTENBERG, 1975). Os óleos utilizados em transformadores têm sido frequentemente analisados dessa forma, devido às regulamentações que visam qualificar os óleos quanto à permanência em uso ou a sua disposição.

\subsection{1. Óleo mineral isolante isento de PCBs}

Com o objetivo de verificar a eficiência da adsorção de PCBs em espuma poliuretânica derivada de óleo de mamona, foi utilizada uma amostra de óleo isento de PCBs para percolação em coluna saturada, imediatamente após a eluição de um óleo contaminado. Esse óleo, isento de PCBs, não deveria apresentar traços de PCBs, após passagem pela coluna. Como os limites de detecção considerados foram de três vezes a altura do ruído, os valores obtidos referentes ao óleo utilizado, cerca de $2 \mathrm{mg} \mathrm{kg}^{-1}$, encontram-se dentro do limite de detecção do método. 


\section{Capítulo IV - Resultados e Discussão}

\section{Sorção de bifenilas policloradas (PCBs)}

A sorção de bifenilas policloradas de uma solução num sólido ocorre como resultado de uma de duas características num dado sistema, ou a combinação de ambas. A primeira força impulsionadora pode ser consequência da falta de afinidade do tipo de PCBs para com o óleo mineral isolante utilizado, lipofilicidade, enquanto a segunda deve-se à maior afinidade dos PCBs para a espuma de poliuretano. $\mathrm{Na}$ maioria das situações existe uma combinação das duas forças (WEBER JUNIOR, 1972). O soluto (PCBs) estabelece ligações com os grupos funcionais da superfície sólida por atrações eletrostáticas, de van der Waals ou de natureza química (VOICE ; WEBER JUNIOR, 1983). Distinguem-se, portanto, três tipos principais de adsorção: a troca iônica, a adsorção física e a adsorção química.

\subsection{Curvas de saturação}

Utilizou-se três tipos de espumas referentes ao comportamento das curvas de saturação, no qual estabelece-se o equilíbrio a partir da ocupação dos sítios ativos de adsorção,:

Espuma funcionalizada contendo polissulfeto de amônio

Espuma funcionalizada contendo tiodiglicol

Espuma não funcionalizada 


\subsubsection{Espuma funcionalizada contendo polissulfeto de amônio}

Foram eluidos $50 \mathrm{~mL}$ de óleo isolante $\left(65 \mathrm{mg} \mathrm{kg}^{-1}\right.$ de PCBs) a $40^{\circ} \mathrm{C}$ temperatura definida como ótima por estar próxima ao limite de temperatura de normal de operação do transformador elétrico, evitando dessa maneira a ocorrência de formação de produtos de oxidação no óleo mineral isolante. Através de $2 \mathrm{~g}$ de espuma funcionalizada contendo polissulfeto de amônio, e em seguida, separou-se uma alíquota de $2 \mathrm{~mL}$ para posterior análise cromatográfica. Após esse procedimento todo o óleo foi eluido novamente separando-se nova alíquota, e assim, sucessivamente até obter-se 10 alíquotas.

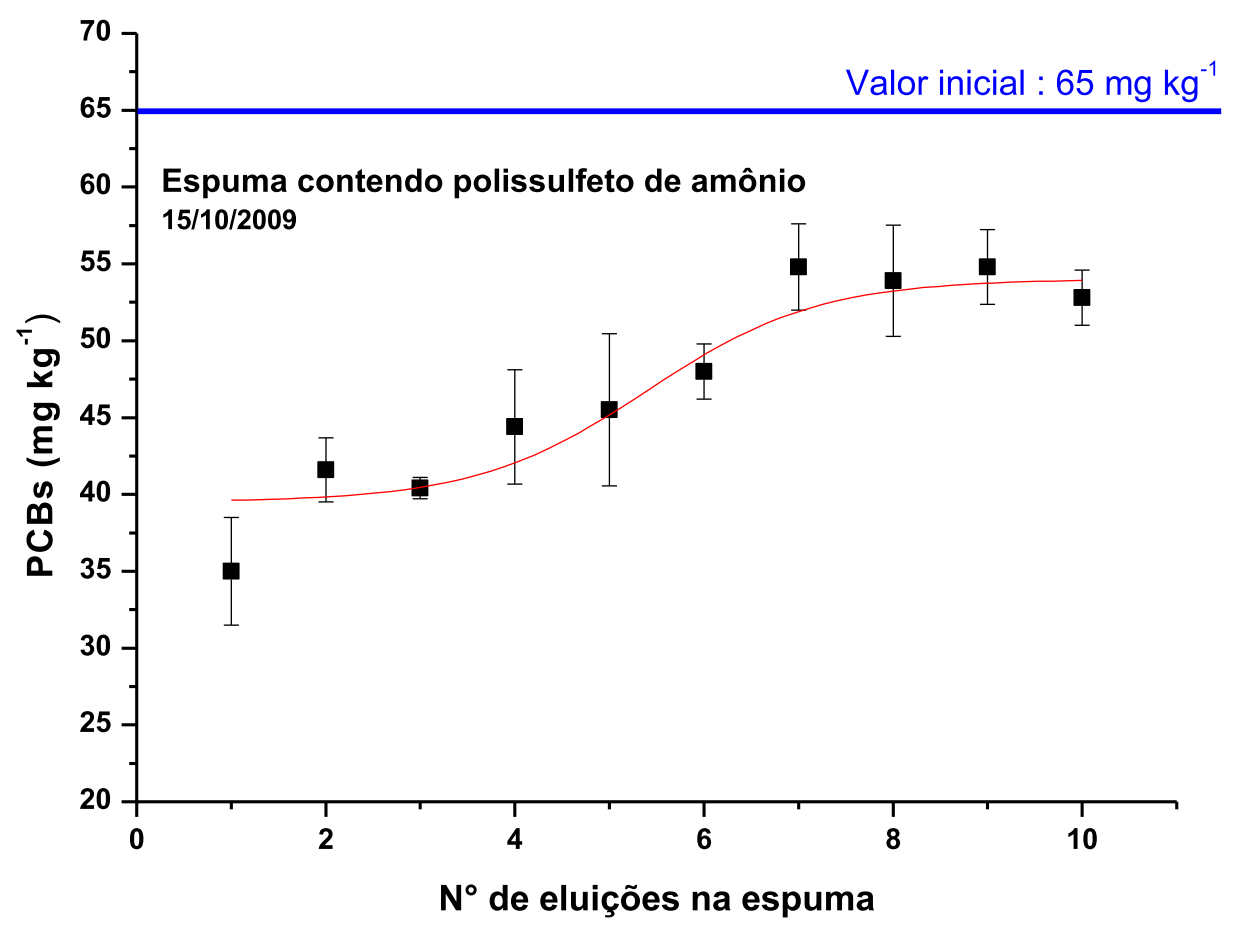

Figura 25 - Curva de saturação da espuma contendo $10 \%$ de polissulfeto de amônio para a adsorção de $\mathrm{PCBs}$ a $40^{\circ} \mathrm{C}$. 


\subsubsection{Espuma funcionalizada contendo tiodiglicol}

Foram eluidos $50 \mathrm{~mL}$ de óleo isolante $\left(65 \mathrm{mg} \mathrm{kg}^{-1}\right.$ de PCBs) a $40^{\circ} \mathrm{C}$ através de $2 \mathrm{~g}$ de espuma funcionalizada contendo tiodiglicol. Separou-se, então, uma alíquota de $2 \mathrm{~mL}$ para posterior análise cromatográfica. Em seguida, todo o óleo foi eluido novamente separando-se nova alíquota, e assim, sucessivamente até obter-se 10 alíquotas conforme mostrado na Figura 26.

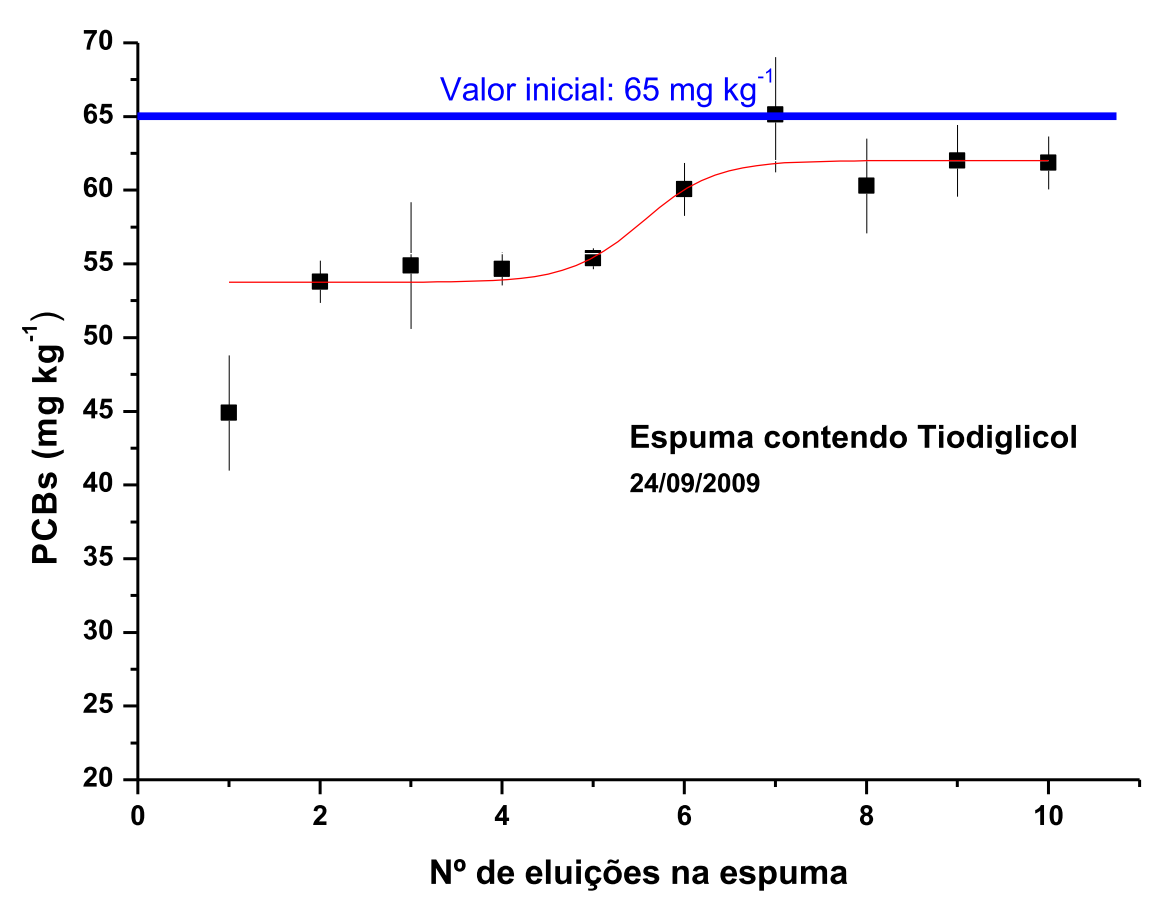

Figura 26 - Curva de saturação da espuma contendo $10 \%$ de tiodiglicol para a adsorção de $\mathrm{PCBs}$ a $40^{\circ} \mathrm{C}$.

\subsubsection{Espuma não funcionalizada}

Foram eluidos $50 \mathrm{~mL}$ de óleo isolante $\left(65 \mathrm{mg} \mathrm{kg}^{-1}\right.$ de PCBs) a $40^{\circ} \mathrm{C}$ através de $2 \mathrm{~g}$ de espuma "2S" (não funcionalizada), após separou-se uma alíquota de $2 \mathrm{~mL}$ para posterior análise cromatográfica. Todo o óleo foi eluido novamente 
separando-se nova alíquota, e assim, sucessivamente até obter-se 10 alíquotas conforme mostrado na Figura 27.

10.1.4 Curvas de saturação de espuma não funcionalizada utilizada com massas de $0,1 \mathrm{~g}$ e $2,0 \mathrm{~g}$

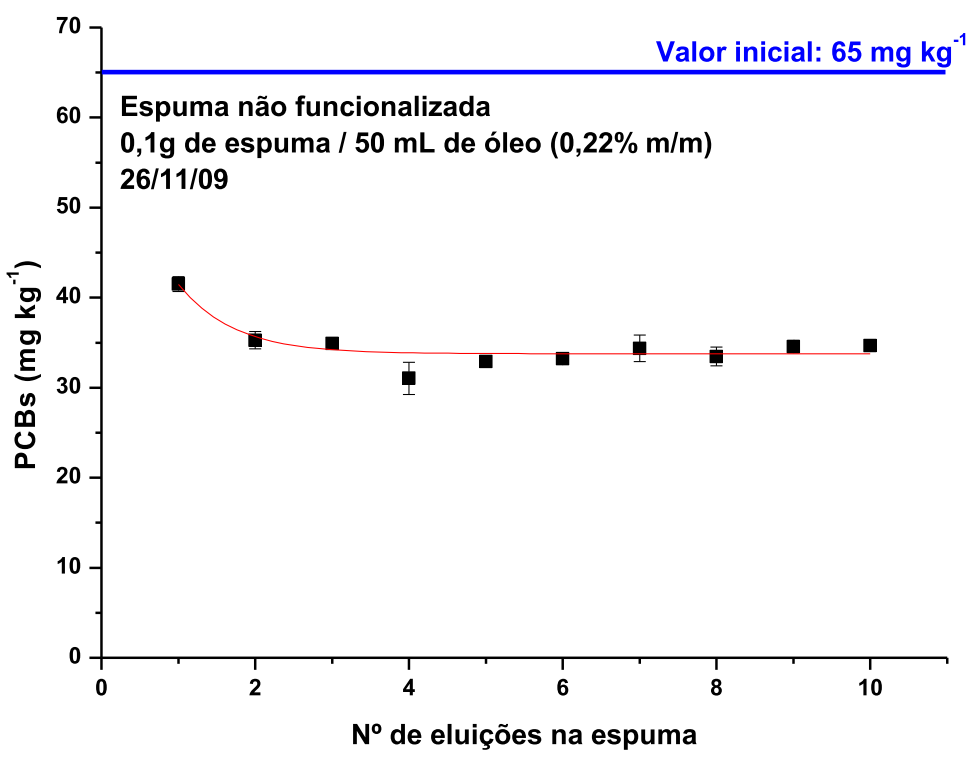

Figura 27 - Curva de saturação da espuma $(0,1 \mathrm{~g})$ não funcionalizada para a adsorção de PCBs a $40^{\circ} \mathrm{C}$.

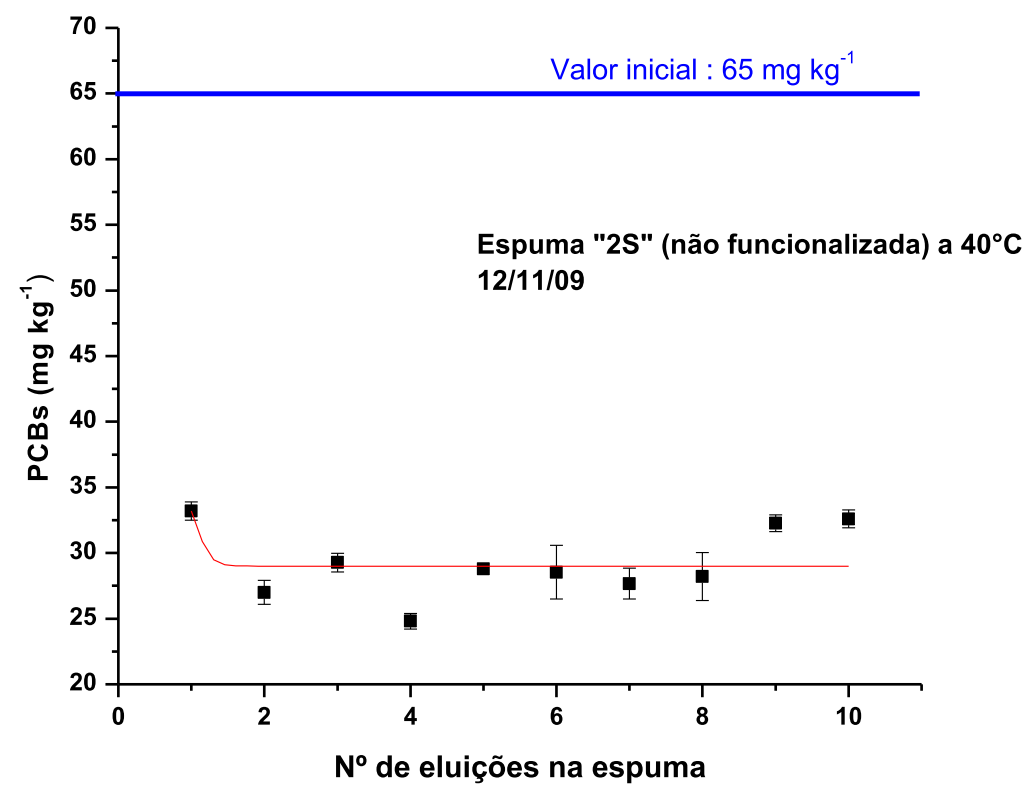

Figura 28 - Curva de saturação da espuma $(2 \mathrm{~g})$ não funcionalizada para a adsorção de $\mathrm{PCBs}$ a $40^{\circ} \mathrm{C}$. 
Os resultados anteriores (Figuras 27 e 28) mostram que as massas utilizadas de espuma 0,1g e 2,0 g apresentam valores de adsorção de PCBs muito próximos, sugerindo uma provável saturação, evidenciando o alto poder de adsorção da espuma não funcionalizada.

10.2. Curvas de saturação das espumas contendo tiodiglicol, polissulfeto de amônio e espuma não funcionalizada a $40^{\circ} \mathrm{C}$

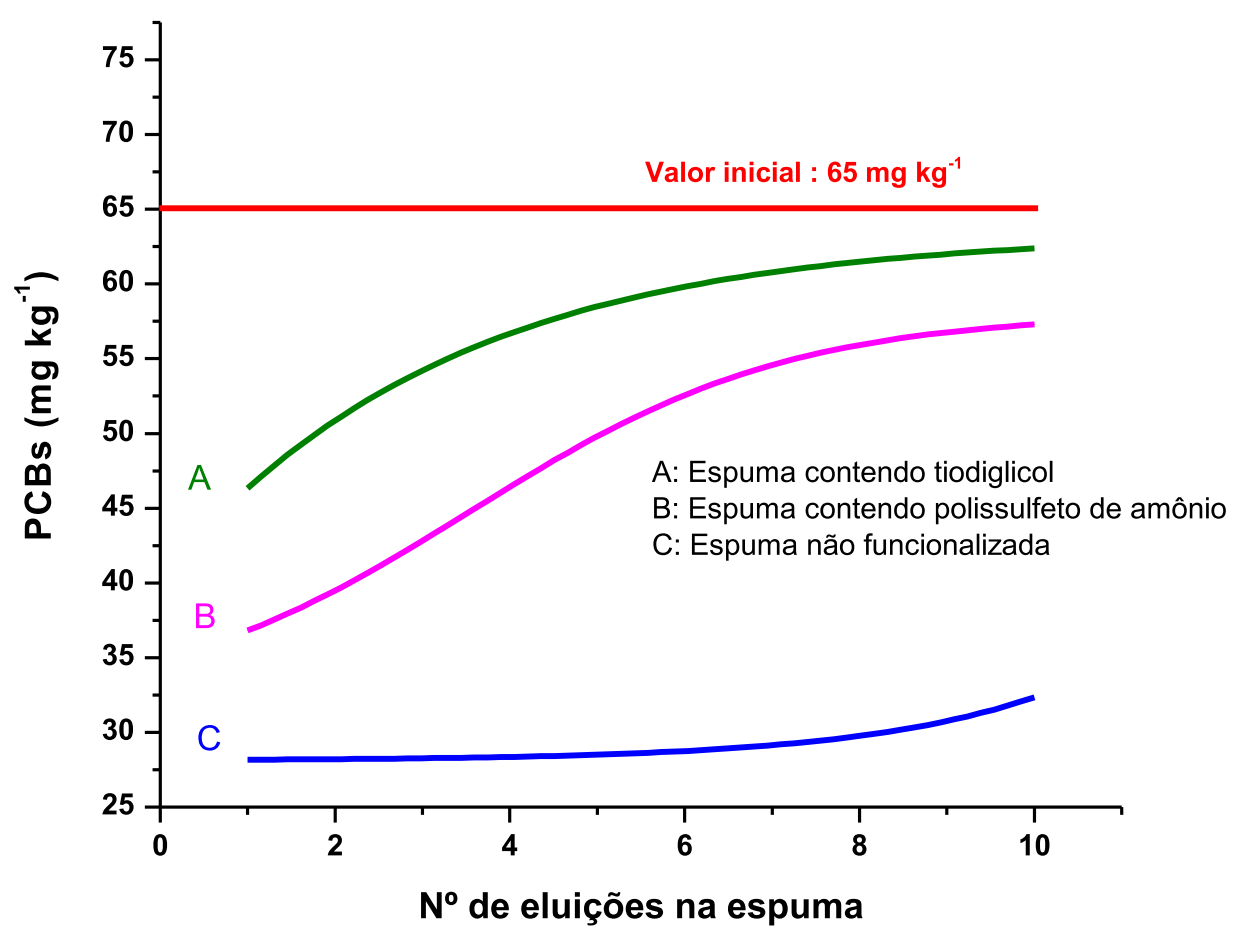

Figura 29 - Curva de saturação das espumas contendo (A) tiodiglicol (B) polissulfeto de amônio e (C) espuma não funcionalizada para a adsorção de PCBs a $40^{\circ} \mathrm{C}$.

Os resultados mostrados na Figura 29 sugerem que, ao utilizar-se a espuma funcionalizada com tiodiglicol e polissulfeto de amônio, há um aumento acentuado da adsorção de PCBs por parte da espuma somente no início do processo, em seguida essa adsorção é diminuída, indicando que poderá haver alguma competição 
do soluto (PCBs) para atingir os centros ativos da superfície (triglicéride do ácido ricinoleico presentes na espuma).

10.3. Curvas de saturação da espuma não funcionalizada nas temperaturas de $20^{\circ} \mathrm{C}, 40^{\circ} \mathrm{C}$ e $60^{\circ} \mathrm{C}$

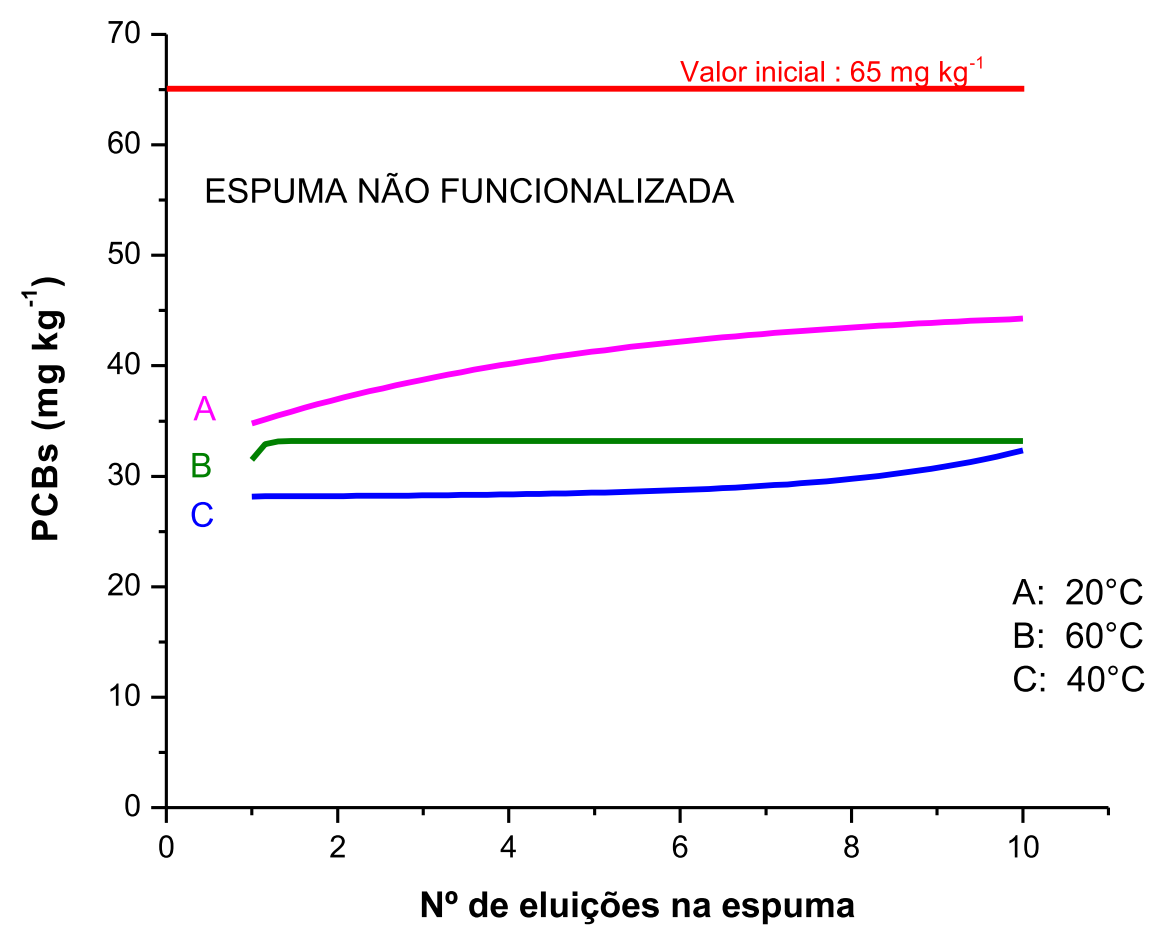

Figura 30 - Curva de saturação da espuma não funcionalizada para a adsorção de PCBs a $20^{\circ} \mathrm{C}, 40^{\circ} \mathrm{C}$ e $60^{\circ} \mathrm{C}$.

A espuma não funcionalizada apresentou uma redução de $55 \%$ dos teores de PCBs em relação ao valor inicial de $65 \mathrm{mg} \mathrm{kg}^{-1}$, sendo o melhor resultado, comparando-se com as espumas funcionalizadas com polissulfeto de amônio $24 \%$ e com tiodiglicol 11\%. Há portanto, uma formação viável entre os sistemas "doadoraceptor" ou "transferência de carga" e entre os diversos complexos de compostos orgânicos e bifenilas policloradas (PCBs), postulados por diversos autores (SENESI ; TESTINI, 1983a). Além de que o soluto poderá estabelecer ligações com os grupos funcionais da superfície sólida por atrações eletrostáticas, de van der Waals ou de natureza química (VOICE ; WEBER JUNIOR, 1983). 


\section{4. Óleo mineral isolante, isento de PCBs}

Com o objetivo de verificar se após a passagem de um óleo novo isento de PCBs, na espuma contendo PCBs adsorvido, causaria a dessorção dos PCBs, utilizou-se um óleo mineral isolante novo, fabricado pela NYNAS (Suécia), fornecido pela ABB - Asea Brown Boveri (Guarulhos-SP). Os resultados da Figura 31, mostram que não houve alteração nos valores de PCBs obtidos, o que significa que o óleo não extraiu os PCBs adsorvidos na espuma.

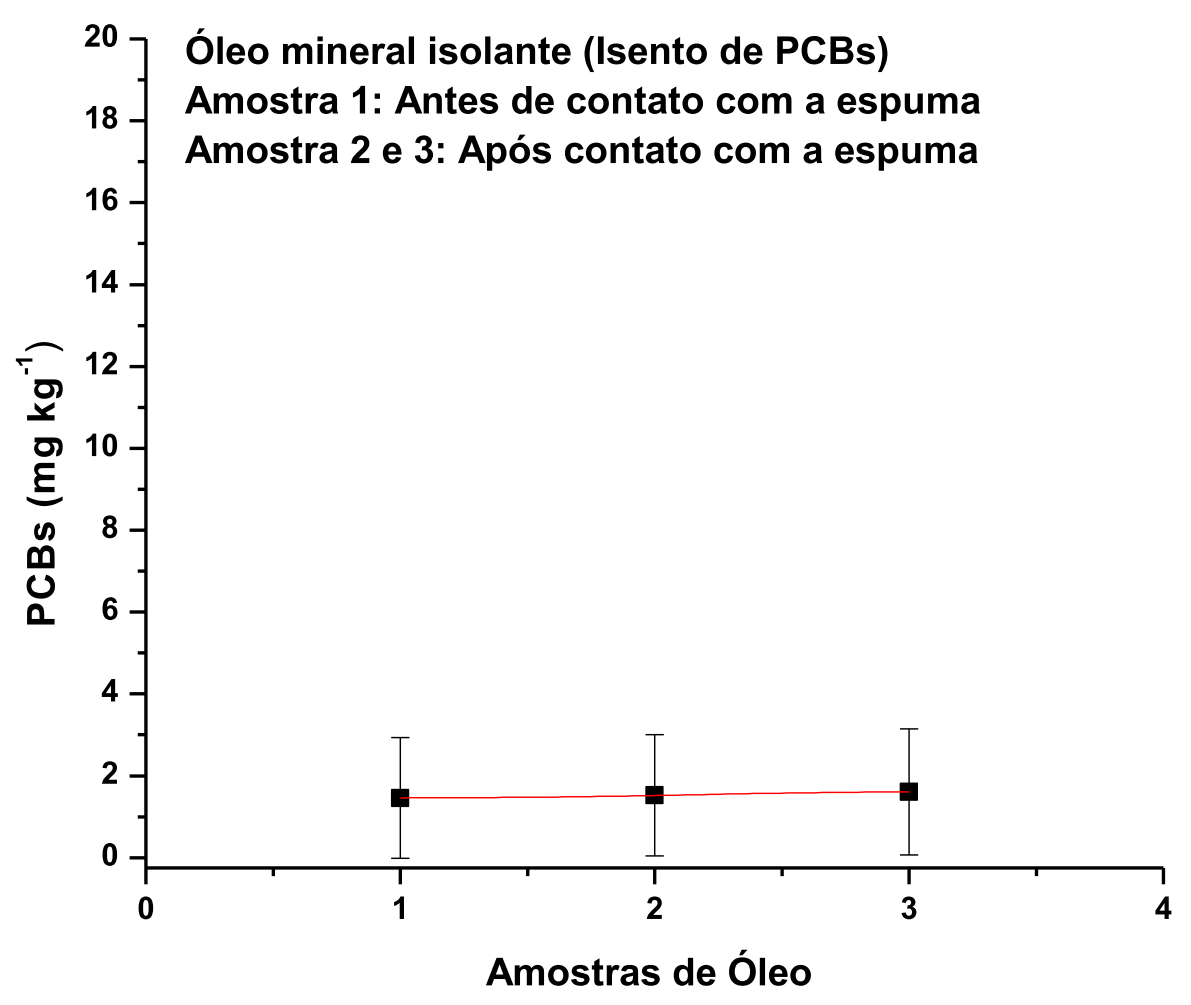

Figura 31 - Óleo Nynas novo, isento de PCBs, antes de contato e após contato com espuma não funcionalizada (após redução de 55\% no teor de PCBs). 


\subsection{Dessorção dos PCBs adsorvidos na espuma de poliuretano}

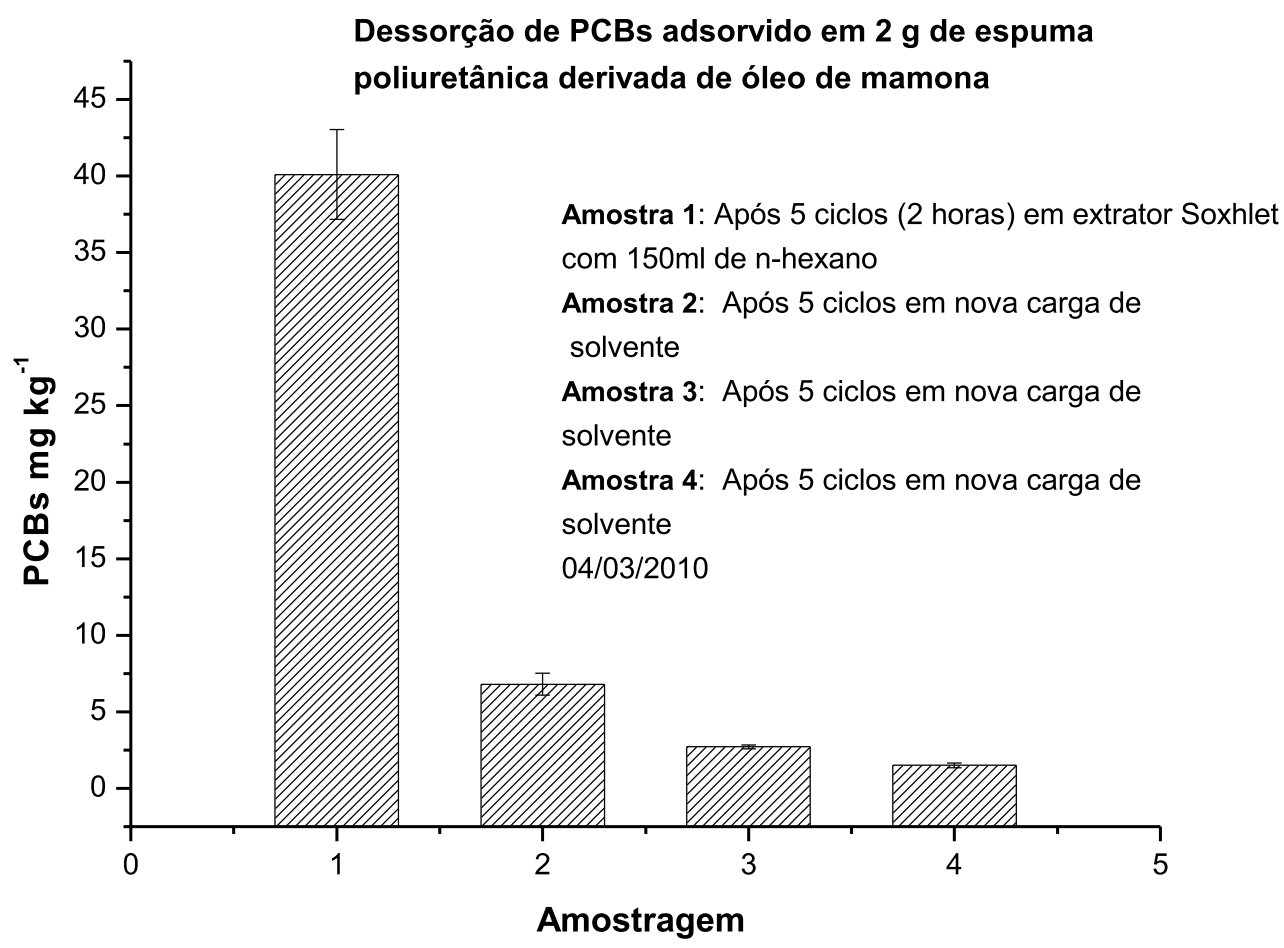

Figura 32 - Dessorção de PCBs adsorvidos em $2 \mathrm{~g}$ de espuma poliuretânica derivada de óleo de mamona.

A figura 32 mostra os resultados de extração dos PCBs adsorvidos na espuma utilizando como solvente o $\mathrm{n}$-hexano. As medições foram realizadas em triplicata levando a uma redução de aproximadamente $40 \mathrm{mg} \mathrm{kg}^{-1}$ para cerca de 2,0 $\mathrm{mg} \mathrm{kg}^{-1}$, em 8 horas de extração em Sohxlet . 


\section{Capítulo V - Conclusões}

\section{Conclusões Gerais}

Estudou-se a adsorção das bifenilas policloradas (PCBs) em óleo mineral isolante, utilizando-se espuma poliuretânica derivada de óleo de mamona. O acompanhamento da adsorção foi efetuado através de cromatografia gasosa (GCECD), utilizando-se coluna cromatográfica RTX5MS (5\% Difenil, 95\% Dimetil polisiloxano). Nos experimentos realizados, observou-se uma alta seletividade da espuma poliuretânica, levando a uma redução de $55 \%$ nos níveis de bifenilas policloradas na espuma não funcionalizada, $24 \%$ na espuma funcionalizada com polissulfeto de amônio e $11 \%$ na espuma funcionalizada com tiodiglicol.

Analisando os resultados destes experimentos verificou-se que o objetivo da pesquisa foi alcançado, uma vez que a redução do teor inicial de PCBs $\left(65 \mathrm{mg} \mathrm{kg}^{-1}\right)$ acima do teor mínimo especificado $\left(50 \mathrm{mg} \mathrm{kg}^{-1}\right)$ para $\left(29 \mathrm{mg} \mathrm{kg}^{-1}\right)$ apresentou uma redução de $55 \%$. Portanto, com esta pesquisa, contribuiu-se para a reutilização dos óleos minerais isolantes submetidos a esse processo de descontaminação, minimizando custos e impactos ambientais.

\subsection{Sugestões para trabalhos futuros}

Como sugestões de trabalhos futuros, podem-se realizar estudos com adsorção individual dos Arocloros 1242, 1254 e 1260 presentes em óleo de transformadores elétricos. Detecção e quantificação de outros Arocloros e estudos para a eliminação total dos níveis de PCBs em óleo mineral isolante. 
ABOUL-KASSIM, T.A.T.; SIMONEIT, B.R.T. Interaction Mechanisms between Organic Pollutants and Solid Phase Systems. In: ABOUL-KASSIM, T.A.T.; SIMONEIT,B.R.T. (Ed.).The handbook of environmental chemistry. Heidelberg: Springer Verlag, 2001. p. 130.

AFGHAN, B. K.; CHAU, A. S. Y. Analysis of trace organic in the aquatic environment. Boca Raton: CRC, 1989. p. 346.

AGENCY FOR TOXIC SUBSTANCES AND DISEASE REGISTRY (ATSDR). Toxicological profile for polychlorinated biphenyls. Atlanta: Public Health Service, U.S. Department of Health and Human Services, 2000. p. 948.

AMERICAN COUNCIL ON SCIENCE AND HEALTH (ASCH). Public health concerns about environmental polychlorinated biphenyls (PCBs). Disponível em: <http://www.acsh.org/publications/publD.875/pub detail.asp>. Acesso em: 12 abr. 2009.

APPELT, D. Óleos isolantes para transformadores. Eletricidade, v. 113, p. 60 - 73, 1975.

ARAÚJO, L.C.R. Contribuição ao estudo dos polímeros flexíveis derivados do óleo de mamona determinando suas propriedades físicas e químicas. 1998. 103 f.Tese (Doutorado em Química Analítica ) - Instituto de Química de São Carlos, Universidade de São Paulo, São Carlos, 1998.

ASSOCIAÇÃO BRASILEIRA DE NORMAS TÉCNICAS. NBR - IEC 60156: Líquidos isolantes - Determinação da rigidez dielétrica à freqüência industrial - Método de ensaio. Rio de Janeiro, 2005. 8 p.

ASSOCIAÇÃO BRASILEIRA DE NORMAS TÉCNICAS. NBR 10576: Óleo mineral isolante de equipamentos elétricos - Diretrizes para supervisão e manutenção. Rio de Janeiro, 2006. 29 p.

ASSOCIAÇÃO BRASILEIRA DE NORMAS TÉCNICAS. NBR 10710: Líquidos isolantes elétricos - Determinação do teor de água. Rio de Janeiro, 2006.7p.

ASSOCIAÇÃO BRASILEIRA DE NORMAS TÉCNICAS. NBR 11341: Produtos de petróleo - Determinação dos pontos de fulgor e de combustão em vaso aberto Cleveland. Rio de Janeiro, 2008. 16 p.

ASSOCIAÇÃO BRASILEIRA DE NORMAS TÉCNICAS. NBR 12133: Líquidos isolantes elétricos, Determinação do fator de perdas dielétricas e da permissividade relativa (constante dielétrica). Rio de Janeiro, 1991. 8 p. 
ASSOCIAÇÃO BRASILEIRA DE NORMAS TÉCNICAS. NBR 12134: Óleo mineral isolante - Determinação do teor de 2,6-di-terciário-butil paracresol. Rio de Janeiro, 1991. $9 \mathrm{p}$.

ASSOCIAÇÃO BRASILEIRA DE NORMAS TÉCNICAS. NBR 13882: Líquidos Isolantes Elétricos - Determinação do Teor de Bifenilas Policloradas. Rio de Janeiro, 2005. $7 \mathrm{p}$.

ASSOCIAÇÃO BRASILEIRA DE NORMAS TÉCNICAS. NBR 14248: Produtos de petróleo - Determinação do número de acidez e de basicidade - Método do indicador. Rio de Janeiro, 2009. 15 p.

ASSOCIAÇÃO BRASILEIRA DE NORMAS TÉCNICAS. NBR 14275: Óleo Mineral Isolante - Determinação do conteúdo de partículas. Rio de Janeiro, 1999. 5 p.

ASSOCIAÇÃO BRASILEIRA DE NORMAS TÉCNICAS. NBR 14483: Produtos de petróleo - Determinação da cor - Método do colorímetro ASTM. Rio de Janeiro, 2005. 7 p.

ASSOCIAÇÃO BRASILEIRA DE NORMAS TÉCNICAS. NBR 6234: Método de ensaio para a determinação de tensão interfacial de óleo-água. Rio de Janeiro, 1965. $3 \mathrm{p}$.

ASSOCIAÇÃO BRASILEIRA DE NORMAS TÉCNICAS. NBR 7148: Petróleo e produtos de petróleo - Determinação da massa específica, densidade relativa e ${ }^{\circ} \mathrm{API}$ - Método do densímetro. Rio de Janeiro, 2001. 2 p.

ASSOCIAÇÃO BRASILEIRA DE NORMAS TÉCNICAS. NBR 8371: Ascarel para transformadores e capacitores - Características e riscos. Rio de Janeiro, 2005. 14 p.

ASSOCIAÇÃO BRASILEIRA DE NORMAS TÉCNICAS. NBR 8840: Guia para amostragem de líquidos isolantes - Procedimento. Rio de Janeiro, 1992. 11 p.

BAIRD, C. Química ambiental. 2. ed. Rio de Janeiro: Bookman, 2003. p. 368.

BALLSCHIMITER, K.; SCHAFER, W.; BUCHER, H.; FRESEN. Z. Quantitation of polychlorodibenzofuran standards by gas chromatography-flame ionization detection. Analytical Chemistry, v. 326, ,p. 253 - 257, 1987.

BALLSCHIMITER, K.; ZELL, M.; FRESEN. Z. Analysis of Polychlorinated Biphenyls (PCB) by Glass Capillary Gas Chromatography - Composition of Technical Aroclorand Clophen-PCB Mixtures. Analytical Chemistry, v. 302, p. 20 - 31, 1980.

BEDARD, D. L.; MAY, R. J. Characterization of the Polychlorinated Biphenyls in the Sediments of Woods Pond: Evidence for Microbial Dechlorination of Aroclor 1260 in Situ. Environmental Science and Technology, v. 30, p. 237- 245,1995. 
BEDARD, D. L.; UNTERMAN, R.; BOPP, L. H.; BRENNAN, M. J.; HABERL, M.L.; JOHNSON, C. Rapid assay for screening and characterizing microorganisms for the ability to degrade polychlorinated biphenyls. Applied and Environmental Microbiology, v. 51, p. 761 - 768. 1986.

BELLAR,T.A. ; LICHTENBERG, J.J. Some factors affecting the recovery of polychlorinated biphenyls (PCB's) from water and bottom samples. In: AMERICAN SOCIETY FOR TESTING AND MATERIALS. Philadelphia: ASTM, 1975. p. 206 - 219 (ASTM special technical publication, 573).

BROWN JUNIOR, J.F. Determination of PCB Metabolic, Excretion, and Accumulation Rates for Use as Indicators of Biological Response and Relative Risk.

Environmental Science and Technology, v. 28, p. 2295 - 2305,1994.

BROWN JUNIOR,J.F.; WAGNER, R.E.; FENG, H.; BEDARD, D.L.; BRENNAN, M.J., CARNAHAN, J.C.; MAY, R. Environmental dechlorination of PCBs. Environmental Toxicology and Chemistry, v. 6, p. 579 - 593. 1987.

CANGEMI, José Marcelo. Biodegradação de Poliuretano Derivado do Óleo de Mamona. 2006. 163f. Tese (Doutorado em Química Analítica) - Instituto de Química de São Carlos, Universidade de São Paulo, São Carlos, 2006.

COONEY, D.O. Adsorption design for wastewater treatment. Boca Raton: CRC, 1998. p. 212.

DABROWSKI, A. Adsorption - from theory to practice. Advances in Colloid and Interface Science, v. 93, p.135 - 224, 2001.

ENVIRONMENTAL PROTECTION AGENCY (EPA). Ambient water quality criteria for polychlorinated biphenyls. Washington, DC: U.S. Criteria and Standards Division, Office of Water Regulations and Standards. EPA 440/5-80-068. 1980. Disponível em: <http://nepis.epa.gov/Exe/ZyPURL.cgi?Dockey=00001M1G.txt>. Acesso em: 12 abr. 2009.

ENVIRONMENTAL PROTECTION AGENCY (EPA). PCB transformer registration database. Office of pollution prevention and toxics. Washington, 2000.

Disponível em: <http://www.epa.gov/opptintr/pcb/xform.htm>. Acesso em: 12 abr. 2009.

ERHART, L.; REY, E.; SUTTER, H. Recherches nouvelles concernant les huiles isolantes à l'aide des méthodes chromatographiques modernes. Paris: CIGRÉ, 1966. p. 21. (CIGRÉ Session).

ERICKSON, M. Analytical chemistry of PCBs. 2. ed. Boca Raton: CRC, 1997. p. 197.

FENT, K. Effects of micropollutants. EAWAG News, v. 40E, p. 8 - 12, 1996. 
FISH, K .M. Influence of Aroclor 1242 Concentration on Polychlorinated Biphenyl Biotransformations in Hudson River Test Tube Microcosms. Applied and Environmental Microbiology, v. 62, p. 3014 - 3016, 1996.

FISH, K .M.;PRINCIPE, J.M. Biotransformations of Aroclor 1242 in Hudson River test tube microcosms. Applied and Environmental Microbiology, v. 60, p. 4289 - 4296, 1994.

FISHER, B.E. Most unwanted: Persistent organic pollutants. Environmental Health Perspectives, v.107, p. A18-A23, 1999.

GAUTHIER, T.D.; BOOTH, K.A.; GRANT, C.L.; SEITZ, W.R. Fluorescence quenching studies of interactions between polynuclear aromatic hydrocarbons and humic materials. American Chemical Society, Division of Analytical Chemistry, v. 27 , p. 246 - 248, 1987.

GILES, C.H.; D'SILVA, A.P.; EASTON, I.A. General treatment and classification of solute adsorption isotherm. 2. Experimental Interpretation. Journal of Colloid and Interface Science, v. 47, p. 766 - 778, 1974a.

GILES, C.H.; SMITH, D.; HUITSON, A. General treatment and classification of solute adsorption isotherm. 1. Theoretical. Journal of colloid and interface science, v. 47, p. 755 - 765, 1974b.

GRAHAM, D. Characterization of physical adsorption systems. III. The separate effects of pore size and surface acidity upon the adsorbent capacities of activated carbon. Journal of Physical Chemistry, v. 59, p. 896 - 900,1955.

GRAY, I.A.R. Guide for polychlorinated biphenyl (pcb) management of insulating oil in south africa. Dated: August 2004. Disponível em:

$<$ http://www.wearcheck.co.za/shared/pcb\%20information\%202004.pdf $>$. Acesso em: 12 abr. 2009.

HARKNESS, M.R.; MCDERMOTT, J.B.; ABRAMOWICZ, D.A.; SALVO, J.J.; FLANAGAN, W.P.; STEPHENS, M.L.; MONDELLO, F.J.; MAY, R.J.; LOBOS, J.H.; CARROLL, K.M. at. al. In situ stimulation of aerobic PCB biodegradation in Hudson River sediments. Science, v. 259, p. 503 - 507, 1993.

HARTKAMP-COMMANDEUR, L. C. M.; GERRITSE, J.; GOVERS, H. A. J.; PARSONS, J. R. Reductive dehalogenation of polychlorinated biphenyls by anaerobic microorganisms enriched from dutch sediments. Chemosphere, v. 32, p.1275 -1286, 1996.

HUTZINGER, O.; SAFE,S.; ZITKO, V. The chemistry of PCBs. New York: CRC Press, 1974. 269 p. 
IGLESIAS-JIMENEZ, E.; POVEDA, E.; SÁNCHES-MARTÍN, M.J.; SÁNCHESCAMAZANO, M. Effect of the nature of exogenous organic matter on pesticide sorption by the soil. Archives of Environmental Contamination and Toxicology, v. 33, p. 117-124, 1997.

JONES, K.C.; VOOGT, P. Persistent organic pollutants (POPs): state of the science. Environmental Pollution, v.100, n.1, p. 209 - 221, 1999.

KEITH, L.H.; TELLIARD, W.A. Prioritary pollutants I - a perspective view. Environmental Science and Technology, v.13, p. 416 - 423,1979.

LANÇAS, F.M. Cromatografia em fase gasosa. São Carlos: Acta, 1993. 240 p.

LIPSHTEIN, R.A.; SHAKNOVICH, M.I. Transformer oil. Jerusalém: Wiener Bindery, 1970. $257 \mathrm{p}$.

MILASCH, M. Manutenção de transformadores em líquido isolante. São Paulo: Edgard Blucher , 2003. 380 p.

MORENO-CASTILLA, C. Adsorption of organic molecules from aqueous solutions on carbon materials. Carbon, v. 42, p. $83-94,2004$.

NAMASIVAYAM, C., KAVITHA, D. Adsorptive removal of 2-chlorophenol by low-cost coir pith carbon. Journal of Hazardous Materials, v. B98, p. 257- 274, 2003.

NATIONAL ACADEMIES PRESS.Committee on Remediation of PCB-Contaminated Sediments, Board on Environmental Studies and Toxicology. National Research Council, and National Research Council . A Risk management strategy for PCBcontaminated sediments. Disponivel em:

<http://www.nap.edu/catalog/10041.html >. Acesso em:12 abr. 2009.

NATIONAL FIRE PROTECTION ASSOCIATION (NFPA). Hazardous chemicals data. New York: Thomson Reuters, 1994. 53 p.

NZENGUN, V.A.; VOUDRIAS, E.A.; NKEDI-KIZZA, P.; WAMPLER, J.M.; WEAVER, C.E. Organic cosolvent effects on sorption equilibrium of hydrophobic organic chemicals by organoclays. Environmental Science and Technology, v. 30, p. 89 96, 1996.

ÖZACAR, M.; ŞENGIL, İ. A. A kinetic study of metal complex dye sorption onto pine sawdust. Process Biochemistry, v. 40, p. 565 - 572, 2005.

PENTEADO, J. C. P; VAZ, J. M. The legacy of the polychlorinated biphenyls (PCBs). Química Nova. v. 24, n. 3, p. 390 - 398, 2001. Disponível em: $<$ http://www.scielo.br/scielo.php?pid=S010040422001000300016\&script=sci abstract>. Acesso em: 12 abr. 2009. 
PEREIRA, Márcia de Souza. Caracterização de produtos e contaminantes no reaproveitamento térmico de resíduos sólidos orgânicos. Estudo de caso: 0 processo de conversão à baixa temperatura. 2002. 243f. Tese (doutorado em Geoquímica Ambiental). Universidade Federal Fluminense, Niterói, 2002.

PINE, S.H. Organic chemistry. 5. ed. New York: McGraw-Hill, 1987. 1187 p.

RODRÍGUEZ-REINOSO, F. The role of carbon materials in heterogeneous catalysis. Carbon, v. 36, p. $159-1$ 75, 1998.

RUTHVEN, D.M. Principles of adsorption and adsorption processes. New York: John Wiley, 1984. 464 p.

SENESI N.;TESTINI C.; MIANO, T.M. Interaction mechanisms between humic acids of different origin and nature and electron donor herbicides: acomparative IR and ESR study. Organic Geochemistry, v.11, p. 25 - 30, 1987.

SENESI, N.; MIANO, T.M.; TESTINI, C. The role of humic substances in the environmental chemistry of chlorinated phenoxyalkanoic acids and esters. Studies in Environmental Science, v. 29, p. 183 - 196, 1986.

SENESI, N.;TESTINI, C. Adsorption of some nitrogenated herbicides by soil humic acids. Ecological Bulletins, Stockolm, v. 35, p. 477 - 490, 1983a.

SENESI,N.; TESTINI, C. Spectroscopic investigation of electron donor-acceptor processes involving organic free radicals in the adsorption of substituted urea herbicides by humic acids. Pesticide Science, v. 14, p. $79-89,1983$ b.

SEVERTSON, S.J.; BANERJEE, S. Sorption of chlorophenols to wood pulp. Environmental Science and Technology, v. 30, p. 1961 - 1969, 1996.

SIMONICH, S.L.; HITES, R.A. Global distribution of persistent organochlorine compounds. Science, v. 269, p. 1851 - 1854, 1995a.

SIMONICH, S.L.; HITES, R.A. Organic pollutant accumulation in vegetation. Environmental Science and Technology, v. 29, p. 2905 - 2914, 1995 b.

SKOOG, D. A.; WEST, D. M.; HOLLER, F. J.; CROUCH, S. R. Fundamentals of analytical chemistry. Belmont: Thomson Learning, 2004. 1051 p.

SOLOMONS, G.; FRYHLE, C. Química orgânica. 5. ed. Rio de Janeiro: Livros Técnicos e Científicos, 2002. 474 p.

SUFFET, I. H.; MACCARTHY, P. Aquatic humic substances: Influence on fate and treatment of pollutants. (Advances in Chemistry Series). Washington: ACS, 1989. v. 219, p.173. 
THE ENVIRONMENT PROGRAMME OF THE UNITED NATIONS. Inventory of worldwide PCB destruction capacity. 1998. Disponível em:

<http://irptc.unep.ch/pops/pdf/pcbrpt.pdf> . Acesso em: 12 abr. 2009.

THEELEN, R.M.C.; LIEM, A.K.D.; SLOB, W.; VAN WIJNEN, J.H. Intake of 2, 3, 7, 8, chlorine substituted dioxins, furans, and planar PCBs from food in the Netherlands: median and distribution. Chemosphere, v. 27, p. 1625 - 1635. 1993.

TRAPP, S.; MIGLIORANZA, K.S.B.; MOSBAEK, H. Sorption of lipophilic organic compounds to wood and implications for their environmental fate. Environmental Science and Technology, v. 35, p. 1561 - 1566. 2001.

TSENG, R.; WU, F.; JUANG, R. Liquid-phase adsorption of dyes and phenols using pinewood-based activated carbons. Carbon, v. 41, p. 487 - 495, 2003.

TURNER, A. Salting out of chemicals in estuaries: implications for contaminant partitioning and modeling. The Science of the Total Environment, v. 314 - 316, p. $599-612,2003$.

UNITES NATIONS INDUSTRIAL DEVELOPMENT ORGANIZATION (UNIDO). Enabling activities to facilitate early action on the implementation of the Stockholm convention on persistent organic pollutants (POPs) in the Czech Republic. PROJECT GF/CEH/01/003. Disponível em: $<$ http://www.unido.org/fileadmin/import/30352 ValwReport.pdf>. Acesso em: 10 jul. 2010.

VALVERDE-GARCIA, A E. GONZALEZ-PRADA, M. VILLAFRANCHA-SANCHEZ, F.D. REY-BUENO AND A. GARCIA-RODDQUEZ. Adsorption of Thiram and Dimethoate on Almeria Soils. Soil Science Society of America Journal, v. 52, p. 1571 - 1574, 1988.

VAN DORT, H.M.; SMULLEN, L. A.; MAY, R. J.; BEDARD, D. L. Priming Microbial meta-Dechlorination of Polychlorinated Biphenyls That Have Persisted in Housatonic River Sediments for Decades. Environmental Science and Technology, v. 31, p. 3300 - 3307, 1997.

VAN DORT, H.M.; BEDARD, D. L. Reductive ortho and meta Dechlorination of a Polychlorinated Biphenyl Congener by Anaerobic Microorganisms. Applied and Environmental Microbiology, v. 57, p. 1576 - 1578. 1991.

VILAR, W. D. Química e tecnologia dos poliuretanos. 2.ed. Rio de Janeiro: Vilar Consultoria, 1998. p. 340.

VOICE, T.C.; WEBER JUNIOR, W.J. Sorption of hydrophobic compounds by sediments, soils and suspended solids - II: Sorbent evaluation studies. Water Research, v. 17, n. 10, p. $1443-1452,1983 b$. 
VOICE, T.C.; WEBER JUNIOR, W.J. Sorption of hydrophobic compounds by sediments, soils and suspended solids - I: Theory and background. Water Research, v. 17, n. 10 , p. $1433-1441,1983 a$.

WEBER JUNIOR, W.J. Physical and chemical processes for water quality control. New York: Wiley - Interscience, 1972. 640 p.

WEBER JUNIOR, W.J. Physicochemical processes for water quality control. New York: Wiley-Interscience, 1972. p. 672.

WEBER JUNIOR, W.J.; MCGINLEY, P.M.; KATZ, L.E. Sorption phenomena in subsurface systems: concepts, models and effects on contaminant fate and transport. Water research, v. 25, p. 199 - 528, 1991.

WELLS, D.; MAIER, E.; GRIEPINK, B. Development in the Analysis of Chlorobiphenyls in Environmental Matrices for Certification Purposes. In:

ALBAIGÉS, J. (Ed.). Environmental analytical chemistry of PCBs. Singapore: Gordon and Breach, v.16, p. 89 - 100. 1993.

WILLIAMS, W. A.; MAY, R.J. Low-temperature microbial aerobic degradation of polychlorinated biphenyls in sediment. Environmental Science and Technology, v. 31, p. 3491 - 3496, 1997.

WITTICH, R.M. Degradation of dioxin-like compounds by microorganisms. Applied Microbiology and Biotechnology, v. 49, p. 489 - 499, 1998.

WORLD HEALTH ORGANIZATION (WHO). Environmental health criteria for PCBs and PCTs. Brussels: International Register of Toxic Chemicals;1990. p. 2.

YOUNG, L. Y.; CERNIGLIA, C. E. (Ed.), Microbial transformation and degradation of toxic organic chemicals. New York: John Wiley, 1995. p.127 - 216. 